SPATIAL INCOME INEQUALITY IN TORONTO: A LONGITUDINAL STUDY

\author{
by \\ Candace Safonovs \\ BA, McGill University, 2014

\begin{abstract}
A Major Research Paper
presented to Ryerson University

in partial fulfilment of the requirements for the degree of

Master of Planning

in

Urban Development
\end{abstract}

Toronto, Ontario, Canada, 2019

(C) Candace Safonovs, 2019 


\section{AUTHOR'S DECLARATION FOR ELECTRONIC SUBMISSION OF A MRP}

I hereby declare that I am the sole author of this MRP. This is a true copy of the MRP, including any required final revisions.

I authorize Ryerson University to lend this MRP to other institutions or individuals for the purpose of scholarly research.

I further authorize Ryerson University to reproduce this MRP by photocopying or by other means, in total or in part, at the request of other institutions or individuals for the purpose of scholarly research. I understand that my MRP may be made electronically available to the public 


\title{
SPATIAL INCOME INEQUALITY IN TORONTO: A LONGITUDINAL STUDY
}

(C) Candace Safonovs, 2019

\author{
Master of Planning \\ in \\ Urban Development \\ Ryerson University
}

\begin{abstract}
This paper examines the trends and changes in both spatial and non-spatial income inequality in the Toronto CMA between 1985 and 2015 at various geographic scales, including both within and between neighbourhoods. Fixed effects panel regression models are used to uncover which local demographic and housing characteristics are most significant in explaining changes in inequality within neighbourhoods over time.

Findings indicate that macro-scale income segregation among neighbourhoods has declined, while microscale intra-neighbourhood income segregation has increased since 1985. Further, compared to overall changes in income inequality in the region, neighbourhoods have become more homogenous in terms of their household income distribution. Thus, neighbourhood sorting by households based on income has increased since 1985.

Consistent with extant literature, local housing characteristics have spillover effects on income segregation. Specifically, variables associated with greater housing affluence are negatively correlated with intra-neighbourhood inequality measures, and thus positively correlated with income homogenization. This confirms and adds to the literature that local land use regulations impact income spatial inequality.
\end{abstract}

\section{KEYWORDS}

Spatial Income Inequality; Segregation; Neighbourhoods; Toronto CMA; Fixed Effects Models; Quantitative Analysis; GIS; Housing Regulation 


\section{ACKNOWLEDGEMENTS}

Firstly, an enormous and sincere thank you to Dr. Lyndsey Rolheiser for her mentorship, guidance, and support throughout this research. Our meetings sometimes turned into mini statistics workshops and I am so grateful for her patience, passion for good metrics, and brilliant advice.

Thank you as well to Dr. Mariana Arcaya. I benefited from her insightful feedback and expertise on the dynamic relationships between neighbourhoods.

I would also like to extend a huge thanks to my family, friends, and partner for supporting me throughout the last few months and graciously putting up with my reduction of time for them. Lastly, I would like to thank my colleagues and friends at Ryerson's Schools of Urban and Regional Planning for their inspiration, camaraderie, and for providing happy distraction outside of my research. The time spent together has been a source of stress release and I thank everyone for keeping me sane this past 2 years. 


\section{TABLE OF CONTENTS}

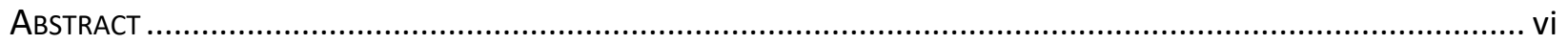

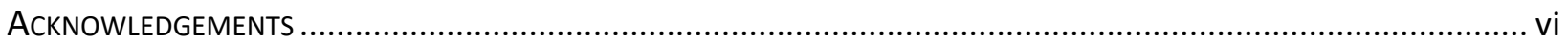

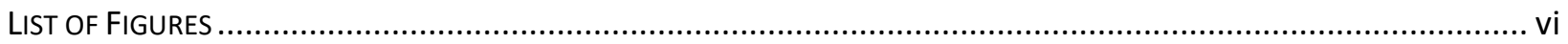

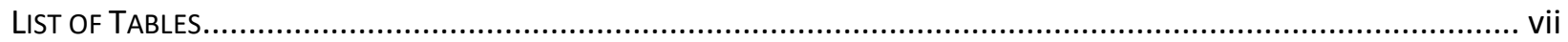

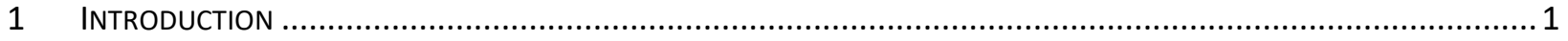

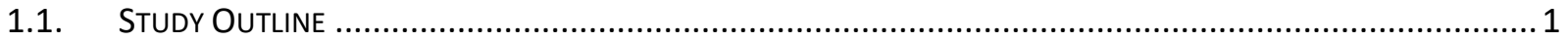

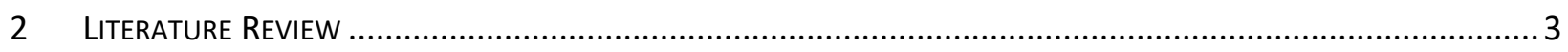

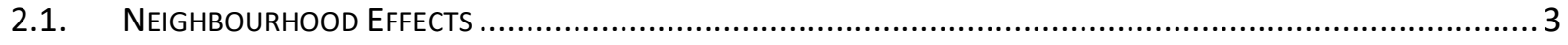

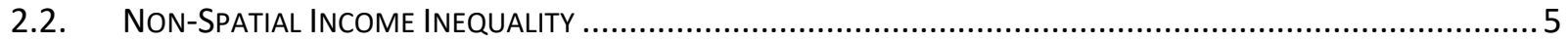

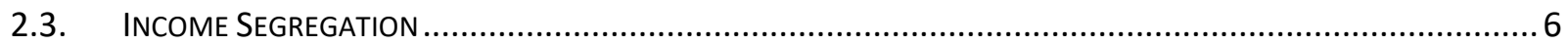

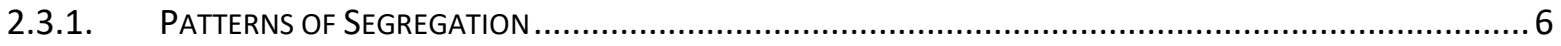

2.3.2. RELATIONSHIP BETWEEN INEQUALITY AND SEGREGATION........................................................... 8

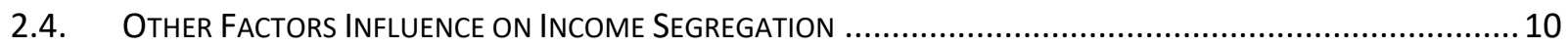

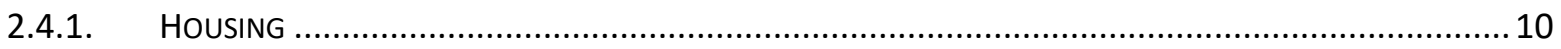

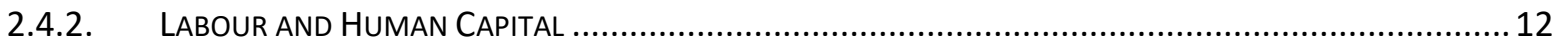

2.4.3. DeMOgRAPHICS - RACE, ETHNICITY, AND MIGRATION StATUS .................................................... 12

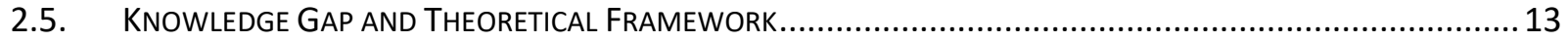

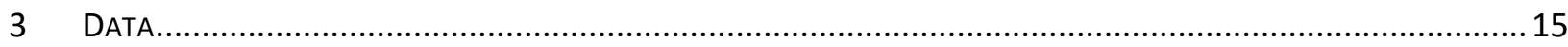

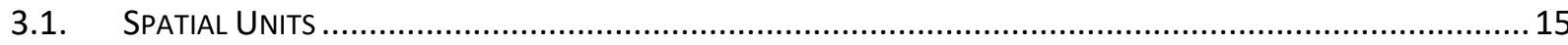

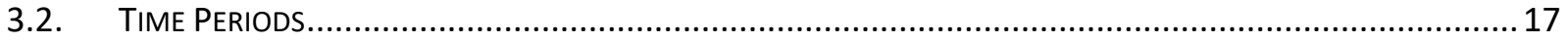

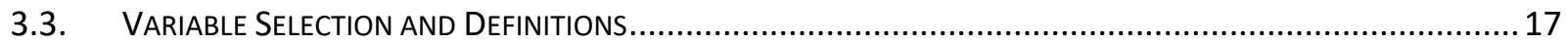

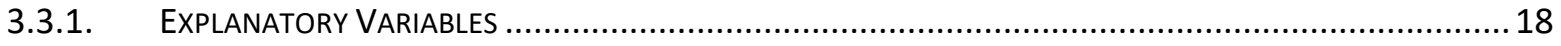

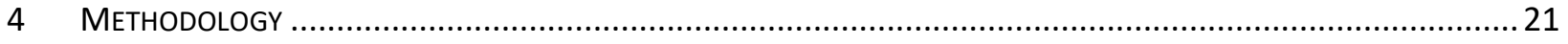

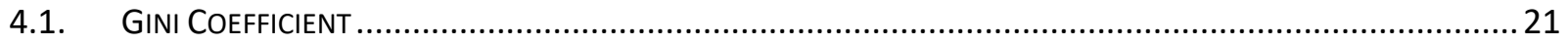

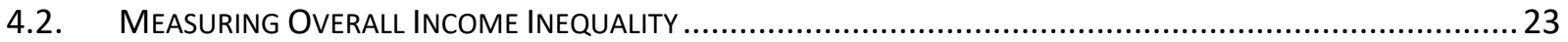

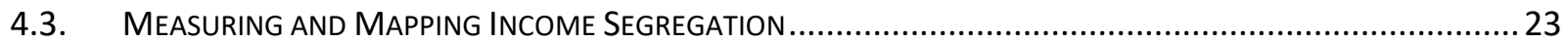




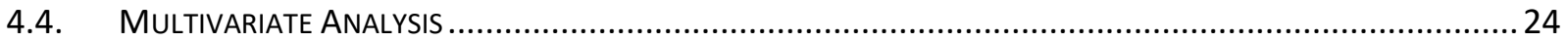

4.4.1. CONTROLLING FOR BIAS USING FIXED-EFFECTS MOdELS........................................................ 25

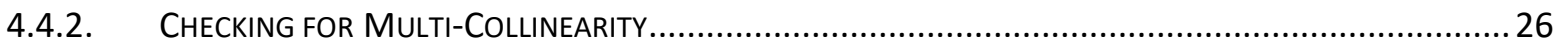

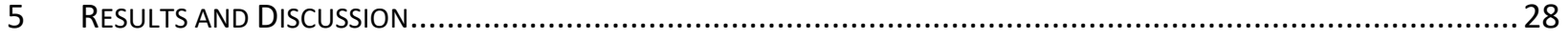

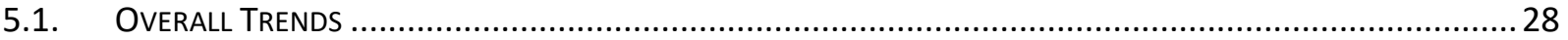

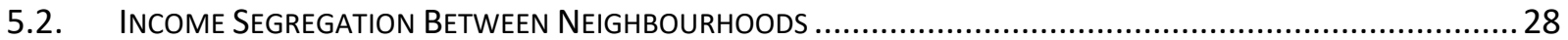

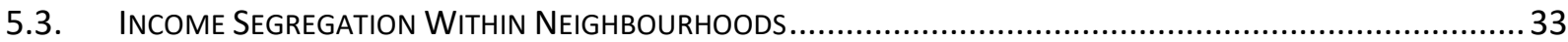

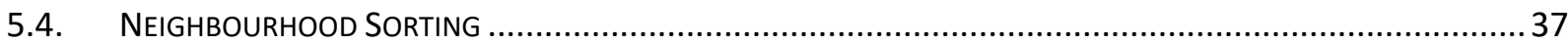

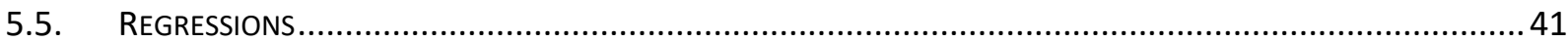

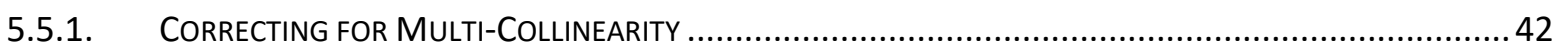

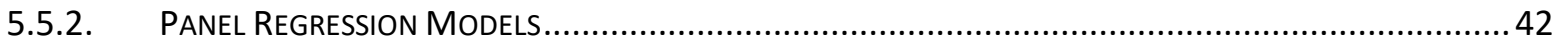

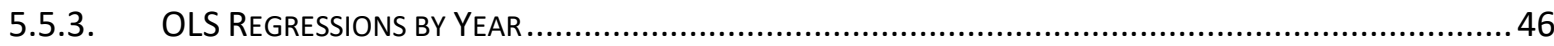

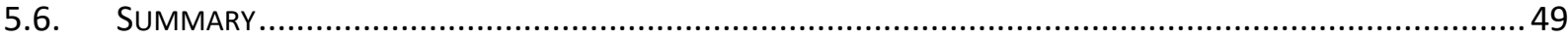

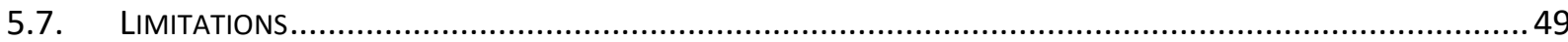

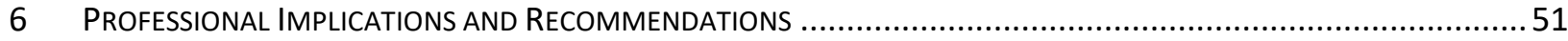

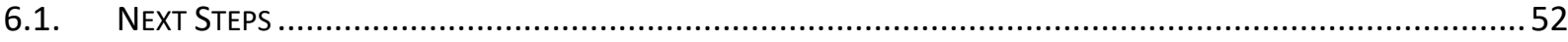

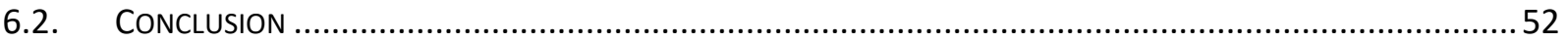

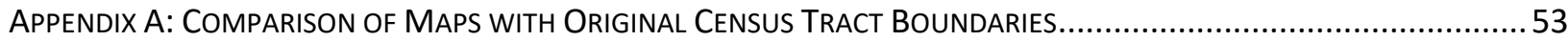

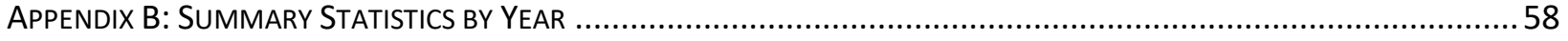

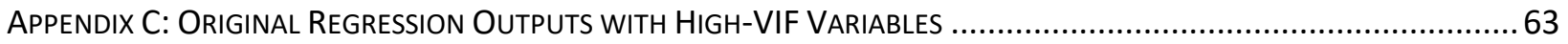

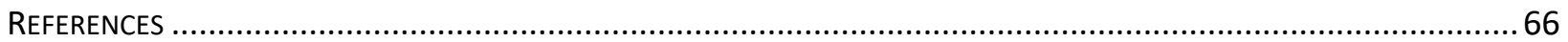




\section{LIST OF FIGURES}

Figure 1: Comparison of Toronto Census Metropolitan Area And the Greater Toronto Area ....................................16

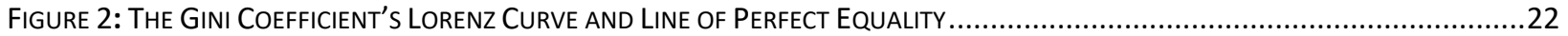

Figure 3: OVERALL NON-SPATIAL GINI COEFFICIENT FOR THE TORONTO CMA, 1985-2015..................................................28

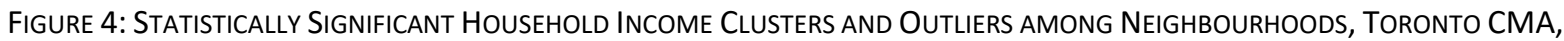
1985

Figure 5: Statistically Significant Household Income Clusters and Outliers among Neighbourhoods, Toronto CMA, 1995

Figure 6: Statistically Significant Household Income Clusters And Outliers among Neighbourhoods, ToRonto CMA, 2005

Figure 7: Statistically Significant Household Income Clusters and OUtliers among NeighbourhoOds, ToRONTo CMA, 2015

Figure 8: Statistically Significant Household Income Clusters and OUtLiers AMONg Neighbourhoods, ToRonto CMA, $1985-2015$

Figure 9: Change in Statistically Significant Household Income Clusters and OutLiers among Neighbourhoods, ToRONto CMA, 1985- 2015

FIGURE 10: HIGHEST INCOME NEIGHBOURHOOD AS A MULTIPLE OF THE LOWEST INCOME NEIGHBOURHOOD, 1985-2015 .................33

FIgURE 11: BoXPlot Diagram OF GINI COEFFICIENTS WITHIN CENSUS TRACTS, TORONTO CMA, 1985- 2015 ...........................34

FiguRE 12: GINI COEFFICIENT OF INCOME INEQUALITY WITHIN CENSUS TRACTS, TORONTO CMA, 1985....................................34

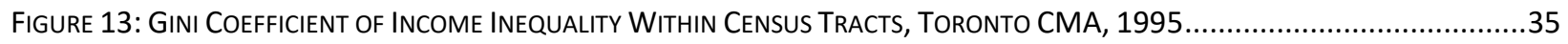

FIgURE 14: GINI COEFFICIENT OF InCOME INEQUALITY WITHIN CENSUS TRACTS, TORONTO CMA, 2005.....................................35

FIgURE 15: GINI COEFFICIENT OF INCOME INEQUALITY WITHIN CENSUS TRACTS, TORONTO CMA, 2015.....................................36

Figure 16: Change In GinI COEFFICIENT Of InCOME INEQUALITY Within CENSUS TRACTS, TORONTO CMA, 1985 - 2015 ..............37

Figure 17: Comparison of OVerall Non-Spatial Gini Coefficient AND MEAN Within Census Tract Gini Coefficient for the

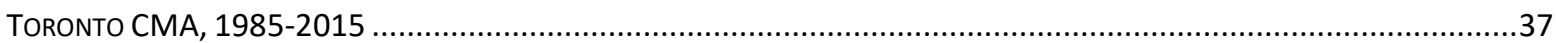

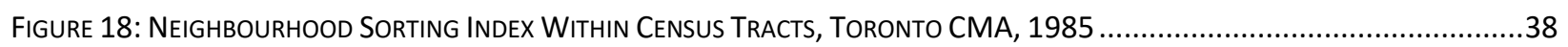

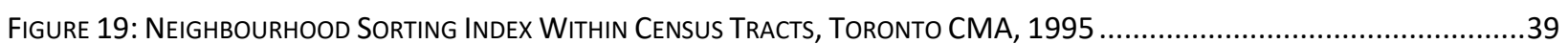

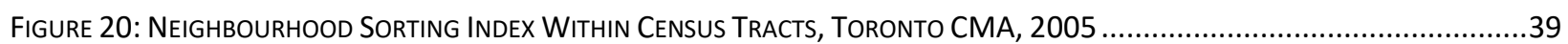

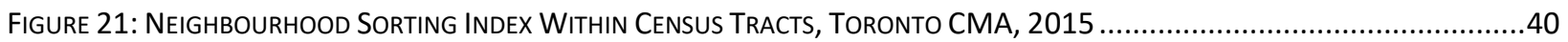

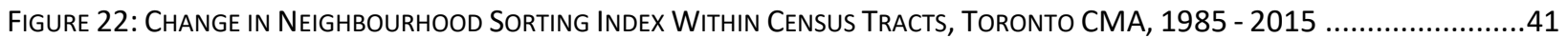


LIST OF TABLES

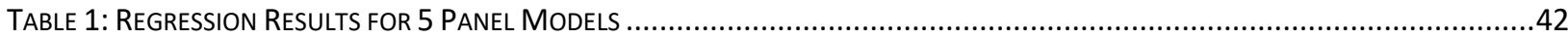

TABLE 2: REgRESSION RESULTS FOR EACH YEAR INDEPENDENTLY.. 


\section{INTRODUCTION}

Income inequality is growing in Canada, with greater inequality being shown to have negative impacts on both society and on individuals (OECD, 2016; Wilkinson \& Pickett, 2009; Wilkinson \& Pickett, 2018). Local and regional land use policies contribute to the way inequality is expressed geographically. Segregation impacts who is able to live in the city as well as where they can live in the city. In turn, the way in which inequality manifests across space has implications on the ability of local governments to respond to households' needs, as well as the potential extent to which structural inequality is perpetuated.

This paper examines the changes in spatial inequality in the Toronto Census Metropolitan Area (CMA) between 1985 and 2015, as compared to overall changes in the region's non-spatial inequality. Of focus are dynamics both across and within neighbourhoods, the macro and micro-scales, of income segregation, as the degree of segregation impacts residents' outcomes differently. Further, the study of inequality at the neighbourhood level is important because neighbourhood effects have been shown to have significant impacts on residents' well-being and intergenerational mobility (Chetty \& Hendren, 2018; Currie, 2011; Johnston et al., 2005; Hulchanski, 2007).

Additionally, neighbourhood level factors - demographics and local housing characteristics - that are most significantly associated with changes in micro-scale spatial income inequality within the Toronto CMA are identified.

This research expands extant literature on income inequality and segregation in the Toronto region (Fong \& Shibuya, 2000; Hulchanski, 2007; Murdie, 2013; Murdie, 2014; Walks, 2013), as well as tests predictions put forth by researchers of inequality in the United States (US). This includes the findings of spillover effects of housing policy on income segregation and inequality (Fong \& Shibuya, 2000; Ganong \& Shoag, 2015; Hulchanski, 2007; Lens \& Monkkonen, 2016; Reardon \& Bischoff, 2011; Saiz, 2010) and the correlation between race, ethnicity and class segregation (Chetty \& Hendren, 2018; Fong \& Shibuya, 2000; Hulchanski, 2018; Reardon \& Bischoff, 2011; Sampson, 2018; Walks \& Bourne, 2006).

\subsection{STUdY OUTLINE}

This paper begins by reviewing the literature on neighbourhood effects, to demonstrate the validity of studying neighbourhood-level phenomena. It then examines the literature on the relationship between 
income inequality and income segregation, as well as the potential impacts of several other local characteristics on income segregation.

The Data section describes each of the neighbourhood characteristic variables to be examined. The Methods section outlines the framework for examining changes in spatial income inequality and explains the statistical analysis approach used to measure neighbourhood characteristics' impact on intraneighbourhood inequality.

The Results and Discussion section provides a descriptive overview of the trends in spatial income inequality throughout the Toronto CMA since 1985 using census data. Estimates of the impacts of the previously examined local characteristics on changes in intra-neighbourhood inequality are presented.

Finally, the Implications and Recommendations section iterates the implications of the findings and offers recommendations for policy-makers and for future research. 


\section{LITERATURE REVIEW}

This literature review summarizes the main findings and theories relating to spatial and non-spatial inequality at both the metropolitan and neighbourhood level. The research derives from a variety of different disciplines including urban studies, economics, sociology, and housing policy.

First, it is important to contextualize the characteristics of spatial and non-spatial inequality, and of the importance of place in driving social and economic outcomes. A brief summary of the evidence linking several variables' potential impacts on income segregation in the city is provided.

This review focuses on evidence from both Toronto and other North American urban areas to inform trends and factors of interest.

\subsection{NEIGHBOURHOOD EFFECTS}

There is evidence that the local neighbourhood conditions of ones' geographic place of residence have a material impact on one's well-being and economic outcomes (Chetty \& Hendren, 2018; Johnston et al., 2005; Hulchanski, 2007), and therefore there is value in studying neighbourhood-level phenomena.

There are at least six theories to explain how neighbourhoods influence individual outcomes: 1) through the quality of local services, particularly schools; 2) socialization; 3) peer influences; 4) social networks; 5) exposure to crime and violence; and 6) physical distance to jobs (Ellen \& Turner, 1997). Regardless, it is unclear as to which neighbourhood conditions matter the most, as well as how each neighbourhood characteristic influences behaviour, well-being, and economic outcomes.

Previous studies found significant impacts of neighbourhood conditions on individuals' labour market and educational outcomes (Galster, 2012), with the effects stronger on children's future outcomes from living in "better" neighbourhoods (Chetty \& Hendren, 2018; Ellen \& Turner, 1997). The effects found may be nonlinear, however, with respect to baseline disadvantage (Reardon \& Bischoff, 2011), and there is credible evidence that concentrated disadvantage has causal effects on several individual outcomes, such as earnings potential and health (Sampson, 2018). The noted neighbourhood effects are smaller, though, than the effects of observed family characteristics, such as income, socioeconomic status, and educational attainment (Ellen \& Turner, 1997). 
The most recent and empirically robust study on the importance of place for intergenerational mobility comes from a quasi-experimental research paper that measured the impacts of the Moving to Opportunity (MTO) program in the United States (Chetty \& Hendren, 2018). By removing bias and family effects from the study's design, the results empirically demonstrated that location has significant effects on children's future earning potential and other outcomes at the county and metro area level.

These effects were found to accumulate through childhood exposure, with low-income children's earning potential converging to that of the high-opportunity area's "permanent residents" at a rate of $4 \%$ per every year of exposure, for children between the ages of 9 and 23 . Since the effect increased proportionately to exposure, rather than through the immediate impact on adults, Chetty and Hendren (2018) argue that local childhood environments matter more than local labour markets in improving intergenerational mobility.

Still, there is a debate among academics and urban planners as to whether "place-focused" policies are legitimate ways of addressing poverty. Skeptics argue that the impacts of neighbourhood effects policies pale in comparison to more structural, macro-level efforts, such as policies that aim to address inequities within the labour market caused by global economic restructuring (Goetz \& Chapple, 2010; Walks, 2013). Further, neighbourhood effects policies are sometimes associated with the "underclass hypothesis", which emphasizes the "undesirable" culture and behaviour of low-income individuals living in highpoverty neighbourhoods brought about through the contagion effects of place (Deluca, 2012; Goetz \& Chapple, 2010). Both views fail to recognize the impacts that local policies and neighbourhood characteristics have on individuals.

While addressing the structural forces of income inequality is important and necessary, meso- and microlevel interventions also have a role to play in ameliorating income inequality and segregation. This includes urban public policies such as those that address migration, discrimination, growth, and the siting of employment and residential areas (Goetz \& Chapple, 2010).

Sampson's (2018) core argument is that neighbourhood structures play an important role in the perpetuation of structural inequality. He notes that neighbourhoods both exert causal effects on a wide variety of everyday life and are in turn mediated by both macro structures (political, economic, and legal) and micro processes (such as perception and choice). Therefore, neighbourhoods need effective policy intervention, both those aimed at enrichment ("place-based") as well that those that encourage integration ("person-based"), described as a hybrid approach (Imbroscio, 2011; Sampson, 2018). 


\subsection{NON-SPATIAL INCOME INEQUALITY}

Cities with more equal income distribution perform better, both economically and socially (OECD, 2016; Wilkinson \& Pickett, 2009). Higher levels of income inequality are also highly correlated with lower intergenerational mobility, a phenomenon known as the "Great Gatsby Curve" (OECD, 2016). This curve is attributed to the fact that parents, relatives, and community members make greater investments in the capabilities of their children to provide them with skills that pay off in the labour market. In this sense, inequality encompasses both income and access to opportunity. Further, factors other than employment income limit or enable economic mobility and thus indirectly impact income inequality. These factors are related to how households spend or invest the income they receive (Procyk, 2014), such as the cost of shelter, and are influenced by local, regional, and national policies.

Though the number of people in absolute poverty has decreased, income inequality in OECD countries (which are mostly high-income economies) has risen steadily for the past half century (OECD, 2018). This trend is what likely led Barrack Obama to declare that inequality, and with it the lack of economic mobility, was "the defining challenge of our time" (Yglesias, 2015).

In Canadian cities, income inequality has increased since the late 1980s, with the most dramatic increase occurring in the 1990s (Hulchanski, 2018; Walks, 2013). The Organization for Economic Cooperation and Development (OECD) found that Canada experienced the second largest increase in inequality of its member countries between the mid-1990s and mid-2000s, as measured by the Gini coefficient (OECD, 2008). This is a similar trend as seen in the Unites States (US), albeit almost a decade later than when they saw their greatest increases in inequality (Reardon \& Bischcoff, 2011).

The high levels of economic growth in Toronto in the last few decades have benefited some more than others. Although income inequality has stabilized in the Toronto region since 2001 (Hulchanski, 2018), it is still "the income inequality capital of Canada" (Dinca-Panaitescu et al., 2017, p. 4), exhibiting the largest gap between rich and poor households of all major Canadian cities.

The unequal distribution of income has negative impacts on individuals (Wilkinson \& Pickett, 2018) and on society (Wilkinson \& Pickett, 2009). Wilkinson and Pickett, social epidemiologists, provide evidence that "inequality promotes strategies that more self-interested, less affiliative, often highly antisocial, more stressful, and likely to give rise to higher levels of violence, poorer community relations, and worse health" (2005, p.22). High levels of income inequality have also been found to undermine democratic practices by concentrating political and economic influence among elites (Glaeser et al., 2002). Thus, the negative 
impacts can be perpetuating; as income inequality rises, access to opportunity decreases (DincaPanaitescu et al., 2017).

Income inequality has a spatial dimension as well: it manifests both among and within countries, provinces, regions, cities, and neighbourhoods (United Nations, 2015; Walks, 2013). The United Way Toronto, in partnership with the Neighbourhood Change Research Partnership, suggest that as income inequality grows, the neighbourhood one lives increasingly matters for intergenerational economic mobility (Dinca-Panaitescu et al., 2017). Therefore, it is important to understand how inequality and segregation are expressed in Toronto.

\subsection{INCOME SEGREGATION}

Spatial income inequality, or segregation, has also increased since the 1980s (Fong \& Shibuya, 2000; Hulchanski, 2007). The income gap between the wealthiest and the poorest census tract in Toronto went from four times to fourteen times between 1950 and 1985 (Fong \& Shibuya, 2000). As well, Toronto's lowincome neighbourhoods have lower average incomes than low-income neighbourhoods in cities with slower-growth and wealth generation, as well as some of the highest income neighbourhoods among cities in Canada (Murdie, 2013). Furthermore, Toronto exhibits one of the highest levels of spatial sorting by income among Canada's largest urban areas (Walks, 2013).

\subsubsection{Patterns of Segregation}

Hulchanski's three cities (2007) describes segregation trends in the Toronto region. Between 1970 and 2015 , census tracts with low average household incomes, referred to as City 3, moved from the core of the city to the edges of the inner suburbs, while census tracts with high average household incomes moved into the centre of the city and remained close to subway lines (Hulchanski, 2007). Income differentiation among households has been highest in neighbourhoods close to the centre of the city since the 1970s (Walks, 2013).

Segregation varies along two dimensions: 1) the extent to which one socioeconomic group is isolated from other socioeconomic households, and 2) the scale at which segregation manifests. 


\subsubsection{SEGREGATION OF POVERTY AND SEGREGATION OF AFFLUENCE}

The segregation of poverty and of affluence is the extent to which one socioeconomic group is isolated from households of other groups. This form of segregation matters since some families are more vulnerable to neighbourhood effects than others.

Poor households' social ties tend to be more localized and are therefore more likely to be impacted by the characteristics of their neighbourhood environment, in relation to wealthy households whom are more likely to have resources and networks outside of their neighbourhood (Ellen and Turner, 1997). Further, poor individuals are more isolated as measured by the number of unique neighbourhoods visited on average, a proxy for the extent of one's network (Sampson, 2018).

Rather than an outcome of income inequality, the segregation of poverty is a suspected consequence housing policy (Reardon \& Bischoff, 2011). Instead, income inequality appears much more strongly linked to the segregation of affluence (Reardon \& Bischoff, 2011), as much of the rise in socio-spatial inequality is driven by wealthy households sorting themselves into high-income neighbourhoods, rather than poor households sorting into low-income neighbourhoods (Walks, 2013). The segregation of affluence ("rich enclaves") creates significant problems, including fractured politics and concentrated negative social outcomes (Lens \& Monkkonen, 2016).

The level of segregation among high-income households is higher than that of low-income households in urban areas in the US (Reardon \& Bischoff, 2011). A similar pattern was found in Murdie et al.'s (2013) study of demographic clusters in Canada's largest metropolitan areas. The "affluent" cluster made up the largest of the fifteen clusters found in Toronto in 2005. In a follow up paper describing the spatial change patterns of neighbourhoods, "central city elite enforcement" made up the second largest cluster in the city (Murdie et al., 2014).

\subsubsection{GEOGRAPHIC SCALE}

The scale at which income segregation manifests within an urban area also varies. These scales impact the tax base and thus the quality of services available to residents differently (Reardon \& Bischoff, 2011). As well, understanding residential segregation patterns at multiple levels could help planners and policy makers develop more appropriate interventions for integration (Arcaya, 2018). 
Intra-neighbourhood income inequality defines the micro-scale. Overall, household income segregation has grown both among different neighbourhoods within in CMA as well as among households within the same neighbourhood (Walks, 2013). This is due to the gentrification of older central city areas and the movement of lower-income households into previously homogenous suburban neighbourhoods (Walks, 2013).

As with the segregation of poverty, income inequality is not responsible for patterns of small-scale segregation (Reardon \& Bischoff, 2011), such as those resulting from the gentrification of urban neighbourhoods that are adjacent to poorer, non-gentrifying neighbourhoods. It's suggested that neighbourhood level inequality captures the process of active household sorting and shorter-term income changes occurring through labour market shifts or changes in government assistance, rather than the result of municipal policies (Walks, 2013).

Almost all income segregation found in US urban areas is at the inter-neighbourhood, macro-scale (Reardon \& Bischoff, 2011). Macro-scale segregation may reduce the likelihood that wealthy residents will have social or casual contact with lower-income residents, thereby making them less willing to invest in metro-wide public resources that would benefit residents of all income levels. Further, it allows for less opportunities for disadvantaged families to benefit from the local spillover of public goods (Bischoff \& Reardon, 2011), and potentially for the lower numbers of neighbourhoods visited by poor individuals in a city (Sampson, 2018).

The trends found in the US are somewhat replicated in the Toronto region. Income segregation between municipalities in the CMA increased between 1980 and 2005, and again appear to be more linked to the segregation of higher-income households rather than that of lower-income households (Walks, 2013).

\subsubsection{Relationship Between Inequality and Segregation}

There is a robust relationship between income inequality and income segregation (Reardon \& Bischoff, 2011; Walks, 2013; Watson, 2009). Research by Reardon and Bischoff (2011) found that inequality can explain between about half and two-thirds of the variation in segregation in US metropolitan areas, with the effects stronger in larger areas. Checking for reverse causation, they found that segregation explains only about one-fifth of the variation in income inequality, showing a small feedback loop. 
While income segregation somewhat feeds back into greater income inequality, it more likely leads to inequality in social outcomes, even more so than the differences in income would predict. There is credible evidence that segregation, particularly concentrated disadvantage, has causal consequences for individuals' income and educational attainment potential, health, and political outcomes (Mayer, 2000; Quillian, 2007; Reardon \& Bischoff, 2011; Sampson, 2018).

High levels of inequality within small spatial units, such as a census tract, are not interpreted in the same negative light as income inequality within larger spatial units, such as a census metropolitan area. Intraneighbourhood inequality must be interpreted in relation to the overall trends in income inequality at larger scales. Between 1970 and 2005, overall household income inequality grew faster than intraneighbourhood inequality in Canada's major cities, even as inter-neighbourhood income segregation grew (Walks, 2013). Thus, the income inequality growth was not reflected within neighbourhoods. As well, segregation was macro-scale in nature, with socio-economic classes living further apart at the same time that certain neighbourhoods became more homogenous.

While segregation between neighbourhoods is mostly due to underlying increases in inequality at the metropolitan-area level (and thus to labour market shifts), a small proportion of the changes are explained by the active sorting of families (Chen et al., 2012). Sorting occurs as households move to different locales based on the local taxes and level of services offered, also known as the Tiebout hypothesis (Tiebout, 1956). Fong and Shibuya (2000) refer to this form of sorting as economic segregation wherein households choose their residential location based on the basket of economic prices and goods offered. This is different from the segregation of poor people, which occurs for reasons other than local economic policy. They found that little of the spatial separation of low-income households in Canadian cities is due to the Tiebout hypothesis, as a result of progressive taxation policies that aim to more evenly distribute resources (Fong \& Shibuya, 2000), including the funding and provision of public amenities, particularly educational facilities. Regardless, considerable segregation of poverty is still occurring in Canadian cities.

Apart from concentrated poverty and forced separation, though, it is unclear whether active sorting into neighbourhoods with like-households has positive or negative effects on well-being (Walks, 2013). More homogenous neighbourhoods might encourage stronger social networks (Goetz \& Chapple, 2010) or they might perpetuate structural inequality (Sampson, 2018). Though mixed-income neighbourhoods are a policy objective in many Canadian cities, in the absence of large variations in service quality income 
segregation may have less deleterious effects than in US cities. But although people may "choose their neighbourhoods, ... it's money that buys choice (Hulchanski, 2007, p. 19).

\subsection{OtHER FACTORS INFLUENCE ON INCOME SEGREGATION}

As income inequality accounts for about fifty to sixty-six percent of the variation in income segregation (Reardon \& Bischoff, 2011), there are other factors at play impacting income segregation. The following reviews the relationships between income segregation and other local variables from previous literature to inform the study of how these factors in turn influence intra-neighbourhood segregation.

\subsubsection{HOUSING}

Many studies have linked land-use regulations and certain housing policies to socio-spatial inequality, both at the micro and macro scale (Fong \& Shibuya, 2000; Ganong \& Shoag, 2015; Hulchanski, 2007; Lens \& Monkkonen, 2016; Reardon \& Bischoff, 2011; Saiz, 2010). Reardon \& Bischoff (2011) even suspect that housing policies drive the segregation of poverty more so than income inequality.

It is not clear how much income segregation occurs de facto, due to individual household preferences and active sorting, and how much occurs de jure, sanctioned by law and government structures, such as through exclusive zoning practices. Evidence suggests, however, that at least a portion of income segregation is due to local regulations (Fong \& Shibuya, 2000; Ganong \& Shoag, 2015; Hulchanski, 2007; Lens \& Monkkonen, 2016; Reardon \& Bischoff, 2011; Saiz, 2010). The two are not necessarily mutually exclusive; voters may prefer policies that enforce such regulations. And while segregation in practice (de facto) is the result of household choices, segregation by law can be remedied.

At the city level, tight land-use and housing regulations result in less regional income divergence and greater inequality between urban areas in the US as fewer lower-income households migrate to productive urban regions (Ganong \& Shoag, 2015). This process occurs whereby tight housing regulations decrease supply (Saiz, 2010), and because higher income households are able to outbid lower-income households for housing (with the strength of the effect increasing with higher levels of income inequality) (Reardon \& Bischoff, 2011) those higher incomes are capitalized into housing prices, increasing the overall price of housing and making housing more out-of-reach for lower income households, thereby perpetuating inequality and segregation (Ganong \& Shoag, 2015). Ganong and Shoag (2015) argue that 
land use restrictions have limited access to productive cities and their amenities for less skilled workers and lower-income households.

At the neighbourhood level, zoning laws that limit where social housing may exist, that prohibit multifamily housing or a mix of housing types, that require minimum lot sizes, and that place excessive restrictions on density have been shown to aggravate income segregation, particularly the segregation of affluence (Goetz \& Chapple, 2010; Lens \& Monkkonen, 2016; Reardon \& Bischoff, 2011). This occurs by increasing the exclusivity of neighbourhoods, rendering them inaccessible to lower-income households.

Housing regulation and policies also impact the level of (re)development in a city, tenure mix, built form and housing type, population density, and housing values, which in turn impacts housing costs (Fong \& Shibuya, 2000; Hulchansi, 2007; Walks, 2013).

Homeownership is a policy objective in both Canada and the US to help lower and middle-income households accumulate wealth. However, wealth inequality is still greater than income inequality in both countries (Chetty \& Hendren, 2018; Walks, 2013). Housing is an "inferior" good, such that within a labour market, low-skilled workers spend a disproportionate share of their income on it (Ganong \& Shoag, 2015). In expensive housing markets, such workers are less able to afford the purchase of a home, and receive below average returns when they do, after adjusting for maintenance and operating costs. Thus, housing prices impact the degree to which lower-income households have access to this means of wealthgeneration, as well as the degree of neighbourhood stability or change (Hulchanski, 2007).

Higher levels of redevelopment, particularly in suburban areas, has led to greater spatial separation of the poor in American cities (Fong \& Shibuya, 2000). New development tends to attract middle and upperincome households, while poor households are left in areas with little new investment or in older neighbourhoods. In Canadian cities, due to the relatively higher quality of public services and amenities, property values remain high and thus attract wealthy households to older housing units in older city centres (Fong \& Shibuya, 2000). New development in these central areas, however, may lead to greater spatial separation of the poor if they are displaced from such development. Uneven development is therefore another potential cause of spatial income inequality, as poor households have more limited access to both new (suburban) and redeveloped (gentrifying) land. 


\subsubsection{LABOUR AND HUMAN CAPITAL}

Shifts in labour market trends has led to greater income inequality and segregation at the macro scale (Ganong \& Shoag, 2015; Walks, 2013). The nature of work has changed in the previous few decades, with an increased demand for highly-skilled and technology-based occupations at the same time as more jobs have become precarious - insecure, temporary, and without benefits (Ganong \& Shoag, 2015; Hulchanski, 2007).

The wage differentials between occupational groups have increased (Walks, 2013). As well, there has been increased skill sorting among American cities, as skilled workers move to higher cost and more productive areas, while unskilled workers move out or stay in less productive cities (Ganong \& Shoag, 2015). Migration used to be directed towards highly productive regions; however, the shift to skill sorting has weakened human capital convergence, widened the gap between incomes, and contributed to macroscale spatial income inequality (Ganong \& Shoag, 2015).

\subsubsection{Demographics - Race, Ethnicity, and Migration Status}

There is a strong relationship between income segregation and racial and ethnic segregation as racialized communities are more likely to have lower incomes. Historically, the presence of low-income, racialized households ignited fear of declining property values in middle and upper-class white neighbourhoods (Rothstein, 2017).

Income segregation is correlated with racial and ethnic separation in both American and Canadian cities (Chetty \& Hendren, 2018; Fong \& Shibuya, 2000; Hulchanski, 2018; Reardon \& Bischoff, 2011; Sampson, 2018; Walks \& Bourne, 2006) and intergenerational racial economic mobility remains low (Sampson, 2018). Using quasi-experimental evidence, Chetty and Hendren (2018) determined that environmental conditions during childhood have causal effects on racial disparities.

In Canadian cities in the 1990s, both poor Asian and poor black Canadians were found to be moderately segregated from white Canadians, with poor black Canadians disproportionately more likely to be living in poor neighbourhoods (Fong \& Shibuya, 2000). Racial and ethnic segregation has significant effects on the spatial separation of poor households, especially among black residents, who are more likely than other racial groups to be low-income (Fong \& Shibuya, 2000, p. 450). Further, high-poverty neighbourhoods tend to be more racially diverse, while neighbourhoods with high concentrations of a 
single visible minority group typically have higher incomes and lower levels of poverty (Walks \& Bourne, 2006). In the Toronto region, visible minority and white populations are increasingly segregated, both within and between census tracts (Hulchanski, 2018).

Patterns of income segregation differ by race and ethnicity (Reardon \& Bischoff, 2011). For instance, since 1980, income segregation among black families in the US was found to be higher than among white families, with the effect higher on the segregation of affluence (Reardon \& Bischoff, 2011). While poor individuals, regardless of race, face greater isolation (based on the number of unique neighbourhoods visited), non-poor African-Americans and Hispanics were also found to visit less "neighbourhoods of opportunity" (Sampson, 2018). Thus, racial segregation not only manifests in where people live but also where they travel throughout the city and to whom they are exposed. As well, racial segregation in the US was found to predominantly occur at the meso, census-tract level, rather than at the macro-scale across urban regions (Arcaya, 2018). Finally, the significance of redevelopment in Canadian cities on the increased segregation of poor households was found to apply only to black Canadians, whom are more vulnerable to changes in their residential environment (Fong \& Shibuya, 2000).

\subsection{KNOWLEDGE GAP AND THEORETICAL FRAMEWORK}

Previous studies either offer a more descriptive picture of income segregation in the Toronto region or an empirical analysis of the impact of a specific aspect on income segregation, mostly in the US. There is a lack of up-to-date knowledge of the various factors which influence income segregation in the Toronto CMA.

Further, most studies use point-in-time data, which have a lot of shortcomings and lack the important insights that longitudinal analyses offer (Ellen \& Turner, 1997; Fong \& Shibuya 2000), such as the ability to test predictions. Moreover, most extant literature lacks analysis at multiple scales, which are important for understanding how geographic levels contribute to segregation in a region (Arcaya, 2018). To address these opportunities, this study describes the trends and current conditions of income inequality in the Toronto region at three different scales and examines the linkages between various neighbourhood characteristics on income segregation. By controlling for location effects, year effects, and overall regional trends, it uncovers the conditions that are likely to lead to either homogenous or more income-diverse neighbourhoods. 
Based on previous literature, it is predicted that both income inequality and income segregation have increased in the Toronto CMA since 1985. Further, it is assumed that the region is not unlike cities in the US, and therefore that differences in housing, labour, and demographic characteristics influence the degree to which segregation manifests at the neighbourhood scale. 


\section{DATA}

The data for this study comes from Statistics Canada's 1986, 1996, 2006, and 2016 Census of Population, a common data source for studies of this kind in Canada (Fong \& Shibuya, 2000; Hulchanski, 2007; Walks, 2013). The profiles provide information on the labour market conditions, neighbourhood qualities, housing costs, and socioeconomic characteristics of census tracts within the Toronto CMA.

\subsection{SPATIAL UNITS}

Toronto represents the largest metropolitan area in Canada. The Toronto CMA, rather than the municipality, more accurately represents residents" "commuting zone" and is common in studies that consider labour and housing markets (Hulchanski, 2007; Murdie et al., 2013, 2014; Reardon \& Bischoff, 2011; Walks, 2013). It thus does not explicitly take into consideration differences in municipalities' local policies that affect residential patterns, such as zoning regulations and land-use controls.

Further, the CMA is analyzed, rather than the Greater Toronto Area (GTA), due to the much greater ease of accessing data. Therefore, the City of Burlington and much of Durham Region are excluded from the study (see Figure 1). Ideally, the study would include census tracts from the Oshawa, Barrie, and Hamilton CMAs, as individuals are increasingly making longer commutes to access employment. However, the boundaries of these CMAs have changed even more so than Toronto's over time. 
Figure 1: Comparison of Toronto Census Metropolitan Area and the Greater Toronto Area

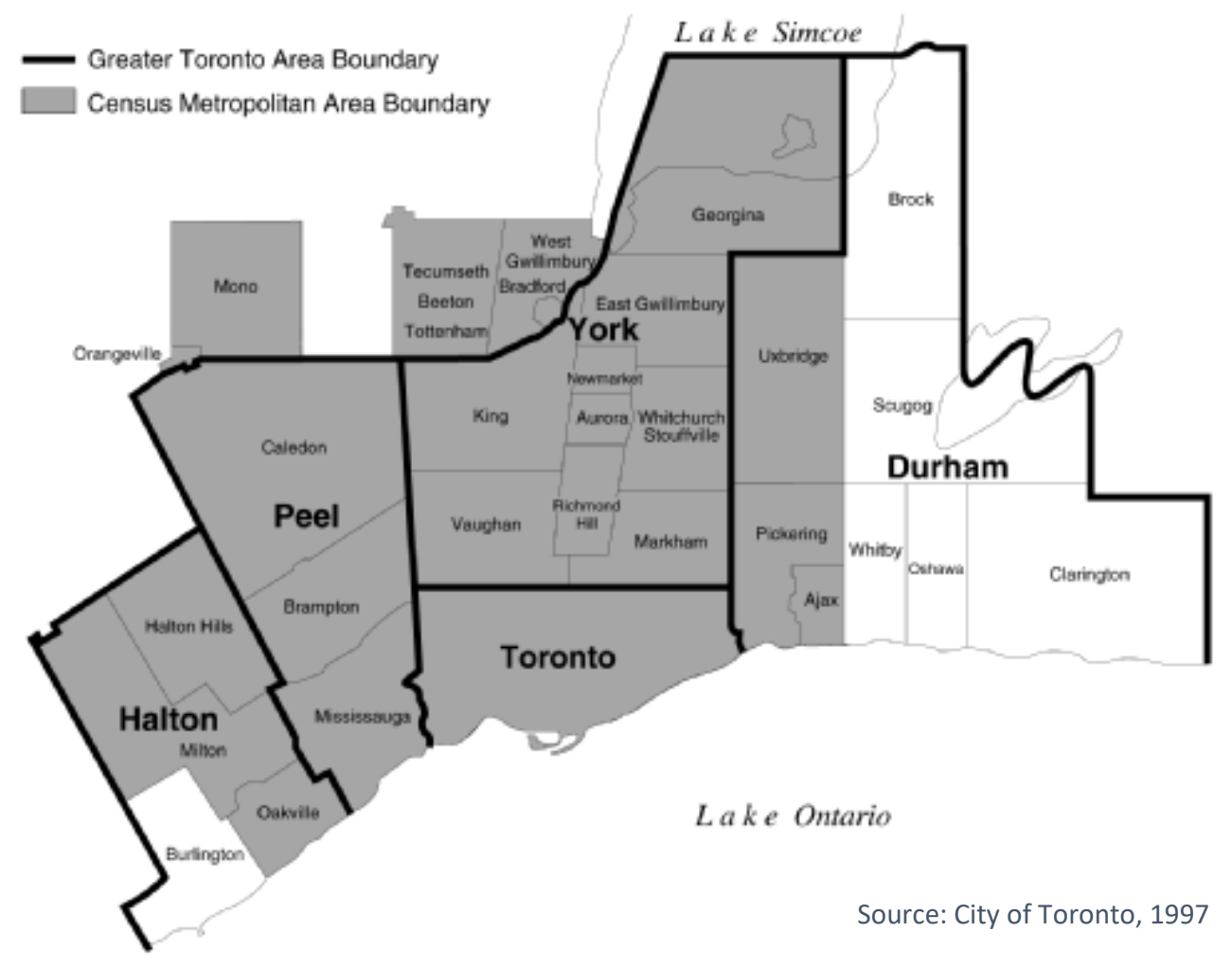

Census tracts are commonly used as a proxy for neighbourhoods (Fong \& Shibuya, 2000; Hulchanski, 2007; Murdie et al., 2013, 2014; Walks, 2013), due to their relative size (about 4,000 people on average) and availability of data. Dissemination areas are smaller (between 400 and 700 people), however they have high data suppression rates and fewer publicly available variables. Ellen and Turner (1997) study phenomena at the school division level, which are larger than census tracts. This could be significant as socialization and peer influences are two mechanisms through which researchers believe neighbourhood effects children's outcomes (Chetty \& Hendren, 2018; Ellen \& Turner, 1997; Sampson, 2018), particularly in the US due to their alternative method for funding education. In Canada, school districts are less common in studies, are predicted to have less of an effect, and are more difficult to aggregate data than are census tracts.

While census tract boundaries mean nothing to most residents and don't "fully capture the reality of neighbourhood activity spaces" (Walks, 2013, p.23), they are nonetheless the most commonly used and comparable small spatial unit available. The total number of census tracts in the Toronto CMA was 732 in 1985; 809 in 1995; 999 in 2005; and 1,151 in 2015, for a total of 3,691 observations. 


\subsection{TIME PERIODS}

This study analyzes the change in income inequality and segregation over a 30-year period, from 1985 to 2015 , the most recent year for which census data are available. The reasons for the selection of 1985 as the initial year are: 1) it enables even 10-year study periods up until the most recent census; 2) there are enough comparable variables for each census year; 3 ) the CMA boundaries are sufficiently comparable to 2015, except for a couple tracts near Barrie; and 4) it precedes many of the major shifts in the labour market and in ethnic composition (Murdie et al., 2014).

Census tracts in years prior to 2015 are linked to 2015 tracts through apportionment tables created by Allen and Taylor in 2018 to help researchers better measure neighbourhood change. The crosswalk tables in the newly created Canadian Longitudinal Tract Database (CLTD) account for population density and land use to link boundary identifiers between years using a set of apportionment weights (Allen \& Taylor, 2018).

This Canadian crosswalk database provides much more precision and allows one-to-one census tract comparisons. Previous studies in Canada relied on courser methodologies to match census tracts between years, such as evenly splitting or averaging values in census tracts that were split over time and dropping “orphan" tracts (Hulchanski, 2007; Murdie et al., 2014).

\subsection{VARIABLE SELECTION AND DEFINITIONS}

The hypothesized relationships between various neighbourhood characteristics and income segregation, in particular that proxies for high dwelling values are correlated with greater levels of intraneighbourhood segregation, are based on previous analyses conducted in Canada and the US. The study began with 31 variables and was narrowed to 14 by examining the collinearity between the 31 variables.

Income and Inequality. Before-tax total household income is used as the income measure. "Total income" includes market income, government transfers, and investment income, and is therefore a better indicator of purchasing power than employment income, which only makes up about two-thirds of total income (Walks, 2013). While after-tax income data is preferable because changes in taxation on the level of inequality would be considered (Walks, 2013), only before-tax income data is available before 2000. The same basic pattern of rising income inequality is true whether looking at before- or after-tax income 
(Walks, 2013), though, and before-tax income measures are common in studies of this kind (Chetty \& Hendren, 2018; Hulchanski, 2007; Walks, 2013).

Finally, income is measured at the household, rather than the family level for three reasons: 1) households represent the primary residential and spending unit (Bourne, 1993; Reardon \& Bischoff, 2011) and consumption capacity (Walks, 2013); 2) therefore, they more accurately provide "information on how individuals might pool resources" to access housing and other goods and services (Walks, 2013, p. 22); and 3 ) the location choices and barriers to household mobility largely determine the extent and pattern of income segregation by neighbourhood (Walks, 2013).

Other researchers, including many Statistics Canada reports, use family income (Chetty \& Hendren, 2018; Reardon \& Bischoff, 2011) and some use individual income (Hulchanski, 2007). While segregation by family income and by household income are highly correlated (Reardon \& Bischoff, 2011), non-family households represent about $30 \%$ of households (Statistics Canada, 2006, 2016), and thus family income measures leave out a significant proportion of the population.

Household income bins are used to compute the Gini coefficient for each census tract (see methodology section), which is then used as the dependent variable in the regressions.

\subsubsection{EXPLANATORY VARIABLES}

Dwelling Value. The average value of dwellings within census tracts is used as a proxy for housing costs. Dwelling values are adjusted for inflation to 2015 Canadian dollars, using Statistics Canada's consumer price index (CPI), less shelter costs, in order to provide a consistent measure of purchasing power over time. Additionally, values are logged to normalize their distribution. Hulchanski (2007) believes that the presence of more affordable housing may be one way to address income segregation, and that the price of housing is a key determinant of neighbourhood stability or change. Therefore, this variable aims to measure the extent to which housing costs have impacted income segregation in the region since 1985.

Rate of Development. The proportion of new housing units, those built within the five years preceding each census, is used as a proxy for urban development and renewal. Extensive redevelopment is thought to be positively related to the spatial separation of the poor (Fong \& Shibuya, 2000). This variable thus aims to measure whether increased development leads to greater income mixing, through gentrification, or to greater economic homogenization within census tracts. 
Dwelling Vintage. In many cities, particularly in the US, lower-income households inhabit older housing units than do higher income households (Fong \& Shibuya, 2000), though this has not been the case in Toronto's central city (Fong \& Shibuya, 2000). The proportion of housing units constructed before 1960 measures the extent to which the pattern holds in areas outside of the core of the city. Hulchanski (2007) found that City 1 , defined as census tracts with a high average household income, has a much higher proportion of its housing units built before 1946. Dwelling units constructed before 1946 would be a more appropriate and informative vintage measure, however this variable is not available in the 2016 census.

Tenure. There is greater wealth than income inequality (Chetty \& Hendren, 2018; Walks, 2013), and homeownership is one way for households to build wealth. In Canadian cities, renter households are much more likely to be low-income (CANCEA \& CUI, 2019) and to spend a greater proportion of their income on housing costs (Hulchanski, 2007) than are households which own their homes. Renters are also more prevalent in Hulchanski's (2007) City 3. The proportion of households which own their dwellings measures the extent to which tenure mix drives income segregation in the region.

Built Form Type and Density. Housing policies that regulate built form and density impacts income segregation in US cities (Ganong \& Shoag, 2015; Lens \& Monkkonen, 2016; Reardon \& Bischoff, 2011; Saiz, 2010). Census tracts' proportion of single-detached housing units, the proportion of apartments with more than five storeys within a census tract, and population density are proxies for density and for the potential existence of restrictive housing policies. The former two measure the extent to which built form impacts micro-scale segregation. The latter measures the extent to which density impacts the homogeneity or heterogeneity of census tracts.

Labour and Human Capital. The employment rate is often used both as a proxy for neighbourhood conditions and as an outcome measure (Chetty \& Hendren, 2018; Ellen \& Turner, 1997). The following two variables are included: 1) the unemployment rate, constructed as the proportion of individuals in the labour force without employment; and 2) the proportion of "blue collar" workers, which includes those employed in manufacturing, construction, transportation, utilities, trades, or processing (Hulchanski, 2007). These variables measure the extent to which labour conditions and the skills of residents drive income segregation.

Race and Ethnicity. The following racial and ethnic groups are included in the analysis: black, Asian, and South Asian. The proportion of individuals in these groups within each census tract measures the extent to which the presence of racialized minorities drives income segregation. Many other studies, particularly 
those looking at US cities, also include Hispanic individuals in comparisons of income inequality and segregation (Currie, 2011; Fong \& Shibuya, 2000; Reardon \& Bischoff, 2011; Sampson, 2018). However, the information is not included in the 1986 census and has too few cases within each census tract to be informative.

Migration Status. The proportion of immigrants measures the extent to which Canadian newcomers impact income segregation. The proportion of residents in a census tract who moved in the five years preceding the census in question is a proxy estimate for net migration (Danong \& Shoag, 2013). Like the rate of development, the variable measures the extent to which resident stability or change effects income segregation at the micro-scale. 


\section{Methodology}

This paper verifies previous descriptions of the spatial and temporal trends in income inequality and segregation in the Toronto region since 1985 (Fong \& Shibuya, 2000; Hulchanski, 2018; Walks, 2013) using more robust measurement techniques. The combination of both multiple geographic scales and temporal changes reveals trends in how segregation has evolved in different places over time (Arcaya, 2018). A closer look at intra-neighbourhood trends answers the following: what various neighbourhood level factors are significant in explaining variations in micro-scale income segregation?

The analysis includes three major steps: 1) descriptive mapping; 2) descriptive statistics at multiple geographic scales; and 3) multivariate analysis, using ordinary linear regression (OLS) and fixed-effects models. It describes the patterns, trends, and changes that have occurred in the Toronto CMA since 1985, as well as determines how much of the variation in income segregation within census tracts is due to various neighbourhood characteristics.

The data are analyzed at three scales. First, non-spatial inequality is measured using household income bins for the entire CMA. Second, inequality between neighbourhoods in the CMA is measured using census tracts as the unit of analysis. Third, inequality within neighbourhoods is measured using household income bins. This study examines how income inequality and segregation at all three scales has changed over time. This multi-scalar approach examines how segregation occurs at different geographic levels in the Toronto CMA (Arcaya, 2018).

This project uses $R$ programming language, RStudio ( $R$ Core Team, 2018) for data management, processing, and statistics, and ArcGIS software (ESRI, 2018) to produce maps and perform spatial analysis.

\subsection{GINI COEFFICIENT}

The Gini coefficient is calculated at two scales to measure both non-spatial and spatial income inequality. The Gini coefficient is a ratio measure of the deviation from an absolutely equal income distribution (Hulchanski, 2018), as shown in Figure 2. It is the most commonly used measurement of inequality and is the best measure to capture shifts in both inequality and segregation (Walks, 2013). 
Figure 2: The Gini Coefficient's Lorenz Curve and Line of Perfect Equality

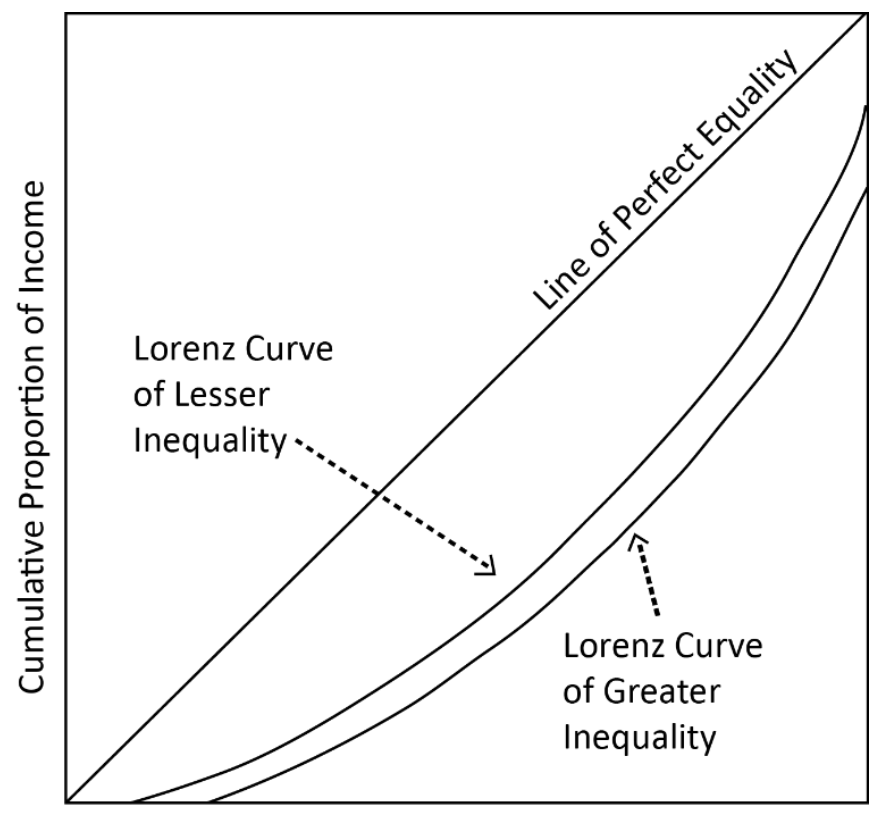

Cumulative Proportion of Population

Source: Walks, 2013

A Gini coefficient value of 0 represents perfect income equality, where all households receive the same income, while a value of 1 represents complete inequality, where one household captures all the income and leaves all other households with nothing. Therefore, the higher the Gini coefficient, the greater the inequality. In reality, Gini coefficients usually range from a low of about 0.24 to a high of about 0.62 among OECD countries, with most countries falling below 0.4 (OECD, 2019). Canada's overall Gini coefficient was 0.31 in 2016 (OECD, 2019).

The equation to estimate the Gini coefficient is:

$$
\sum_{i=1}^{n-1}\left|x_{i} y_{i+1}-x_{i+1} y_{i}\right|
$$

where, $x_{i}$ represents the cumulative proportion of the population in census tract (or CMA) $\mathrm{i}$, using population weights from income bins, and $y_{i}$ represents the cumulative proportion of household income in census tract (or CMA) i. 


\subsection{MEASURING OVERALL INCOME INEQUALITY}

The Gini coefficient is first used to calculate non-spatial income inequality for each year, using household income bins for the entire Toronto CMA. The ratios are used to verify previous findings regarding income inequality trends in the region, and to interpret neighbourhood level Gini coefficient values, as changes in micro-scale inequality can only be interpreted in relation to the overall changes in income inequality at the regional scale (Walks, 2013).

\subsection{MEASURING AND MAPPING InCOME SEGREGATION}

Segregation can exist at several levels simultaneously. Spatial income inequality is measured both among neighbourhoods within the Toronto CMA and among households within each census tract in the region.

Neighbourhood segregation is first calculated through a cluster and outlier analysis using Anselin Local Moran's I statistic in ArcMap. Moran's I measures the extent that similar income levels cluster and determines the degree of similarity between nearby census tracts. The resulting z-scores reveal the statistically significant clusters and census tract outliers, at a 95\% confidence level. High positive z-scores produce the following cluster types: 1) high-income tracts surrounded by other high-income tracts and 2) low-income tracts surrounded by other low-income tracts. High negative z-scores produce the following outlier types: 3) high-income tracts surrounded by low income tracts and 4) low-income tracts surrounded by high income tracts. Low z-scores represent census tracts that are not significantly clustered.

Like Hulchanski's (2007) study, this measure uses the average income of each census tract to estimate the degree of neighbourhood spatial segregation. This measure aims to both verify the previous patterns found as well as provide a more robust and statistically significant measure of neighbourhood income clustering within the Toronto CMA.

While many studies have looked at income inequality among census tracts (Fong \& Shibuya, 2000; Hulchanski, 2007) not many have not looked at income inequality within census tracts. The Gini coefficient is calculated using household income bins within each census tract to measure intra-neighbourhood inequality. This measure of micro-scale inequality captures the degree of class homogeneity in each census tract. This provides more detail about changes in income segregation in the region.

Gini coefficients at the neighbourhood level are not interpreted in the same way as they are at larger geographic scales, such as the region or country. Low Gini coefficients at larger scales represent more 
equal societies, while at the micro-scale can be an indication of class concentration. Likewise, high Gini coefficients at macro-scales represent more unequal societies, while at the neighbourhood level may either represent class integration, an aim of "mixed-income community" policies, or may be indicative of increased income polarization or gentrification in a neighbourhood.

The Neighbourhood Sorting Index (NSI), developed by Kim and Jargowsky (2005), gives a relative measure of the inequality one would expect in each census tract, based on the overall level of inequality in the CMA. The NSI is calculated by dividing the census tract Gini coefficients (segregation) by the CMA's overall Gini coefficient (inequality). The result measures the level of neighbourhood sorting and "provides a picture of the proportion of total household income inequality accounted for by differences between neighbourhoods" (Walks, 2013, p. 51). That is, the extent to which micro-scale inequality is or is not explained by the region's level of inequality. An NSI below 1 indicates that the income distribution within each census tract is less varied than the CMA, while an NSI above 1 indicates that the income distribution within a census tract is more varied, or unequal, than the CMA as a whole.

\subsection{Multivariate AnAlysis}

In addition to merely describing the trends and current level of intra-neighbourhood income inequality, statistical analysis identifies and evaluates the influence of various neighbourhood characteristics on micro-scale income segregation.

To account for variation in income segregation, the within census tract Gini coefficient is regressed on 14 explanatory variables including housing characteristics, labour conditions, racial and ethnic composition, and rate of stability or change.

There are six regression specifications: 1) a baseline OLS regression with lagged variables, 2) an ordinary least squares (OLS) pooled regression using panel data, 3) a panel regression controlling only for year fixed-effects, 4) a panel regression controlling only for neighbourhood fixed-effects, 5) a panel regression controlling for both neighbourhood and year fixed-effects, and 6) OLS regressions for each year in the series to determine the significance of each variable in each year.

The OLS regression with lagged variables measures the extent to which conditions in the previous time period influences intra-neighbourhood inequality in the following period and is used as a baseline. The 
pooled OLS regression models combines all census years into one regression but ignores unmeasured heterogeneity inherent in the time-constant neighbourhood effects.

The equations for the baseline OLS regression using lagged variables and the pooled OLS regression, without the fixed-effects, are:

$$
\begin{array}{ll}
Y_{i t}=\beta_{1} Y_{i t-1}+\beta_{1} X_{i t-1}+u_{i t} & \text { [baseline OLS regression using lagged variables] } \\
Y_{i t}=\beta_{1} X_{i t}+u_{i}+u_{i t} & \text { [pooled OLS regression, without fixed-effects] }
\end{array}
$$

where, $Y_{i t}$ represents the Gini coefficient (the dependent variable) for census tract $i$ at year $t, Y_{i t-1}$ represents the lagged Gini coefficient for census tract $\mathrm{i}$ at the previous year $\mathrm{t}-1, \mathrm{X}_{\mathrm{it}}$ represents the timevariant independent variables (IV) for census tract $\mathrm{i}$ at the previous year $\mathrm{t}-1, \mathrm{u}_{\mathrm{i}}$ represents the timeinvariant independent variables (IV) in census tract $i$, such as distance to the downtown core, $\beta_{1}$ represents the coefficient for the IVs, and $\mathrm{u}_{\mathrm{it}}$ represents the unobserved errors.

\subsubsection{CONTROLLING FOR Bias USIng FIXED-EfFECTS MOdELS}

Fixed-effects models control for confounding factors and unobserved bias, thereby removing heterogeneity. They are commonly used in neighbourhood effects literature to control for family effects, both observed (income, race, etc.) and unobserved, such as values (Chetty \& Hendren, 2018; Ellen \& Turner, 1997), as well as in economics research to control for metropolitan-area confounding covariates (Galster, 2012; Reardon \& Bischoff, 2011; Watson, 2009; Yang \& Jargowsky, 2006).

Fixed-effects are a sophisticated method for controlling for bias in non-experimental research design (Galster, 2012), and get closer to causal, rather than merely descriptive, explanations (Chetty \& Hendren, 2018; Ellen \& Turner, 1997; Reardon \& Bischoff, 2011). The models treat census tracts and years as sets of dummy variables and removes the effect of their time-invariant characteristics in order to assess the net effect of the predictors on the outcome variable, the intra-neighbourhood Gini coefficient. Thus, any time-constant variable gets "absorbed" by the fixed effect. The equation for the entity (census tract) fixedeffects model is:

$$
\mathrm{Y}_{\mathrm{it}}=\beta_{1} \mathrm{X}_{\mathrm{it}}+\alpha_{\mathrm{i}}+\mathrm{u}_{\mathrm{it}}
$$


where, $\alpha_{i}$ represents an unobserved time-constant unit effect ("fixed effect"), $Y_{\text {it }}$ represents the Gini coefficient (dependent variable) for census tract $\mathrm{i}$ at time $\mathrm{t}, \mathrm{X}_{\mathrm{it}}$ represents the independent variables (IV), $\beta_{1}$ represents the coefficient for the IVs, and $\mathrm{u}_{\mathrm{it}}$ represent the unobserved errors.

The time-effects capture temporal changes that are common to all census tracts in the Toronto CMA (Angrist \& Pischke, 2015). The final regression model combines the census tract and year effects to control for both fixed location characteristics, such as suburban effects, and overall trends in the region, including declining household size and the strength of the economy and labour market. The equation for the time and entity fixed-effects model is:

$$
Y_{i t}=\beta_{0}+\beta_{1} X_{1, i t}+\ldots+\beta k X_{k, i t}+\gamma_{2} E_{2}+\ldots+\gamma_{n} E_{n}+\delta_{2} T_{2}+\ldots+\delta_{t} T_{t}+u_{i t}
$$

where, $Y_{\text {it }}$ represents the Gini coefficient (dependent variable) for census tract $i$ at time $t, X_{k}$, it represents the independent variables (IV), $B_{k}$ represents the coefficient for the IVs, $u_{i t}$ represents the unobserved errors, $E_{n}$ represents census tract $n$ (since they are binary there are $n-1$ entities included in the model, totalling 1,150 census tracts), $\gamma_{2}$ represents the coefficients for the binary regressors (census tracts), $T_{t}$ represents time as a binary variable (so we have $\mathrm{t}-1$ time periods, totalling 3 years), and $\delta_{\mathrm{t}}$ represents the coefficients for the binary time regressors.

If the unobserved variable does not change over time, then any changes in the Gini coefficient can be said to be due to influences other than these fixed characteristics. By controlling for place and time effects, the fixed-effects regression models are able to attribute the degree to which each variable impacts the micro-level inequality within neighbourhoods in the Toronto CMA. The hypothesis is that each of the explanatory variables will have a significant effect on the level of household income inequality in a neighbourhood.

\subsubsection{CheCKIng FOR MULTI-COlLINEARITY}

When two or more predictor variables are correlated with each other in multiple regression there is redundancy in the model, known as collinearity. Multi-collinearity, an overcounting type of bias, is the extreme version where collinearity exists between three or more variables. For each predictor variable, multi-collinearity can be assessed by computing the variance inflation factor (VIF), which measures how much of the regression coefficient is inflated due to multicollinearity in the model (James et al., 2014). The smallest VIF value is 1 , representing an absence of multi-collinearity, while a VIF value that exceeds 5 
or 10 indicates a problematic amount of collinearity. The predictor variables with VIFs above 8 are not included in the final model, since their presence indicates that the information provided is redundant in the presence of other variables. 


\section{RESULTS AND DISCUSSION}

\subsection{OVERALL TRENDS}

In line with other research, the non-spatial Gini coefficient measure of income inequality increased substantially between 1985 and 1995, levelled off in the early 2000s, and has risen slightly since, though still not returning to 1995 's inequality level (Hulchanski, 2018; Walks, 2013), as shown in Figure 3. While the overall income inequality measure describes trends in household income distribution for the region over time, it says nothing about how inequality is expressed geographically and distributed throughout the region.

Figure 3: Overall Non-Spatial Gini Coefficient for the Toronto CMA, 1985-2015

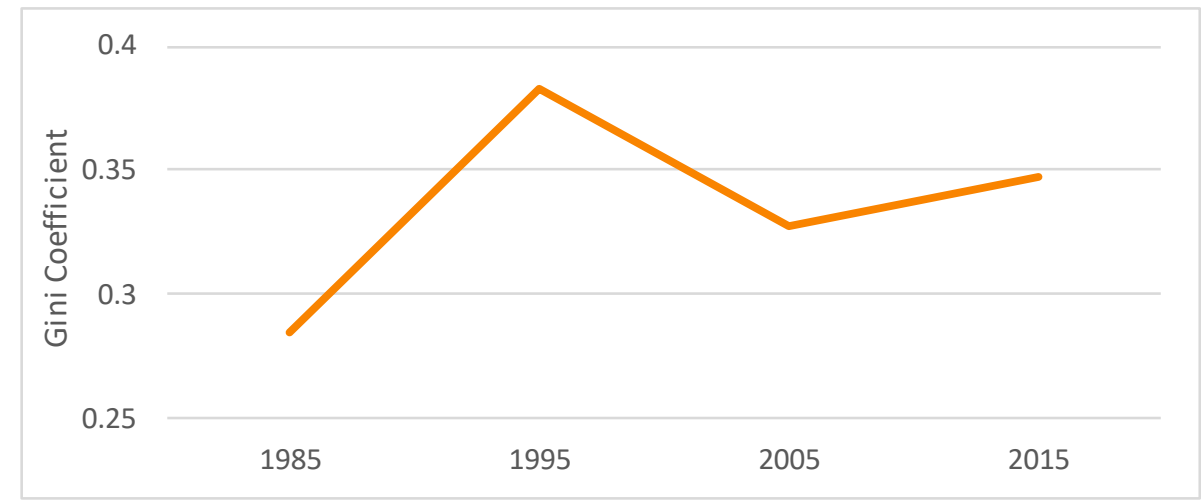

\subsection{InCOME SEgREgation BetWeEn NeighbourhoOdS}

Between 1985 and 1995, clusters of high-income neighbourhoods spread slightly throughout the 905 region, and clusters of low-income neighbourhoods spread slightly to the northwestern and northeastern parts of the City of Toronto, as shown in Figures 3 and 4. For a comparison of the data using original census tract boundaries, before apportioned with the crosswalk table, see Appendix A. 
Figure 4: Statistically Significant Household Income Clusters and Outliers among Neighbourhoods, Toronto CMA, 1985

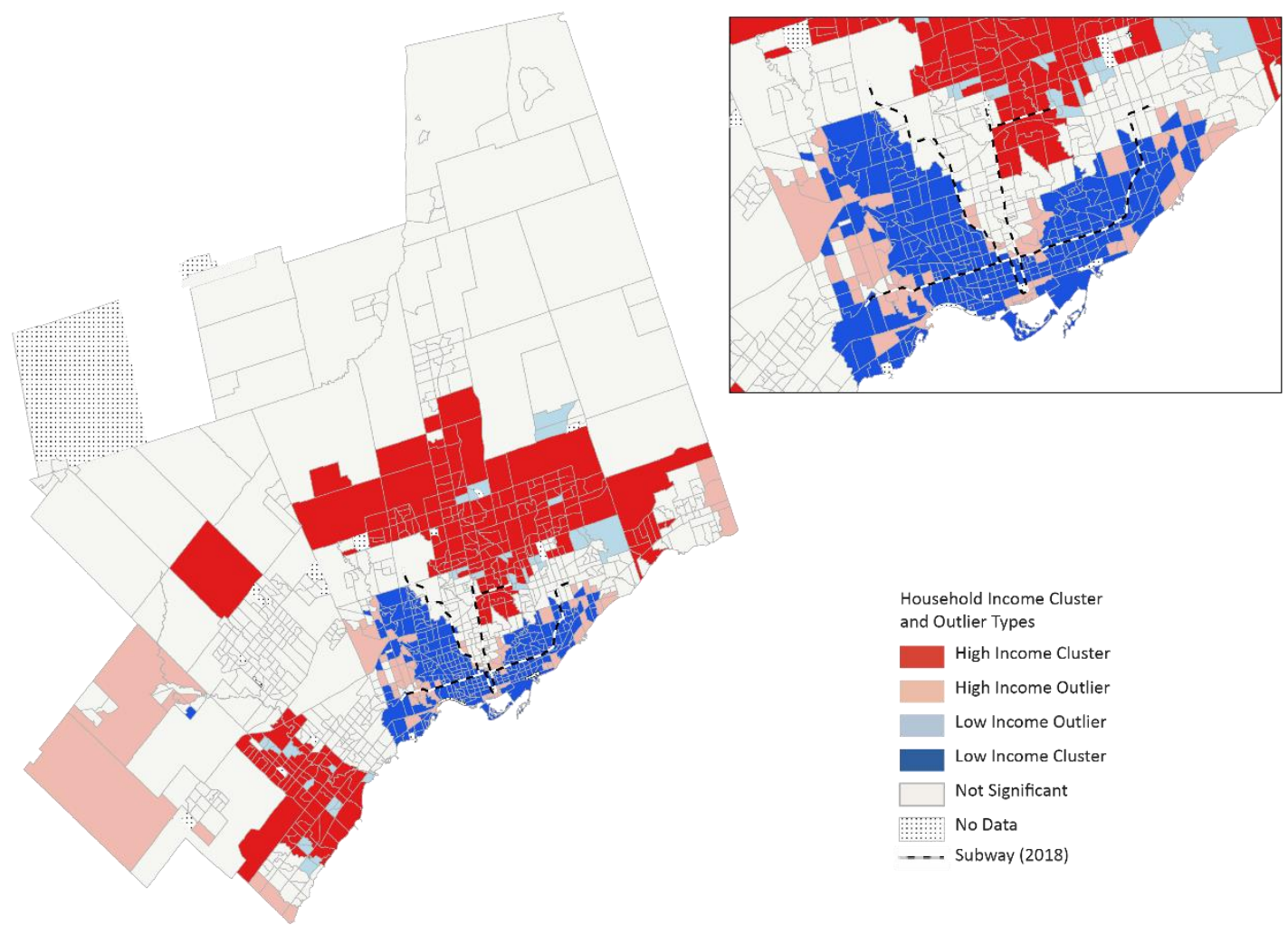

Figure 5: Statistically Significant Household Income Clusters and Outliers among Neighbourhoods, Toronto CMA, 1995
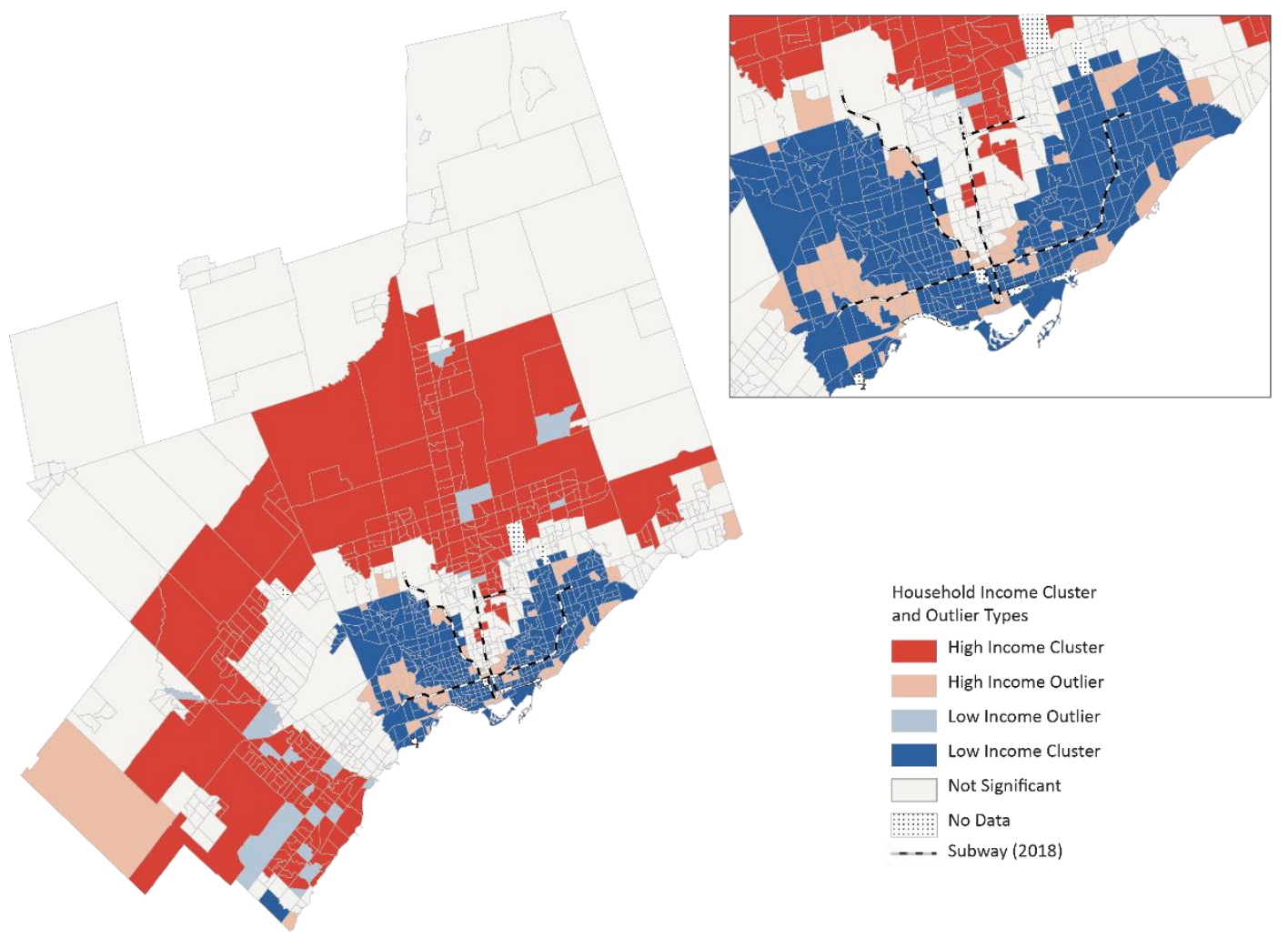
In 2005, the remaining clusters of high-income neighbourhoods were located in a few pockets in the outer suburbs, and along the Yonge subway line, north of Bloor (see Figure 6). At the same time, many of the clusters of low-income neighbourhoods moved out of the downtown core, apart from the areas in and around Parkdale. Most of the low-income clusters at this time were located in Scarborough, the northwest of the City of Toronto, and parts of Peel Region, including Brampton.

Figure 6: Statistically Significant Household Income Clusters and Outliers among Neighbourhoods, Toronto CMA, 2005

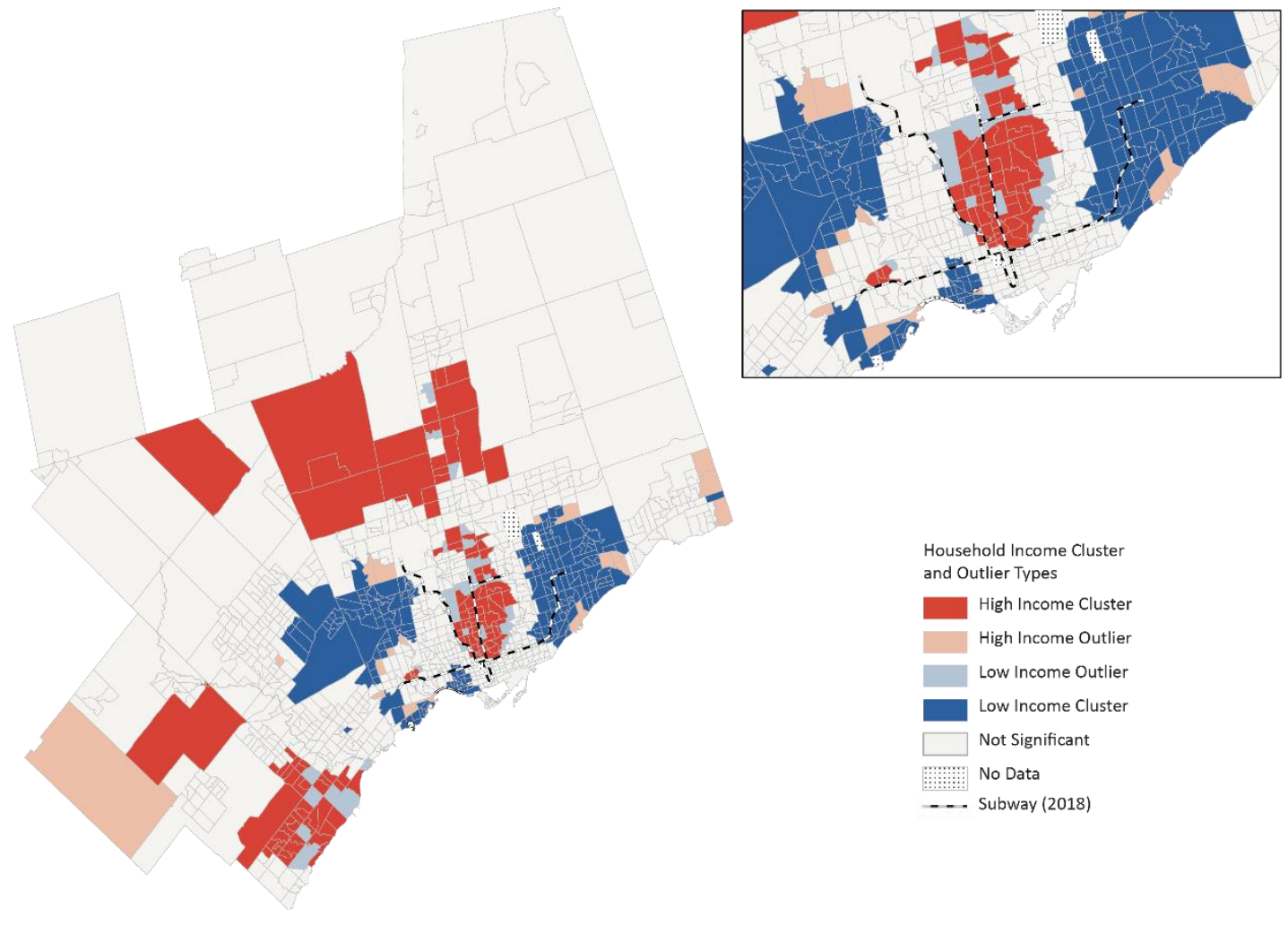

The clusters of high-income neighbourhoods along the Yonge subway line, around the High Park subway station, and in the south part of Halton Region, including Oakville, appear to be reinforced in 2015, while the high-income clusters in the northern part of the CMA lost significance in 2015 (see Figure 7). The clusters of low-income neighbourhoods, on the other hand, expanded in the Peel Region and in the eastern and northwestern parts of the City of Toronto, while the low-income cluster around Parkdale lost significance. 


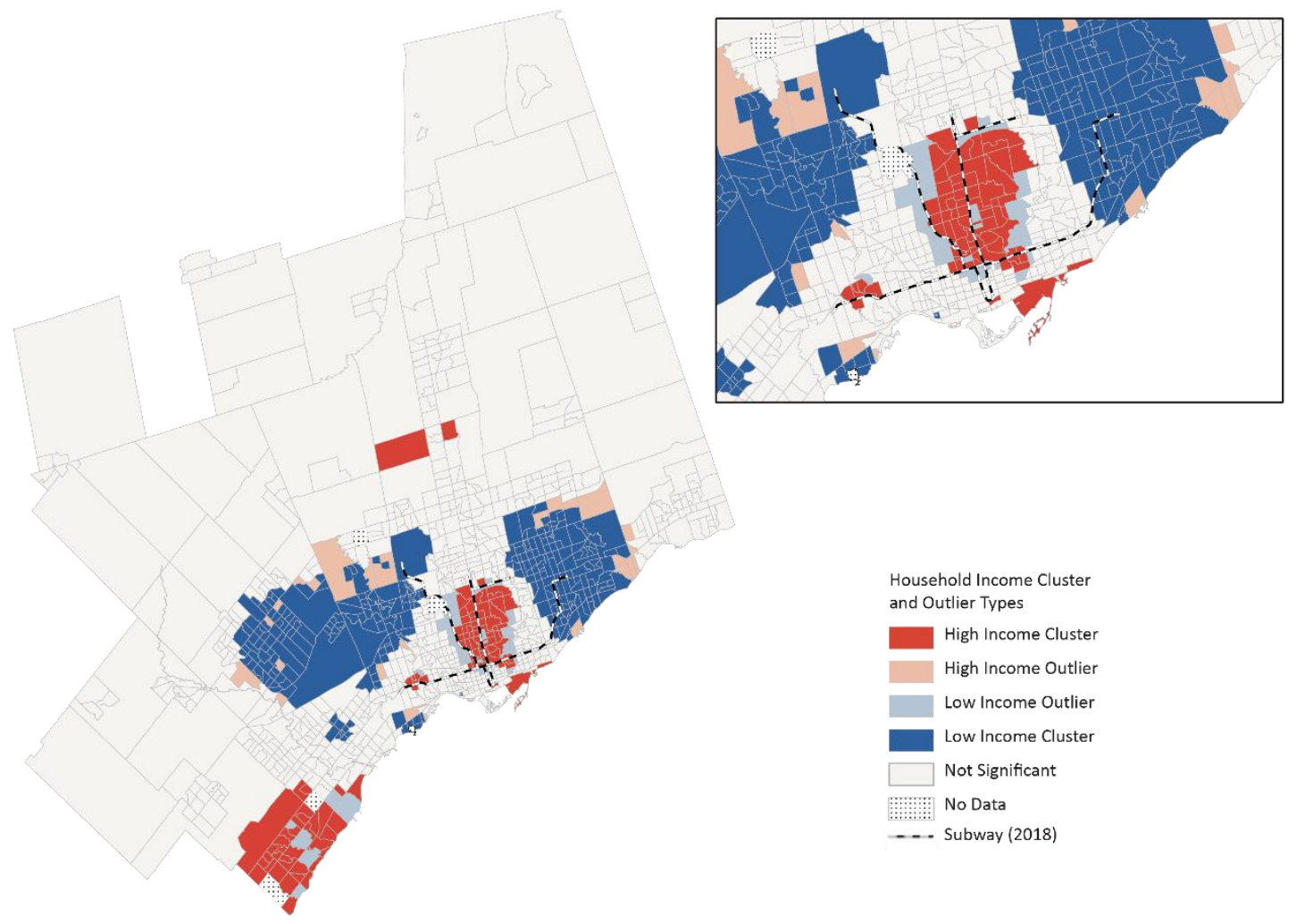

The period with the highest levels of spatial clustering by neighbourhood was in 1995 and the lowest levels was in 2005 (see Figure 8). However, this study does not account for the possibility of polarization. High polarization signals that household incomes are in the extremes and that the middle class is hollowing out. Gentrification in the core could lead to this scenario, resulting in medium average incomes and masking inequality trends at the micro-scale. Walks (2013) found intra-neighbourhood income polarization increased between 1970 and 2005 in Toronto.

Figure 8: Statistically Significant Household Income Clusters and Outliers among Neighbourhoods, Toronto CMA, 1985 - 2015

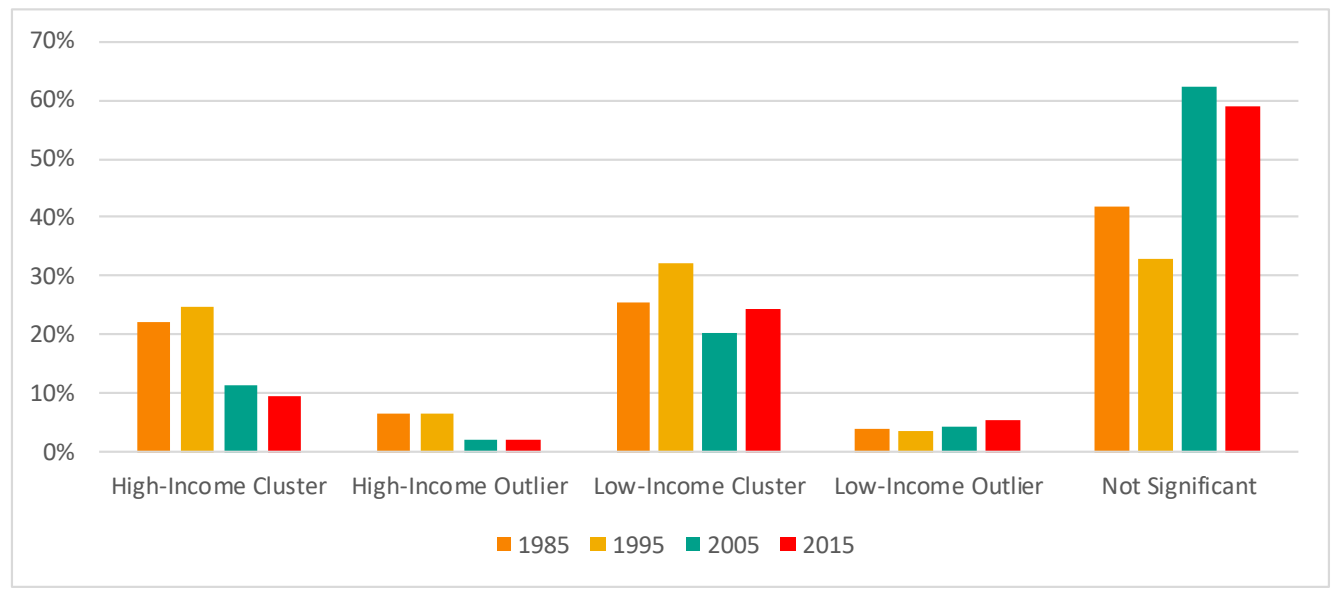


Using Anselin Local Moran's I statistic of spatial autocorrelation, it seems that contrary to much of the literature (Lens \& Monkkonen, 2016; Reardon \& Bischoff, 2011), increasing income inequality in the Toronto CMA has not led to an increase in the segregation of affluence, based on the number of census tracts that have high average household income values and that are surrounded by other census tracts with high values, at least not at the macro-scale. As well, outlying neighbourhoods with high average incomes surrounded by census tracts with low average incomes decreased substantially since 1995, while outlying census tracts with low average incomes surrounded by census tracts with high average incomes have increased slightly over time. This could potentially be the result of increasing gentrification of previously lower-income, central neighbourhoods. Finally, neighbourhoods with low average household incomes have remained relatively constant over time.

In general, most census tracts within the CMA have either not changed their cluster or outlier type or their cluster or outlier type lost their significance since 1985 (see Figure 9). The emerging clusters of low-income neighbourhoods are in and towards the northeast and northwest corners of the City of Toronto, including in Scarborough, Rexdale, and Brampton. Clusters of high-income neighbourhoods emerged along the Yonge subway line, the eastern waterfront, in and around Richmond Hill, and in and around Oakville.

Figure 9: Change in Statistically Significant Household Income Clusters and Outliers among Neighbourhoods, Toronto CMA, 1985- 2015

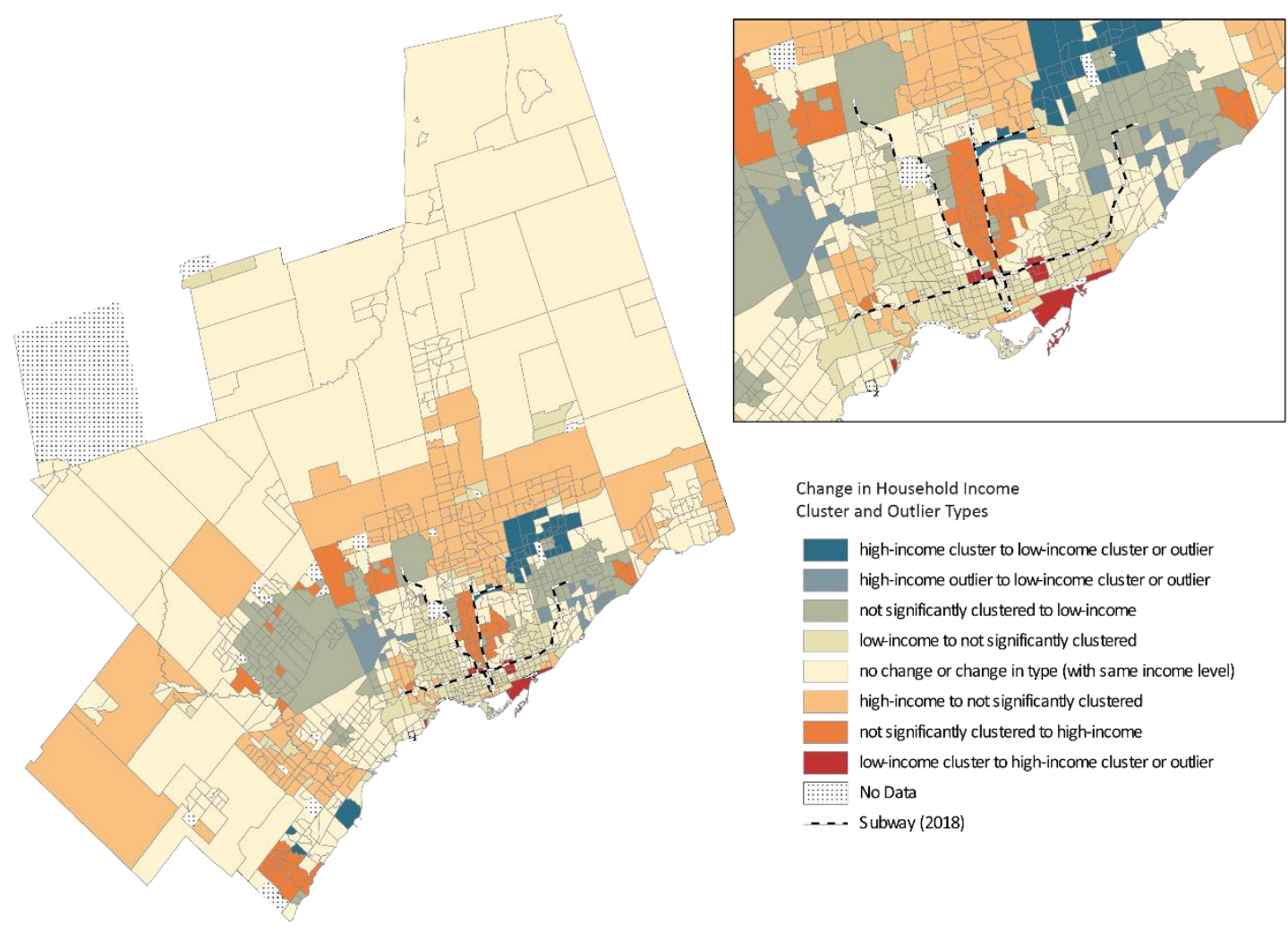


The overall clustering of wealthy neighbourhoods, based on average household incomes, declined in the Toronto CMA between 1985 and 2015, but the difference between the clusters that remain may be more extreme. While Fong and Shibuya (2000) found that the income gap between the wealthiest and the poorest census tract in Toronto went from four times to fourteen times between 1950 and 1985, the highest average income census tract is now over 27 times the lowest average census tract income. As shown in Figure 10, the peak in inequality among neighbourhoods occurred in 2005, when the highest census tract was over 30 times greater than the lowest census tract.

Figure 10: Highest Income Neighbourhood as a Multiple of the Lowest Income Neighbourhood, 1985-2015

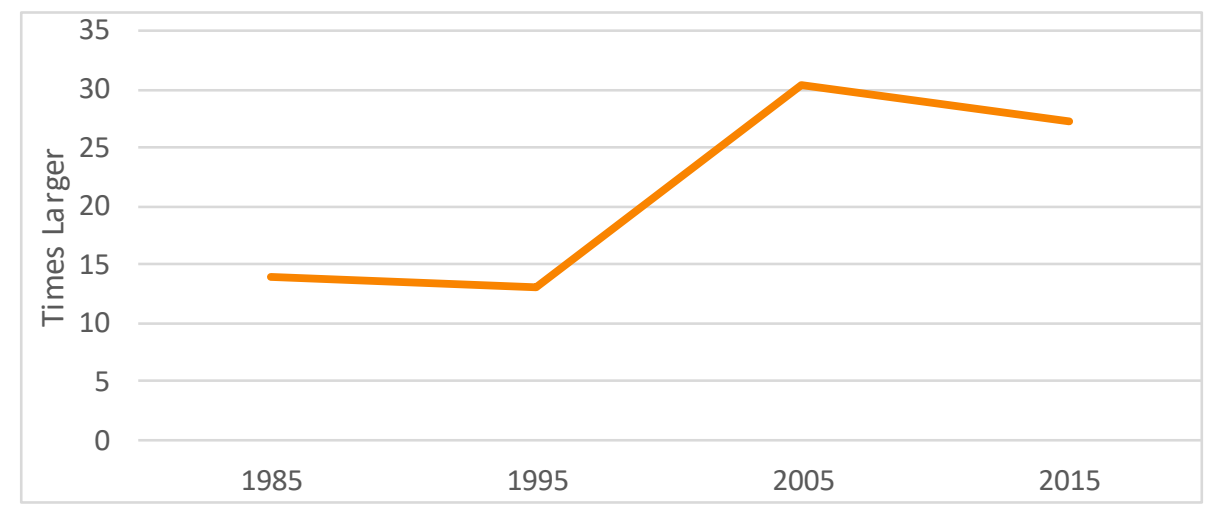

\subsection{InCOME SEgREgATION Within NeIGHBOURHOOdS}

While the preceding shows changes in income inequality between census tracts, it does not say anything about changes within them. For instance, it does not necessarily mean that households within neighbourhoods have become more mixed in terms of income. It is sometimes incorrectly presumed that census tracts are homogenous, and household income diversity within neighbourhoods is masked when comparing averages.

Along with the greatest number of significantly clustered census tracts, the mean within-census tract Gini coefficient was also highest in 1995 (see Figures 11 to 15). Thus, while income segregation among neighbourhoods was widespread in 1995, there was at the same time relatively more income mixing within them. High Gini coefficients have always been present in the central areas of the City of Toronto, indicating much greater household income variation than in the outer suburbs. This contrasts most starkly with the 905 region in 2015, which for the most part has become relatively homogenous in terms of household income. 
Figure 11: Boxplot Diagram of Gini Coefficients Within Census Tracts, Toronto CMA, 1985- 2015

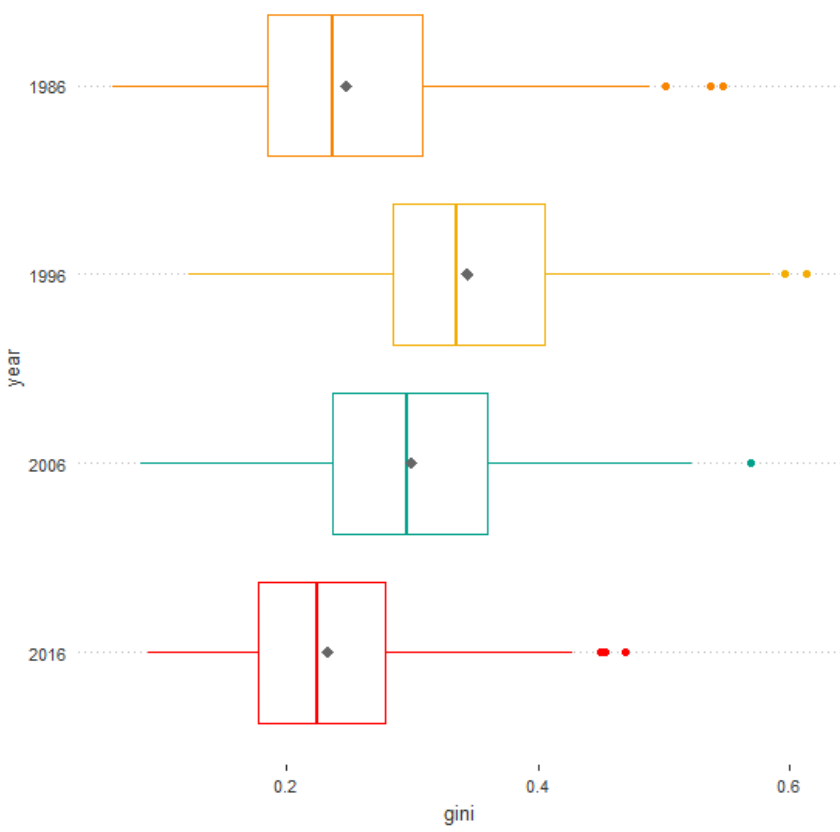

Figure 12: Gini Coefficient of Income Inequality Within Census Tracts, Toronto CMA, 1985

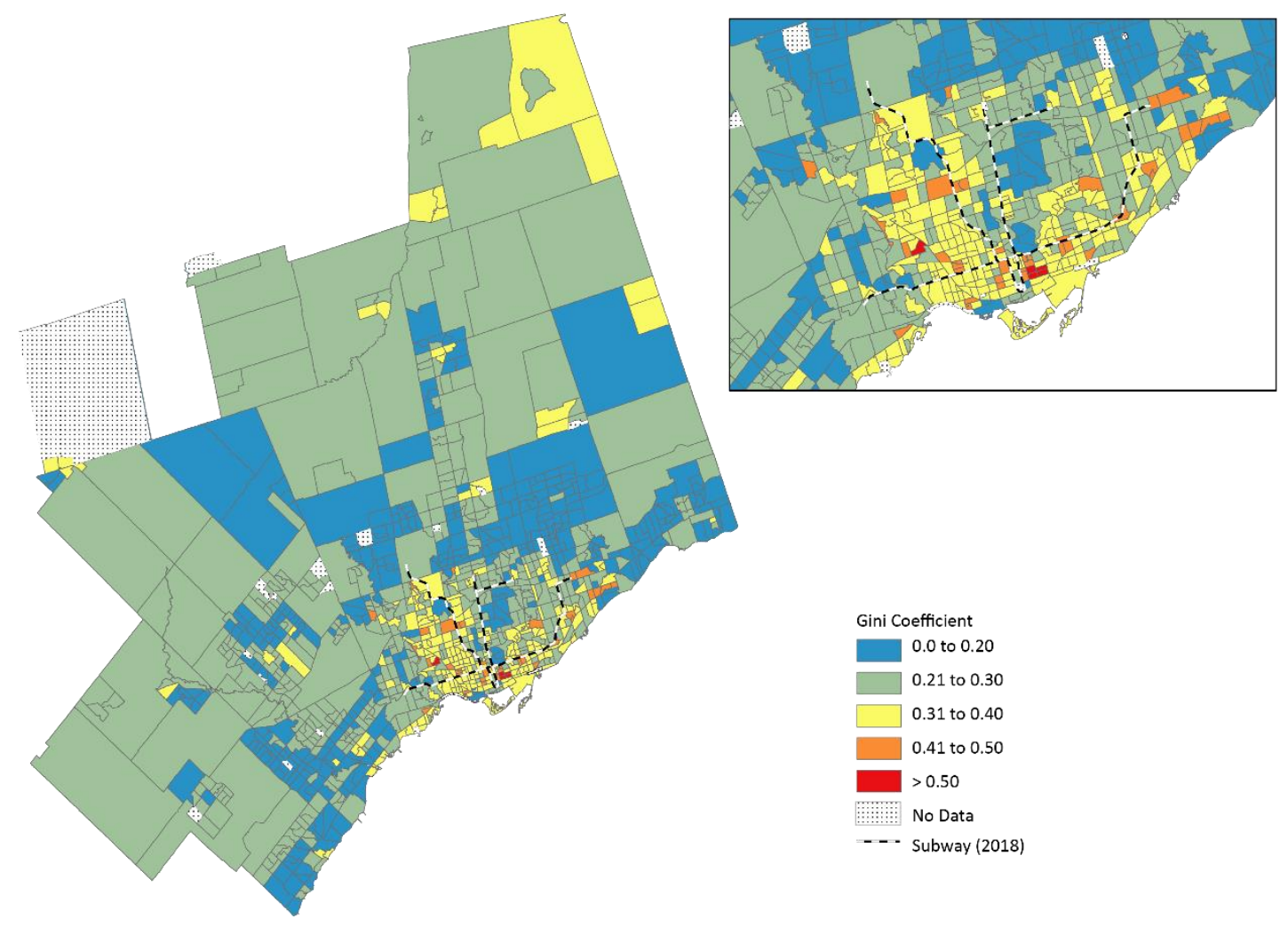


Figure 13: Gini Coefficient of Income Inequality Within Census Tracts, Toronto CMA, 1995

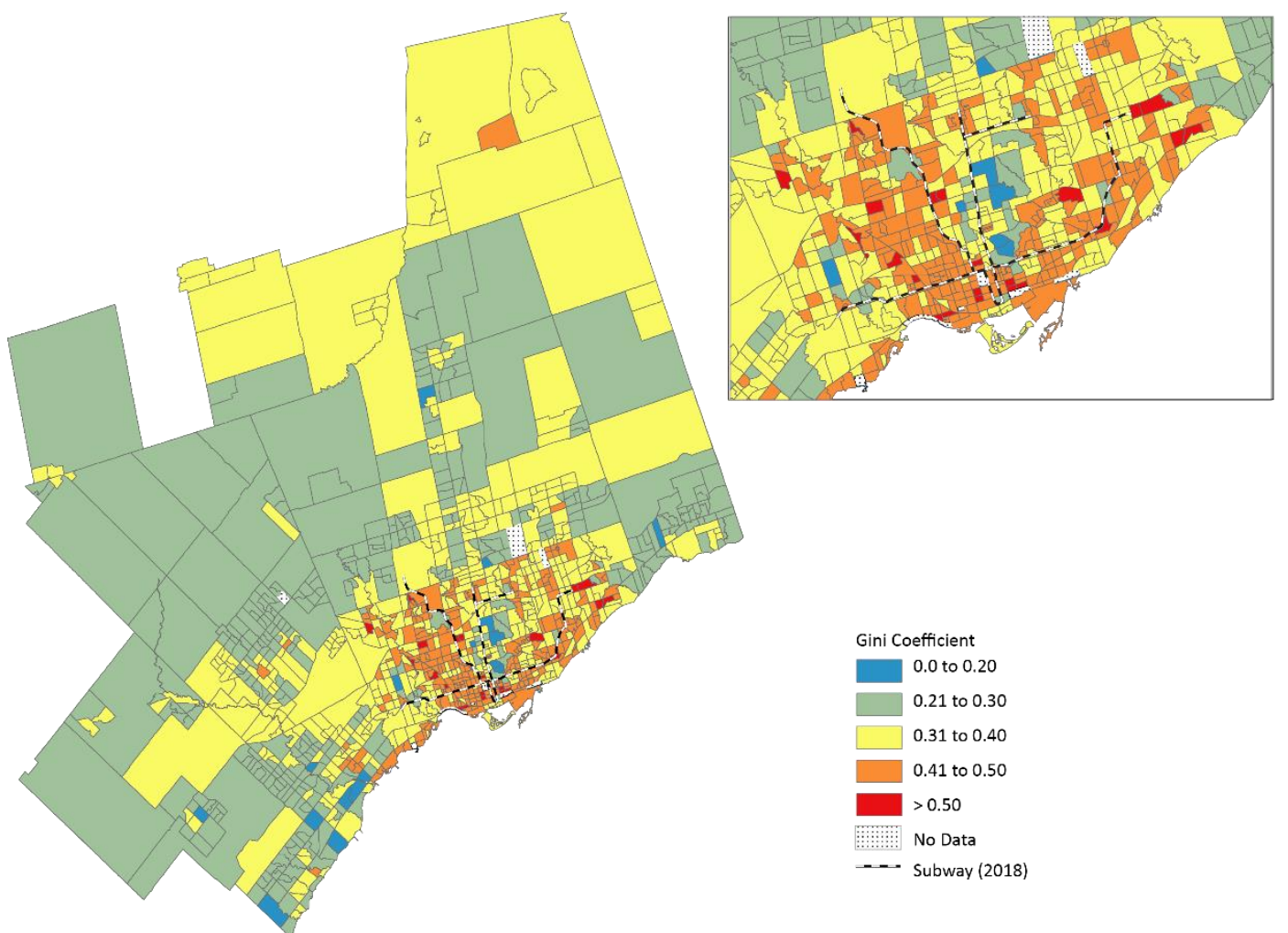

Figure 14: Gini Coefficient of Income Inequality Within Census Tracts, Toronto CMA, 2005
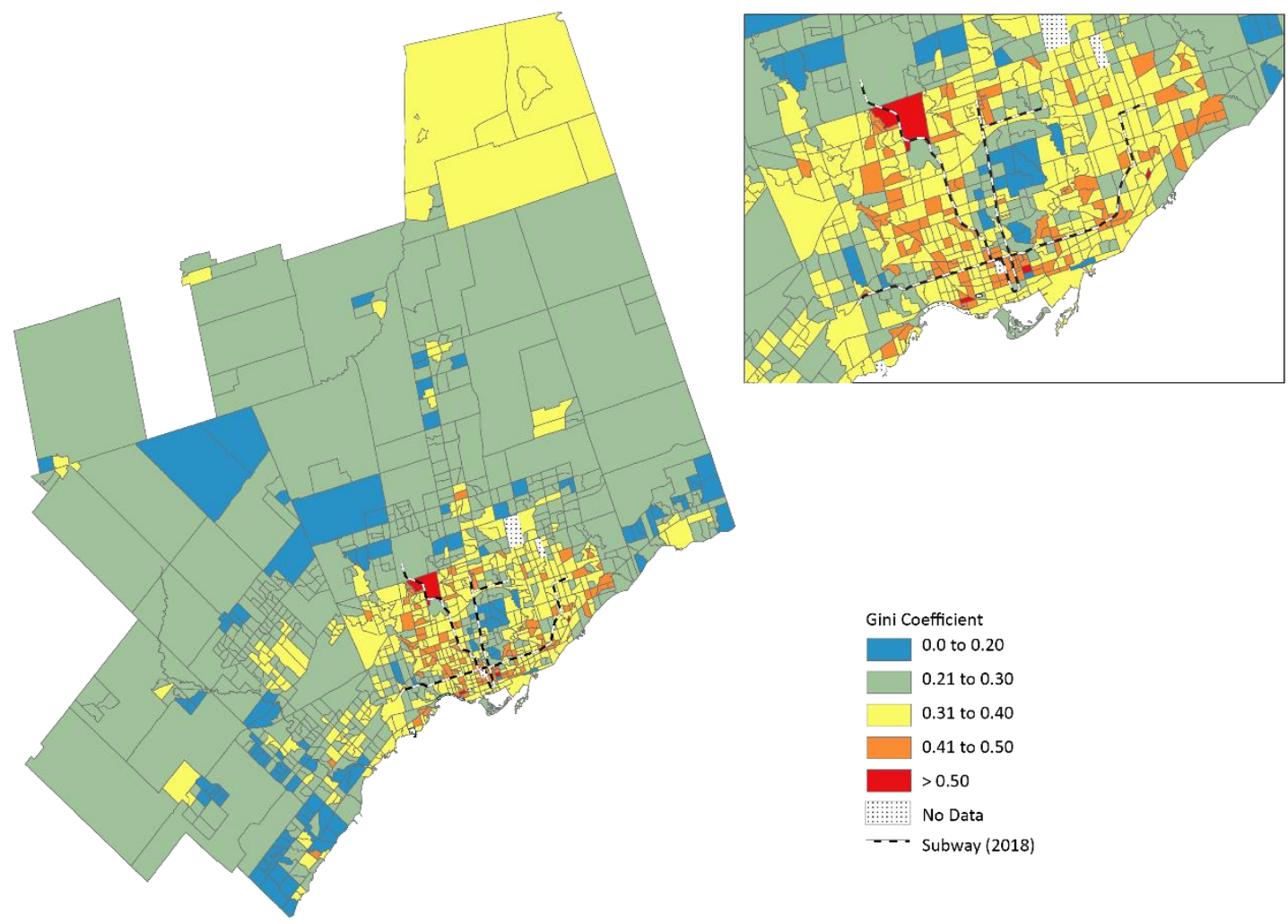


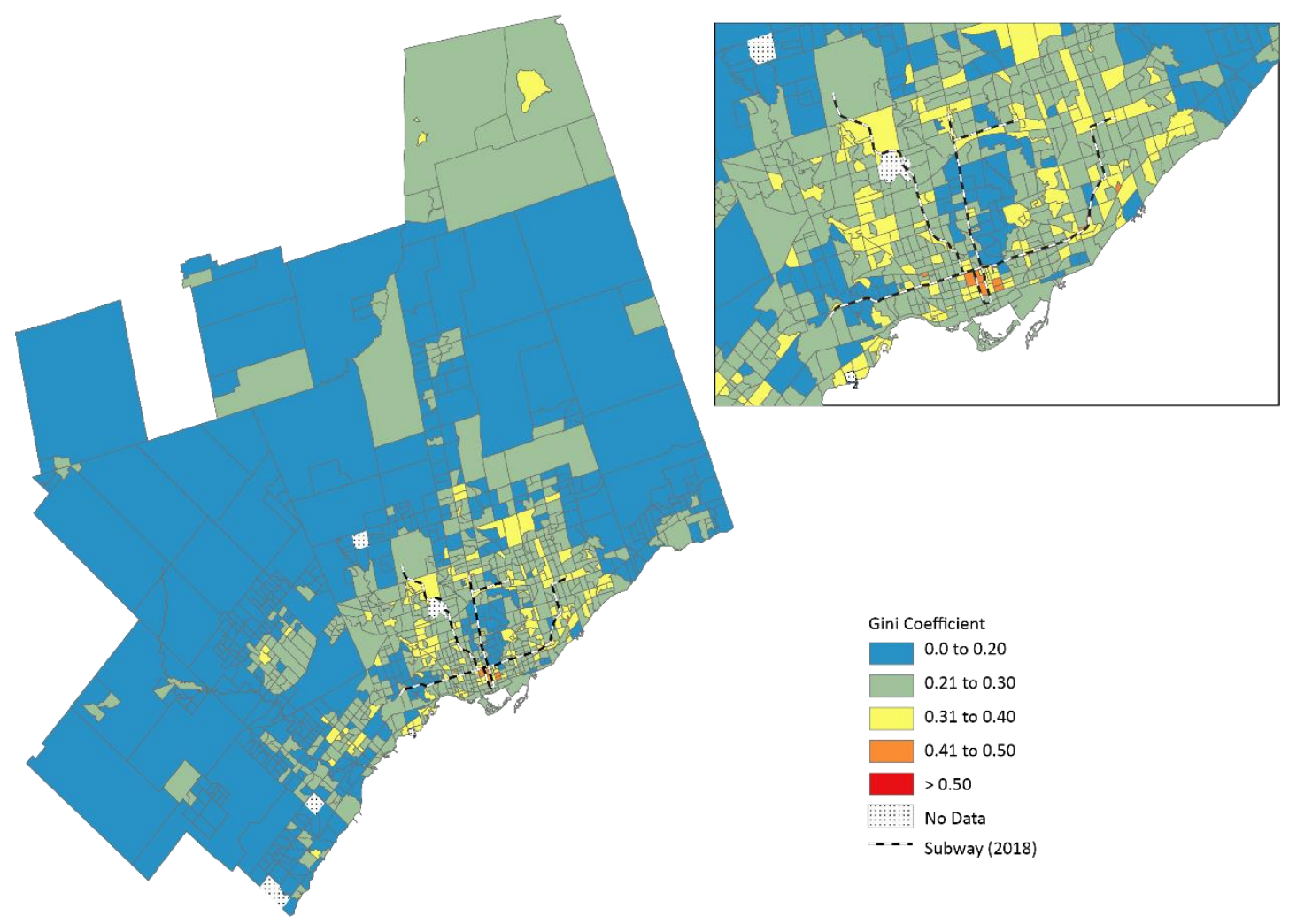

Even though the Gini coefficients in the central areas of the City have remained relatively higher than elsewhere in the region, these areas have also experienced a decline in intra-neighbourhood inequality since 1985 (see Figure 16). The areas that have seen an increase in intra-neighbourhood inequality are located along the outer edges of the City of Toronto, particularly in the northeast of Scarborough and North York, as well as the southern regions of Peel and Halton. 


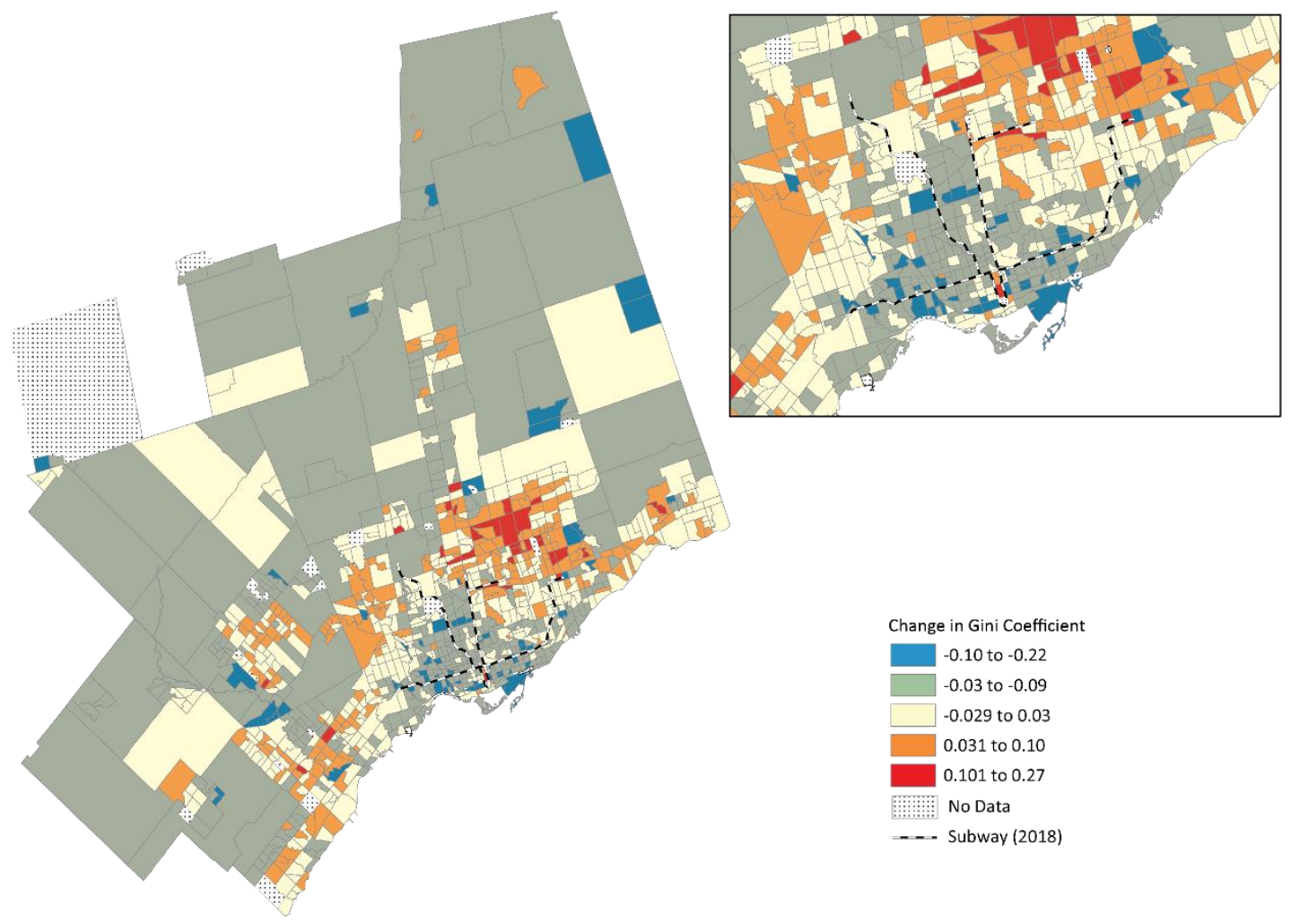

\subsection{NEIGHBOURHOOD SORTING}

Between 1985 and 2005, the mean Gini coefficient was only slightly lower than the overall CMA Gini coefficient at the time, signalling that the income range within census tracts closely mirrored the overall makeup of the city (see Figure 17). Between 2005 and 2015, however, the gap between the two measures increased substantially, potentially meaning that there has been both an increase in income homogenization within census tracts as well as an increase in income segregation among census tracts.

Figure 17: Comparison of Overall Non-Spatial Gini Coefficient and Mean Within Census Tract Gini Coefficient for the Toronto CMA, 1985-2015

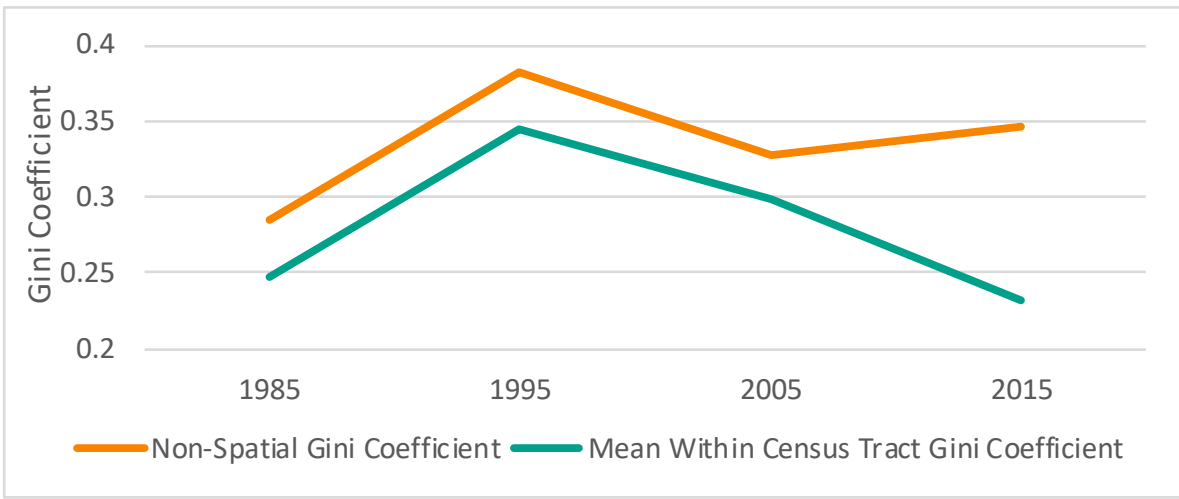


The high intra-neighbourhood Gini coefficients in 1995 may just be reflective of the overall high regional Gini coefficient in the same year. The Neighbourhood Sorting Index (NSI) measures the deviance from the CMA's overall level of inequality for each census tract, and therefore better accounts for overall regional changes in intra-neighbourhood income inequality (see Figures 18 to 21).

In 1985, many census tracts had a similar income distribution, as measured by the Gini coefficient, compared to the CMA as a whole (plus or minus 0.2 ). Most of the neighbourhoods that had much greater household income distributions than the CMA as a whole were located in the City of Toronto (see Figure 18).

Figure 18: Neighbourhood Sorting Index Within Census Tracts, Toronto CMA, 1985

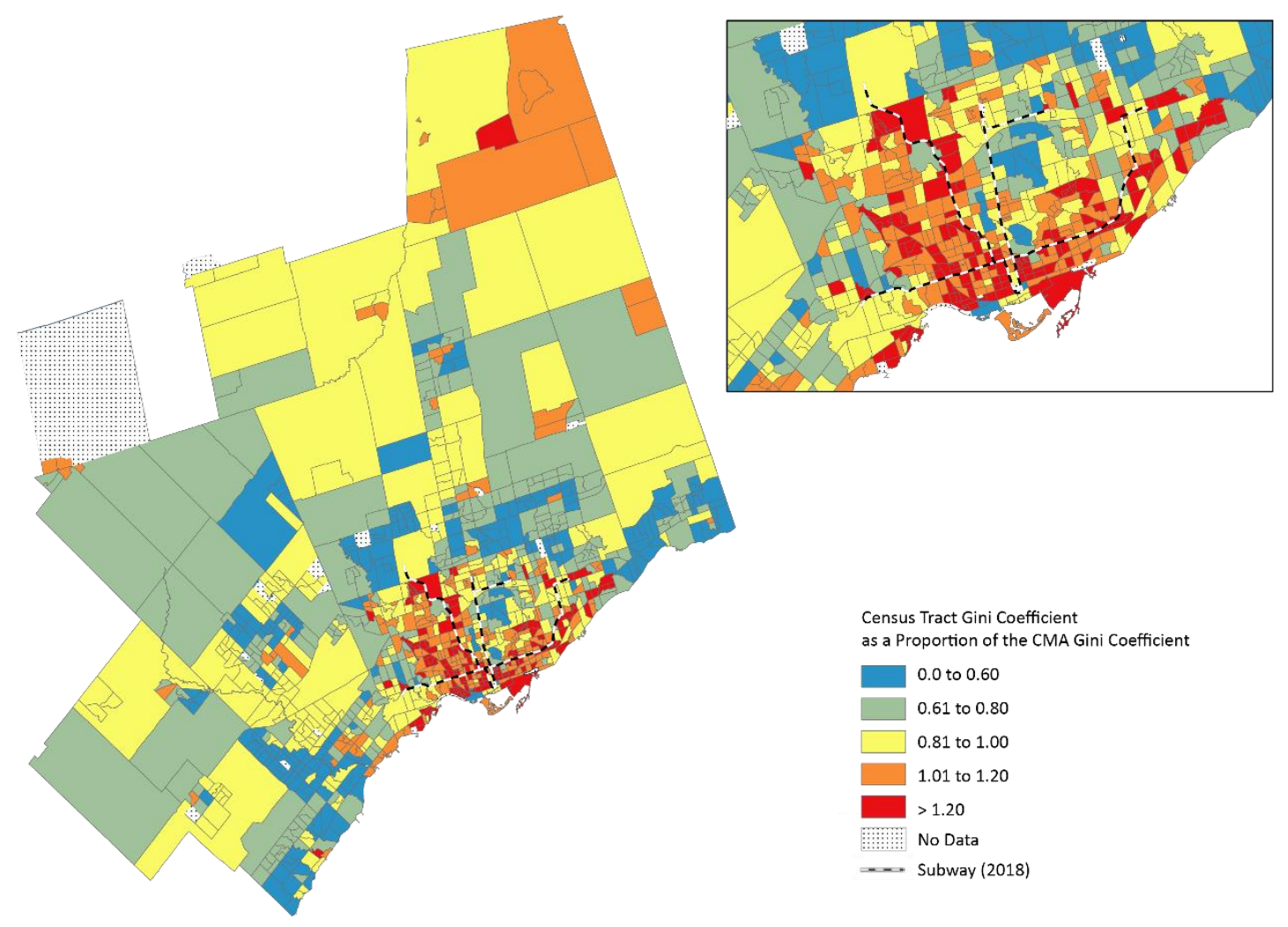

In 1995, many neighbourhoods' Gini coefficients decreased in comparison to the overall CMA Gini coefficient, though many parts of the 905 region were still within 0.2 of the CMA's overall Gini coefficient (see Figure 19). Thus, although intra-neighbourhood income inequality was highest in 1995, on average, much of this can be explained by the drastic increase in the CMA's overall income inequality. 
Figure 19: Neighbourhood Sorting Index Within Census Tracts, Toronto CMA, 1995

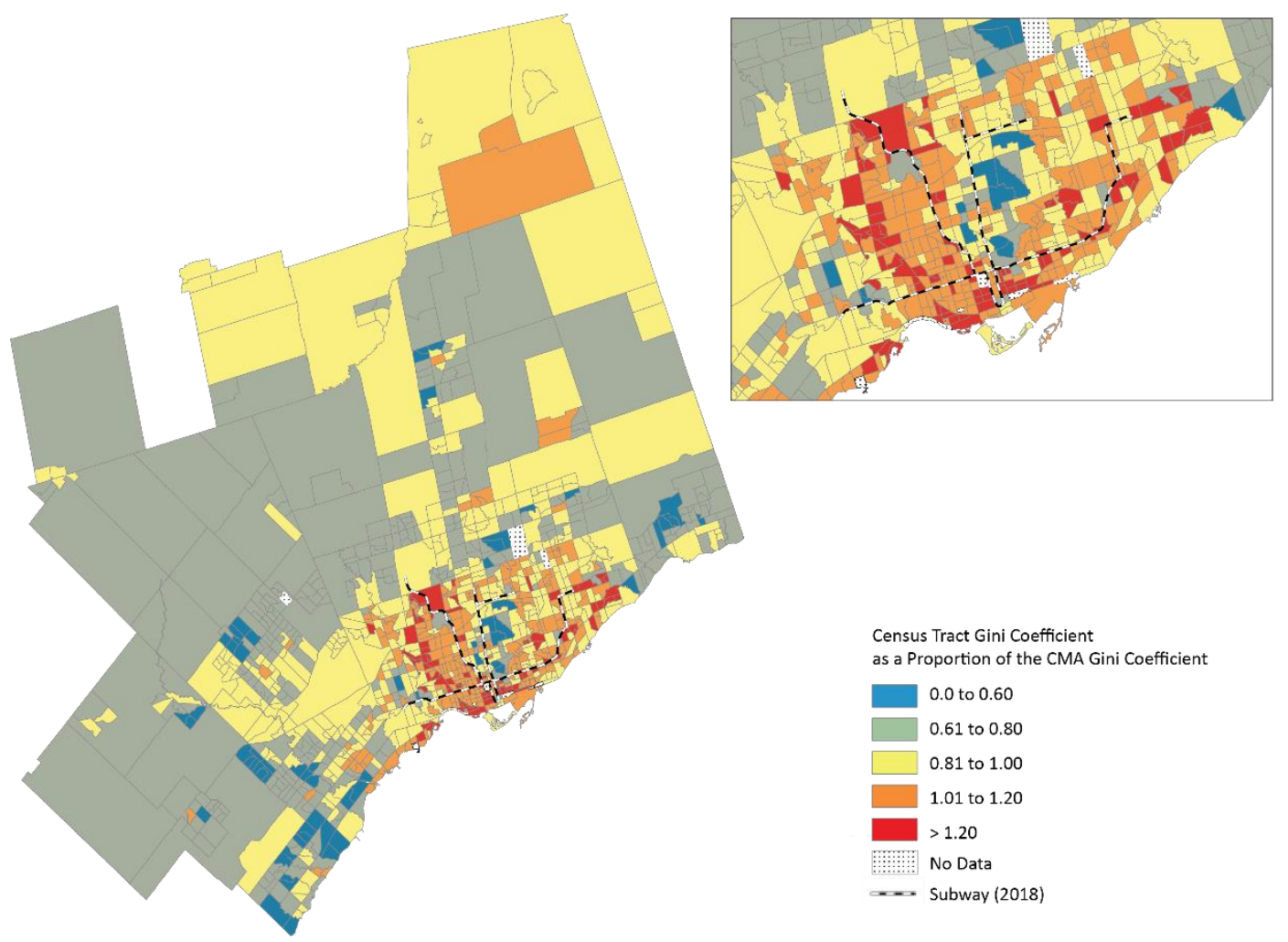

Figure 20: Neighbourhood Sorting Index Within Census Tracts, Toronto CMA, 2005
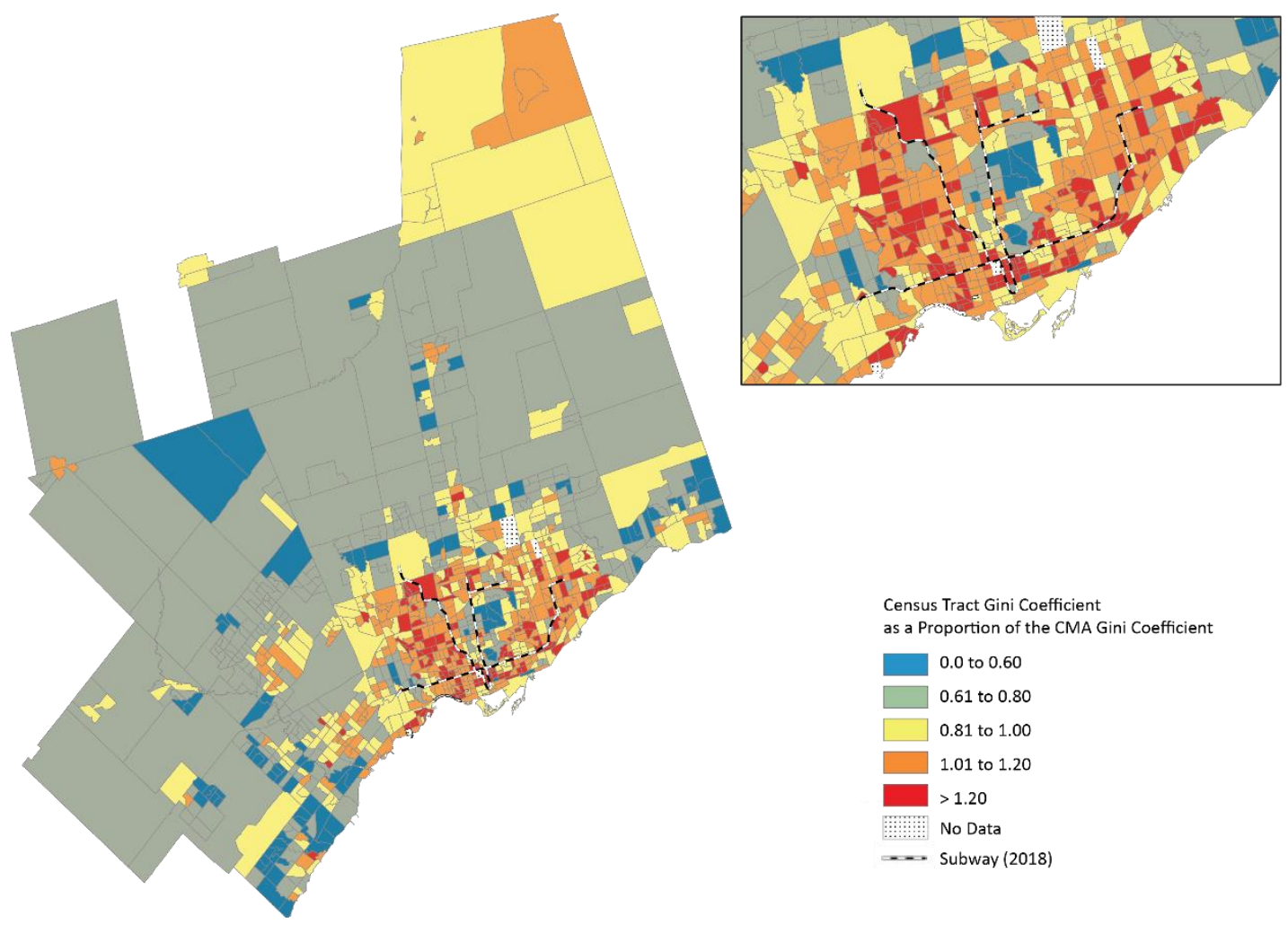

Census Tract Gini Coefficient as a Proportion of the CMA Gini Coefficient

0.0 to 0.60

0.61 to 0.80

0.81 to 1.00

1.01 to 1.20

$>1.20$

No Data

C.. Subway (2018) 
The most drastic change in NSI scores occurred in 2015, when most census tracts had substantially lower income distribution ranges than the Toronto CMA overall (see Figure 21). Further, quite a few census tracts within the City of Toronto also exhibited more household income homogeneity than the CMA, a departure from trends in the preceding three decades.

Figure 21: Neighbourhood Sorting Index Within Census Tracts, Toronto CMA, 2015

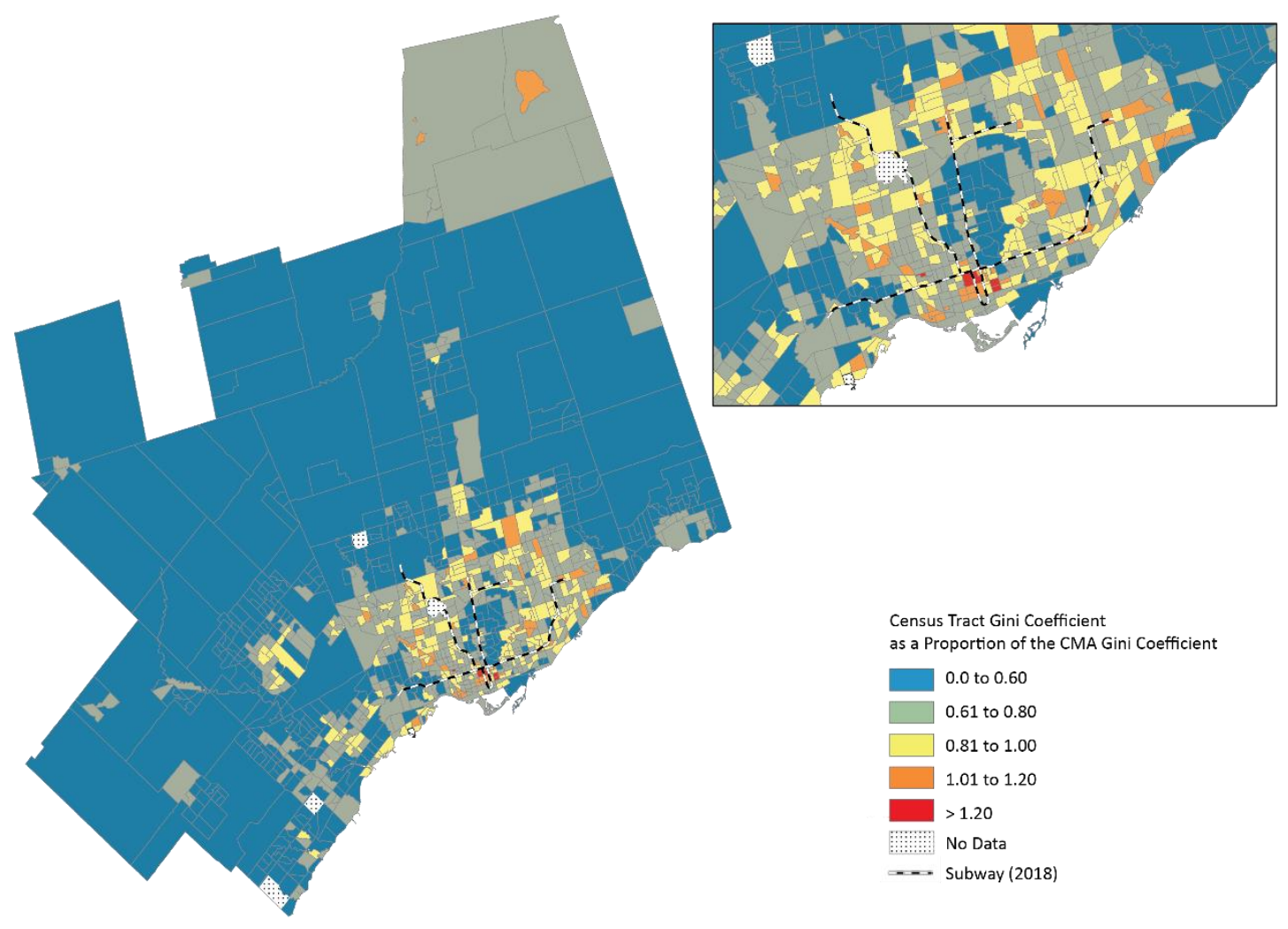

The strongest evidence that neighbourhoods have become more homogenous since 1985 is that the NSI decreased in most census tracts in the CMA (see Figure 22). Due to the fact that the rate of intraneighbourhood inequality is lower than the income inequality among all households in the CMA, there has been greater sorting of households into different neighbourhoods based on socio-economic status. Thus, although overall income inequality is high, as measured by the CMA's Gini coefficient, the region's income distribution is not represented within each neighbourhood. 


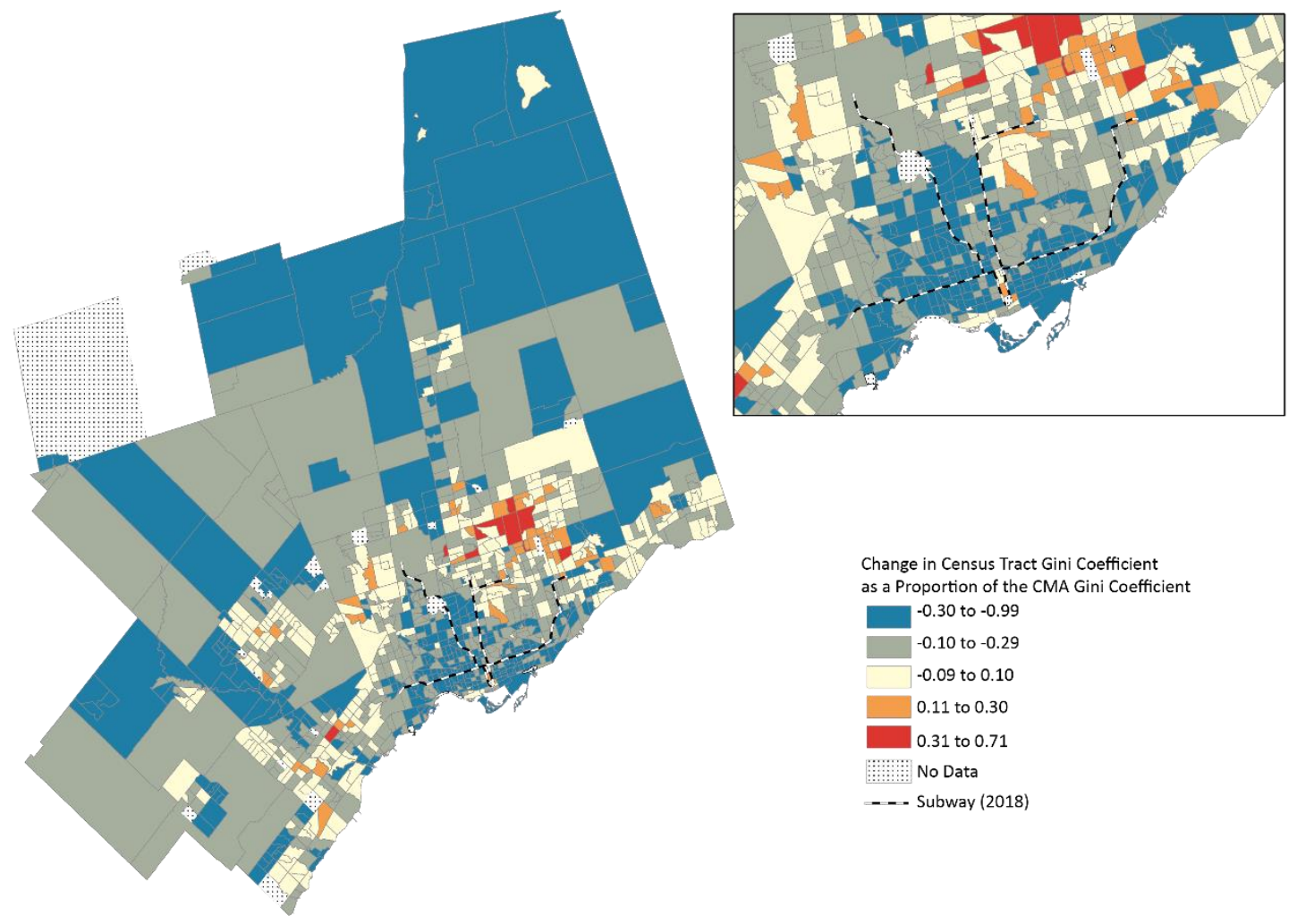

Taking together, it's found that macro-scale income segregation decreased in the Toronto CMA (as indicated by Moran's I statistic), while micro-scale income segregation increased (as indicated by the within-census tract Gini coefficients) between 1985 and 2015.

\subsection{REGRESSIONS}

The trend of increased micro-scale income segregation within the Toronto CMA is clear. Next, this paper examines the extent to which various neighbourhood characteristics each influence intra-neighbourhood income inequality, as measured by the Gini coefficient within census tracts.

The cross-sectional time-series dataset, created from the census profiles for the years 1985, 1995, 2005, and 2015 produced a balanced panel, meaning that all census tracts have data for all years. Summary statistics reports for the variables used in the analysis are available in Appendix B. 


\subsubsection{CORRECTING FOR MULTI-COlLINEARITY}

Seven variables were removed because they had an unacceptably high level of multi-collinearity (a VIF above 8 ) and were thus redundant and adding bias into the models. The 7 variables that were removed are: the Moran's Index of spatial autocorrelation z-scores, socioeconomic status, average household income, average monthly gross rent, average monthly payments for owned dwellings, the proportion of renter households, and the proportion of residents with a bachelors' degree or higher. The original regression outputs with the high-VIF variables are included in Appendix C.

\subsubsection{Panel Regression Models}

The years studied are significant and are therefore included in the final model using both census tract and year fixed-effects. A regular pooled regression model, without controlling for any area or year fixed-effects shows that the distance from the centre of each census tract to the downtown (as proxied by City Hall) is significantly correlated with intra-neighbourhood income inequality. Table 1 presents the results of the five series of regressions.

Table 1: Regression Results for 5 Panel Models

Dependent variable:

Gini Coefficient

\begin{tabular}{lcc}
\hline baseline & fixed effects \\
& year only $\quad$ census tract only two-way
\end{tabular}

(1)

(2)

(3)

(4)

(5)

\begin{tabular}{llllll}
\hline Average Dwelling Value & $-0.115^{* * *}$ & $-0.060^{* * *}$ & $-0.047^{* * *}$ & $-0.086^{* * *}$ & $-0.016^{* * *}$ \\
& $(0.003)$ & $(0.002)$ & $(0.002)$ & $(0.003)$ & $(0.003)$ \\
$\begin{array}{l}\text { Proportion of Dwellings } \\
\text { Constructed in Previous 5 Years }\end{array}$ & $0.041^{* * *}$ & -0.009 & $0.027^{* * *}$ & $-0.078^{* * *}$ & $-0.019^{* * *}$ \\
& $(0.009)$ & $(0.008)$ & $(0.006)$ & $(0.009)$ & $(0.005)$ \\
$\begin{array}{l}\text { Proportion of Dwellings } \\
\text { Constructed Before 1960 }\end{array}$ & $0.039^{* * *}$ & $0.067^{* * *}$ & $0.068^{* * *}$ & $0.034^{* * *}$ & $0.105^{* * *}$ \\
& & & & $(0.003)$ & $(0.009)$
\end{tabular}




\begin{tabular}{|c|c|c|c|c|c|}
\hline \multirow[t]{2}{*}{ Proportion of Owner Households } & $-0.239^{* * *}$ & $-0.181^{* * *}$ & $-0.187^{* * *}$ & $-0.198^{* * *}$ & $-0.161^{* * *}$ \\
\hline & $(0.008)$ & $(0.007)$ & $(0.005)$ & $(0.012)$ & $(0.007)$ \\
\hline \multirow[t]{2}{*}{$\begin{array}{l}\text { Proportion of Single-Detached } \\
\text { Dwellings }\end{array}$} & $0.035^{* * *}$ & $-0.009^{* *}$ & $-0.015^{* * *}$ & 0.008 & $-0.026^{* * *}$ \\
\hline & $(0.005)$ & $(0.004)$ & $(0.003)$ & $(0.009)$ & $(0.005)$ \\
\hline \multicolumn{6}{|l|}{ Proportion of Apartment } \\
\hline \multirow{3}{*}{$\begin{array}{l}\text { Dwellings with More than } 5 \\
\text { Storeys }\end{array}$} & -0.006 & -0.006 & $0.021^{* * *}$ & 0.010 & $0.071^{* * *}$ \\
\hline & & & & & \\
\hline & $(0.006)$ & $(0.005)$ & $(0.004)$ & $(0.010)$ & $(0.006)$ \\
\hline \multirow[t]{2}{*}{ Population Density per 1,000} & -0.0003 & $-0.001^{* * *}$ & $-0.0004^{* * *}$ & $-0.002^{* * *}$ & $-0.0005^{* *}$ \\
\hline & $(0.0002)$ & $(0.0002)$ & $(0.0001)$ & $(0.0003)$ & $(0.0002)$ \\
\hline \multirow[t]{2}{*}{ Unemployment Rate } & -0.044 & $0.803^{* * *}$ & $0.428^{* * *}$ & $0.791^{* * *}$ & $0.174^{* * *}$ \\
\hline & $(0.040)$ & $(0.033)$ & $(0.028)$ & $(0.035)$ & $(0.022)$ \\
\hline \multirow[t]{2}{*}{ Proportion of Blue-Collar Workers } & $-0.030^{*}$ & $-0.177^{* * *}$ & $0.039^{* * *}$ & $-0.309^{* * *}$ & $-0.043^{* * *}$ \\
\hline & $(0.018)$ & $(0.015)$ & $(0.011)$ & $(0.021)$ & $(0.013)$ \\
\hline \multirow[t]{2}{*}{ Proportion of Black Canadians } & $-0.184^{* * *}$ & $0.025^{*}$ & $-0.025^{* *}$ & $0.191^{* * *}$ & -0.011 \\
\hline & $(0.018)$ & $(0.015)$ & $(0.011)$ & $(0.022)$ & $(0.013)$ \\
\hline \multirow[t]{2}{*}{ Proportion of Asian Canadians } & $-0.018^{*}$ & $0.075^{* * *}$ & $0.090^{* * *}$ & $0.210^{* * *}$ & $0.071^{* * *}$ \\
\hline & $(0.011)$ & $(0.008)$ & $(0.006)$ & $(0.014)$ & $(0.008)$ \\
\hline \multirow[t]{2}{*}{$\begin{array}{l}\text { Proportion of South Asian } \\
\text { Canadians }\end{array}$} & $-0.166^{* * *}$ & $-0.077^{* * *}$ & $-0.054^{* * *}$ & $-0.036^{* * *}$ & $-0.030^{* * *}$ \\
\hline & $(0.011)$ & $(0.008)$ & $(0.006)$ & $(0.013)$ & $(0.007)$ \\
\hline \multirow[t]{2}{*}{$\begin{array}{l}\text { Proportion of Movers in Previous } \\
5 \text { Years }\end{array}$} & $-0.060^{* * *}$ & -0.007 & $-0.067^{* * *}$ & $0.077^{* * *}$ & 0.007 \\
\hline & $(0.014)$ & $(0.012)$ & $(0.009)$ & $(0.015)$ & $(0.008)$ \\
\hline \multirow[t]{2}{*}{ Proportion of Immigrants } & $0.189^{* * *}$ & $0.129^{* * *}$ & $0.071^{* * *}$ & $0.042^{* * *}$ & $0.142^{* * *}$ \\
\hline & $(0.010)$ & $(0.010)$ & $(0.006)$ & $(0.016)$ & $(0.009)$ \\
\hline \multirow[t]{2}{*}{ Lagged Gini Coefficient } & $0.063^{* * *}$ & & & & \\
\hline & $(0.017)$ & & & & \\
\hline Distance to City Hall & & $-0.005^{* *}$ & & & \\
\hline
\end{tabular}


Distance to City Hall²

1995 (dummy)

2005 (dummy)

2015 (dummy)

Constant

$1.851^{* * *}$

(0.044)
$0.002^{* * *}$

(0.0003)

$0.081^{* * *}$

(0.001)

$0.051^{* * *}$

(0.002)

$-0.013^{* * *}$

(0.004)

\begin{tabular}{lccccc}
\hline Observations & 3,378 & 4,521 & 4,521 & 4,521 & 4,521 \\
$\mathrm{R}^{2}$ & 0.754 & 0.741 & 0.815 & 0.575 & 0.873 \\
Adjusted $\mathrm{R}^{2}$ & 0.752 & 0.741 & 0.814 & 0.428 & 0.829 \\
& & & & \\
F Statistic & $685.130^{* * *}(\mathrm{df}=$ & $807.274^{* * *}(\mathrm{df}=$ & $1,415.074^{* * *}(\mathrm{df}=$ & $324.756^{* * *}(\mathrm{df}=$ & $1,359.603^{* * *}(\mathrm{df}=$ \\
& $15 ; 3362)$ & $16 ; 4504)$ & $14 ; 4503)$ & $14 ; 3359)$ & $17 ; 3356)$
\end{tabular}

Note:

${ }^{*} p<0.1 ;{ }^{* *} p<0.05 ;{ }^{* * *} p<0.01$

The reported $\mathrm{R}^{2}$ for both the year-only and census tract-only fixed-effects models comes from "within" regressions, as only one fixed-effects dummy variable is considered in each. The year-only fixed-effects produces a stronger model than the census tract-only fixed-effects model. Indeed, all the years in the final model (with 1985 as the base) are significant as covariates in explaining changes in intra-neighbourhood income inequality.

The reported $\mathrm{R}^{2}$ for both the pooled (without fixed-effects) and two-way fixed-effects models comes from "between" regressions. After controlling for both year and census tract fixed-effects, the "between" model improves. Thus, the final model performs best in helping predict the significance of the impact from each neighbourhood characteristic variable on intra-neighbourhood income inequality.

Dwelling Value. For a given census tract, a 10\% increase across time in a neighbourhood's average dwelling value results in a 0.0015 decrease in intra-neighbourhood inequality, as measured by the within-census 
tract Gini coefficient which ranges from 0 to 1 . This validates Hulchanski's (2007) prediction that the presence of affordable housing can decrease segregation. This is intuitive, as average dwelling value within a census tract increases, dwelling units within the neighbourhood become more unaffordable and thus exclusionary to lower-income households.

Rate of Development. For a given census tract, a 10-percentage point increase across time in the proportion of dwellings within a neighbourhood built in the preceding 5 years results in a 0.0019 decrease in intra-neighbourhood inequality. Thus, Fong and Shibuya's (2000) prediction that extensive redevelopment leads to greater economic homogenization within census tracts is validated. However, while they found that the relationship between urban redevelopment and the economic segregation of the poor pertained only to Black Canadians, this model finds that the prediction holds more generally.

Dwelling Vintage. For a given census tract, a 10-percentage point increase across time in the proportion of dwellings within a neighbourhood built before 1960 results in a 0.0105 increase in intra-neighbourhood inequality. Thus, neighbourhoods with an older housing stock are associated with greater income mixing among households, and because the model controlled for census tracts fixed-effects, the pattern can be said to hold in neighbourhoods both in and outside of the downtown core.

Tenure. For a given census tract, a 10-percentage point increase across time in the proportion of households in a neighbourhood that own their dwelling results in a 0.0161 decrease in intraneighbourhood inequality. Thus, the increased presence of households with wealth, as proxied by those which own their home, is correlated with greater micro-scale segregation.

Built Form Type and Density. For a given census tract, a 10-percentage point increase across time in the proportion single-detached dwellings in a neighbourhood results in a 0.0026 decrease in intraneighbourhood inequality. Like average dwelling value, the increased presence of a single-detached dwelling unit on a property lot is significantly linked with greater household homogeneity within a neighbourhood, likely through increasing the exclusivity of the neighbourhood for low-income households.

Inversely, a 10-percentage point increase across time in the proportion of apartments with five or more storeys in a neighbourhood results in a 0.0071 increase in intra-neighbourhood inequality. Thus, the presence of higher density dwellings on property lots is correlated with greater heterogeneity of income classes in a neighbourhood. The combination of these two variable coefficients validate previous studies which find that built form impacts micro-scale segregation. 
Additionally, a 10-percentage point increase time in a neighbourhood's population density, measured per 1,000 inhabitants, results in a 0.00005 decrease in intra-neighbourhood inequality, in contrast to the previous variable. However, the effect of density on intra-neighbourhood inequality is less strong than the effects from the dwelling type variables.

Labour and Human Capital. For a given census tract, a 10-percentage point increase across time in a neighbourhood's unemployment rate results in a 0.0174 increase in intra-neighbourhood inequality. This implies that neighbourhoods with higher rates of unemployment have more heterogeneity in terms of household incomes. On the other hand, a 10-percentage point increase in the proportion of "blue collar" workers in a neighbourhood results in a 0.0043 decrease in intra-neighbourhood inequality. This validates previous findings that neighbourhoods are becoming more segregated by occupation type (Ganong \& Shoag, 2015; Walks, 2013).

Race and Ethnicity. For a given census tract, a 10-percentage point increase across time in the proportion of residents in a neighbourhood who identify as black, as East Asian, and as South Asian results in a 0.0111 increase, a 0.0071 increase, and a 0.0030 decrease in intra-neighbourhood inequality, respectively. However, the result for Black Canadians is not statistically significant. Thus, while the presence of individuals of east Asian descent is indicative of more mixed-income neighbourhoods, the presence of individuals of South Asian descent is correlated with higher levels of income homogeneity.

Migration Status. There is not a significant effect from the proportion of a neighbourhood's residents who have moved in the previous five years on intra-neighbourhood income inequality.

Alternatively, for a given census tract, a 10-percentage point increase across time in the proportion of immigrants in a neighbourhood results in a 0.0142 increase in intra-neighbourhood inequality. Thus, Canadian newcomers in the Toronto CMA are settling in relatively more mixed-income neighbourhoods.

\subsubsection{OLS REGRESSIONS BY YEAR}

The relationship between most of the variables and intra-neighbourhood inequality was fairly stable over time (see Table 2). However, the proportion of newly constructed dwellings, of single-detached dwellings, of residents of Asian descent, and of the population which had moved in the previous five years did not have a significant impact on within-census tract income inequality in 1985. Additionally, the proportion of 
"blue collar" workers in a neighbourhood was only significant in 1995 and the proportion of Black Canadians in a neighbourhood was not significant in 2005.

Table 2: Regression Results for Each Year Independently

\begin{tabular}{|c|c|c|c|c|}
\hline & \multicolumn{4}{|c|}{$\begin{array}{c}\text { Dependent variable: } \\
\text { Gini Coefficient }\end{array}$} \\
\hline & 1985 & 1995 & 2005 & 2015 \\
\hline & (1) & $(2)$ & (3) & (4) \\
\hline \multirow[t]{2}{*}{ Average Dwelling Value } & $-0.032^{* * *}$ & $-0.041^{* * *}$ & $-0.048^{* * *}$ & $-0.041^{* * *}$ \\
\hline & $(0.005)$ & $(0.005)$ & $(0.005)$ & $(0.004)$ \\
\hline \multirow[t]{2}{*}{$\begin{array}{l}\text { Proportion of Dwellings Constructed in } \\
\text { Previous } 5 \text { Years }\end{array}$} & -0.004 & $0.064^{* * *}$ & $0.076^{* * *}$ & $0.038^{* * *}$ \\
\hline & $(0.013)$ & $(0.011)$ & $(0.011)$ & $(0.012)$ \\
\hline \multirow[t]{2}{*}{$\begin{array}{l}\text { Proportion of Dwellings Constructed Before } \\
1960\end{array}$} & $0.090^{* * *}$ & $0.070^{* * *}$ & $0.064^{* * *}$ & $0.048^{* * *}$ \\
\hline & $(0.007)$ & $(0.006)$ & $(0.006)$ & $(0.006)$ \\
\hline \multirow[t]{2}{*}{ Proportion of Owner Households } & $-0.172^{* * *}$ & $-0.204^{* * *}$ & $-0.196^{* * *}$ & $-0.187^{* * *}$ \\
\hline & $(0.011)$ & $(0.011)$ & $(0.010)$ & $(0.008)$ \\
\hline \multirow[t]{2}{*}{ Proportion of Single-Detached Dwellings } & 0.002 & $-0.025^{* * *}$ & $-0.054^{* * *}$ & $-0.023^{* * *}$ \\
\hline & $(0.009)$ & $(0.007)$ & $(0.007)$ & $(0.006)$ \\
\hline \multirow[t]{2}{*}{$\begin{array}{l}\text { Proportion of Apartment Dwellings with } \\
\text { More than } 5 \text { Storeys }\end{array}$} & $0.045^{* * *}$ & $0.016^{*}$ & $0.021^{* * *}$ & $0.020^{* * *}$ \\
\hline & $(0.010)$ & $(0.008)$ & $(0.007)$ & $(0.006)$ \\
\hline \multirow[t]{2}{*}{ Population Density per 1,000} & -0.001 & $-0.001^{* * *}$ & -0.0003 & -0.0003 \\
\hline & $(0.0004)$ & $(0.0002)$ & $(0.0002)$ & $(0.0002)$ \\
\hline \multirow[t]{2}{*}{ Unemployment Rate } & $0.727^{* * *}$ & $0.379^{* * *}$ & $0.298^{* * *}$ & $0.266^{* * *}$ \\
\hline & $(0.079)$ & $(0.048)$ & $(0.059)$ & $(0.049)$ \\
\hline \multirow[t]{2}{*}{ Proportion of Blue-Collar Workers } & $0.049^{*}$ & $-0.084^{* * *}$ & 0.036 & 0.019 \\
\hline & $(0.028)$ & $(0.023)$ & $(0.026)$ & $(0.020)$ \\
\hline
\end{tabular}




\begin{tabular}{|c|c|c|c|c|}
\hline \multirow[t]{2}{*}{ Proportion of Black Canadians } & $0.239^{* * *}$ & $0.082^{* * *}$ & -0.020 & $-0.038^{* *}$ \\
\hline & $(0.055)$ & $(0.025)$ & $(0.019)$ & $(0.015)$ \\
\hline \multirow[t]{2}{*}{ Proportion of Asian Canadians } & 0.043 & $0.097^{* * *}$ & $0.056^{* * *}$ & $0.085^{* * *}$ \\
\hline & $(0.027)$ & $(0.013)$ & $(0.011)$ & $(0.007)$ \\
\hline \multirow[t]{2}{*}{ Proportion of South Asian Canadians } & $-0.282^{* * *}$ & $-0.126^{* * *}$ & $-0.032^{* * *}$ & $-0.042^{* * *}$ \\
\hline & $(0.047)$ & $(0.018)$ & $(0.011)$ & $(0.008)$ \\
\hline \multirow[t]{2}{*}{ Proportion of Movers in Previous 5 Years } & -0.007 & $-0.143^{* * *}$ & $-0.163^{* * *}$ & $-0.072^{* * *}$ \\
\hline & $(0.019)$ & $(0.019)$ & $(0.019)$ & $(0.016)$ \\
\hline \multirow[t]{2}{*}{ Proportion of Immigrants } & $0.140^{* * *}$ & $0.132^{* * *}$ & $0.120^{* * *}$ & $0.081^{* * *}$ \\
\hline & $(0.019)$ & $(0.016)$ & $(0.014)$ & $(0.010)$ \\
\hline \multirow[t]{2}{*}{ Distance to City Hall } & -0.004 & 0.0003 & $-0.014^{* * *}$ & $-0.007^{* * *}$ \\
\hline & $(0.004)$ & $(0.003)$ & $(0.003)$ & $(0.003)$ \\
\hline \multirow[t]{2}{*}{ Distance to City Hall² } & $0.002^{* * *}$ & $0.002^{* * *}$ & $0.003^{* * *}$ & $0.002^{* * *}$ \\
\hline & $(0.001)$ & $(0.0004)$ & $(0.0004)$ & $(0.0004)$ \\
\hline \multirow[t]{2}{*}{ Constant } & $0.620^{* * *}$ & $0.961^{* * *}$ & $1.053^{* * *}$ & $0.875^{* * *}$ \\
\hline & $(0.067)$ & $(0.068)$ & $(0.068)$ & $(0.058)$ \\
\hline Observations & 1,117 & 1,134 & 1,136 & 1,134 \\
\hline$R^{2}$ & 0.813 & 0.850 & 0.853 & 0.857 \\
\hline Adjusted $\mathrm{R}^{2}$ & 0.811 & 0.848 & 0.851 & 0.855 \\
\hline Residual Std. Error & $0.035(\mathrm{df}=1100)$ & $0.031(d f=1117)$ & $0.031(d f=1119)$ & $0.025(d f=1117)$ \\
\hline F Statistic & $\begin{array}{c}299.489^{* * *}(d f=16 \\
1100)\end{array}$ & $\begin{array}{c}394.818^{* * *}(d f=16 \\
1117)\end{array}$ & $\begin{array}{c}407.256^{* * *}(d f=16 \\
1119)\end{array}$ & $\begin{array}{c}417.086^{* * *}(d f=16 \\
1117)\end{array}$ \\
\hline
\end{tabular}

Note:

${ }^{*} \mathrm{p}<0.1 ;{ }^{* *} \mathrm{p}<0.05 ;{ }^{* * *} \mathrm{p}<0.01$

Finally, while all years perform similarly as measured by their $\mathrm{R}^{2}$, the strength of the overall regressions increase slightly in each subsequent year. This could be contributed to the fact that intra-neighbourhood income inequality increased in the Toronto CMA between 1985 and 2015. 


\subsection{SUMMARY}

After controlling for fixed-effects in the final model, the coefficients can be interpreted as the expected change in the intra-neighbourhood Gini coefficient from a 10-percentage point change (or a $10 \%$ change for the logged average dwelling value) in each variable over time. While the findings are particular to the Toronto CMA, they validate findings from previous research on other cities in North America. As predicted, an increase in the proxies for high dwelling values, including average dwelling value, newly constructed dwellings, owner households, and single-detached dwellings, are significantly correlated with greater levels of micro-scale segregation. In turn, these variables are significantly impacted by local land use regulations (Fong \& Shibuya, 2000; Ganong \& Shoag, 2015; Hulchanski, 2007; Lens \& Monkkonen, 2016; Reardon \& Bischoff, 2011; Saiz, 2010).

\subsection{LIMITATIONS}

While these results are further proof that built form and wealth indicators influence intra-neighbourhood income inequality (Fong \& Shibuya, 2000; Ganong \& Shoag, 2015; Goetz \& Chapple, 2010; Hulchanski, 2007; Lens \& Monkkonen, 2016; Reardon \& Bischoff, 2011), they do not show how each variable is related to macro-scale income segregation, as well as whether they more strongly influence the segregation of affluence or of poverty. Additionally, they do not say whether high Gini coefficients within census tracts are due to income polarization, that is whether they only contain households at the extreme ends of the income distribution, or due to a true mix of incomes.

Further, and more importantly, these results do not say anything about how changes in the homogeneity or heterogeneity of household incomes impacts residents' outcomes, such as well-being or intergenerational mobility. Nor does it say whether increased intra-neighbourhood income homogeneity is the result of new higher income households replacing lower income households, or the result of lowerincome households converging to outcomes of higher earning households in their neighbourhood.

At the macro-scale, this paper also does not account for whether low-income households have left the CMA altogether for other, more affordable regions. The overall Gini coefficient for the Toronto CMA somewhat levelled off since 2005. Thus, perhaps the increased intra-neighbourhood income homogenization is due to the out-migration and reduced influx of lower-income households, similar to 
Ganong and Shoag's (2015) finding that unskilled workers have been migrating away from productive areas in the US. 


\section{PROFESSIONAL IMPLICATIONS AND RECOMMENDATIONS}

The increase in income inequality over the past few decades requires action from higher levels of government, such as taxation and labour force strategies that are aimed at ensuring all segments of the population benefit from the relative wealth and economic growth of the country. Policies to reduce income inequality are recommended, as there is very strong evidence that greater levels of equality are better for both society and the individuals within them (OECD, 2016; Wilkinson \& Pickett, 2009; Wilkinson \& Pickett, 2018).

At the same time, this study further proves that local land use policies have significant impacts on the way income inequality is expressed spatially. While it is not yet completely clear whether active sorting, in and of itself, has positive or negative impacts on residents, there is strong evidence that concentrated poverty and segregation have negative impacts on low-income households and on the perpetuation of structural inequality (Dinca-Panaitescu et al., 2017; Glaeser et al., 2002; Lens \& Monkkonen, 2016; Mayer, 2000; Quillian, 2007; Reardon \& Bischoff, 2011; Sampson, 2018). Further, the concentration of affluence and poverty affects municipalities' capacity for delivering services, collecting property taxes, and undertaking redistribution programs.

Thus, while segregation by household choice is one thing, local governments and policy-makers should limit exclusionary policies that enforce or perpetuate income segregation. Such policies create barriers for households at the lower end of the income distribution to be able to choose their neighbourhood.

Income segregation can concentrate negative social outcomes and fracture politics (Lens \& Monkkonen, 2016). Therefore, municipal and regional governments should worry about the extent to which they are creating more such neighbourhoods. The exclusionary nature of some land-use regulations and housing policies impact who is able to live in the city as well as where they can live in the city. Thus, the Toronto CMA will likely see more income segregation in neighbourhoods with more exclusionary zoning regulations and in municipalities with stricter housing policies.

The creation of mixed-income communities is a stated policy objective for both the federal government (through Canada's National Housing Strategy) and for the city of Toronto (in its Official Plan). However, policies such as minimum lot sizes and the prohibition of built form diversity, as encoded in the City's Zoning By-Law, are directly counter to city's stated policy objectives. The city of Toronto and all other municipalities within the CMA should move towards more inclusionary policies, as "inclusionary policies have a greater potential to reduce income segregation than bringing higher-income households into 
lower-income parts of the city" (Lens \& Monkkonen, 2016, p. 6). Thus, removing single-detached only zones and minimum lot sizes from the Zoning By-Law, or relaxing density restrictions, could have a greater impact on income integration than other more costly projects, such as the revitalization of Regent Park.

\subsection{NEXT STEPS}

There are three areas ripe for further research to build off this study. For one, future research should expand on our current understandings of the consequences of segregation, as this study only looks at the patterns and potential causes of income segregation in the Toronto CMA since 1985. Additionally, a regression model could be run on the household income clusters and outliers in order to explain changes in macro-scale segregation over time. Finally, future research should study the effect of specific local land use regulations and policies, such as property taxes, and their impact on income segregation in the Canadian context.

\subsection{CONCLUSION}

Macro-scale income segregation among neighbourhoods in the Toronto CMA declined between 1985 and 2015, while micro-scale intra-neighbourhood income segregation increased. Compared to overall changes in income inequality in the region in the same time period, neighbourhoods have become more homogenous in terms of their household income distribution. Thus, neighbourhood sorting by households based on income has increased.

Consistent with extant literature, this study finds that local housing characteristics have significant spillover effects on income segregation. Specifically, variables associated with greater housing affluence are negatively correlated with intra-neighbourhood inequality measures, and thus positively correlated with income homogenization. This confirms and adds to the literature that local land use regulations impact income spatial inequality. Thus, municipal and regional governments should reduce their exclusionary housing policies and land-use regulations and instead enact more inclusionary policies. 


\section{APPENDIX A: COMPARISON OF MAPS WITH ORIGINAL CENSUS TRACT BOUNDARIES}

A.1: Statistically Significant Household Income Clusters and Outliers among Neighbourhoods, Toronto CMA, 1985

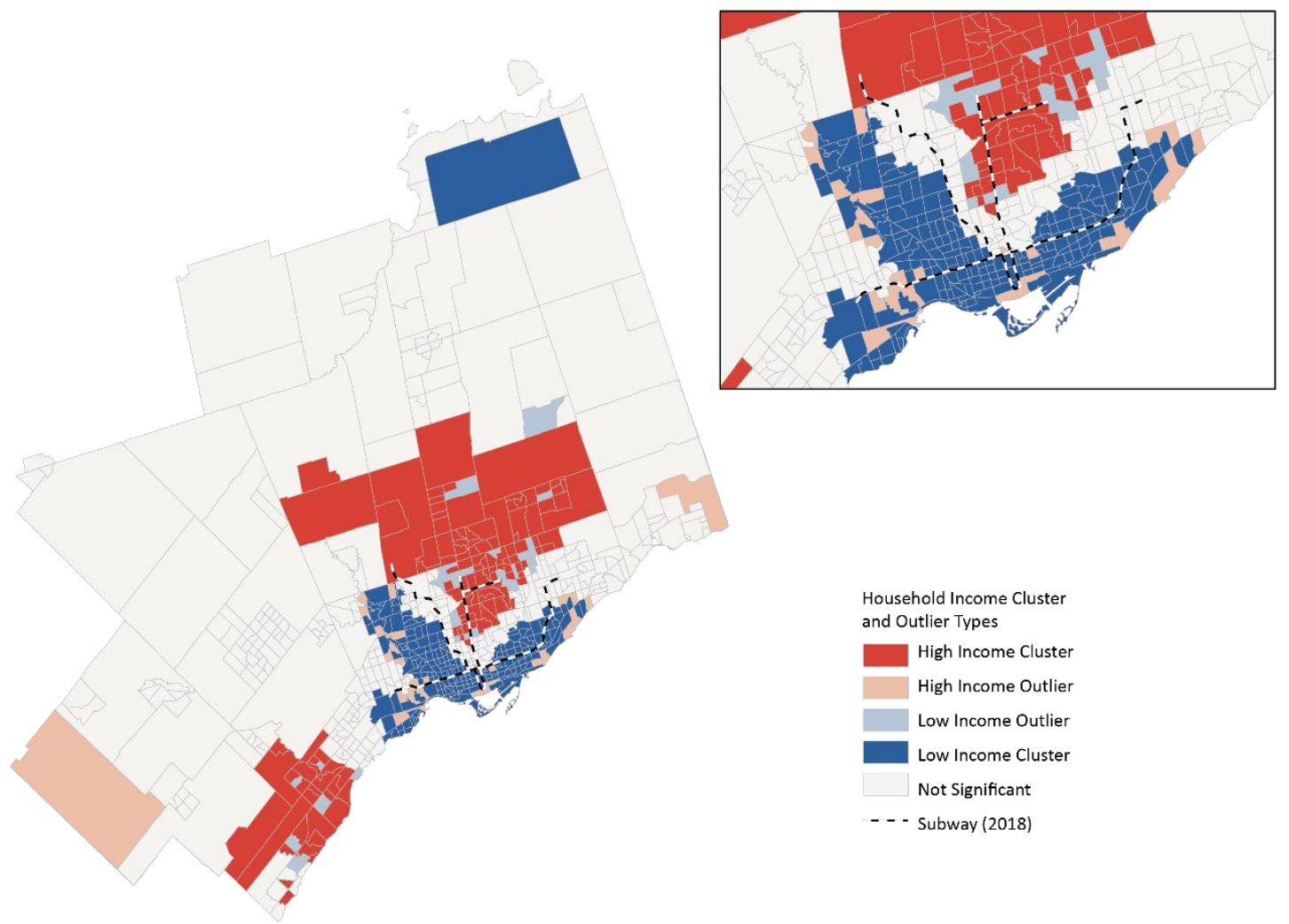




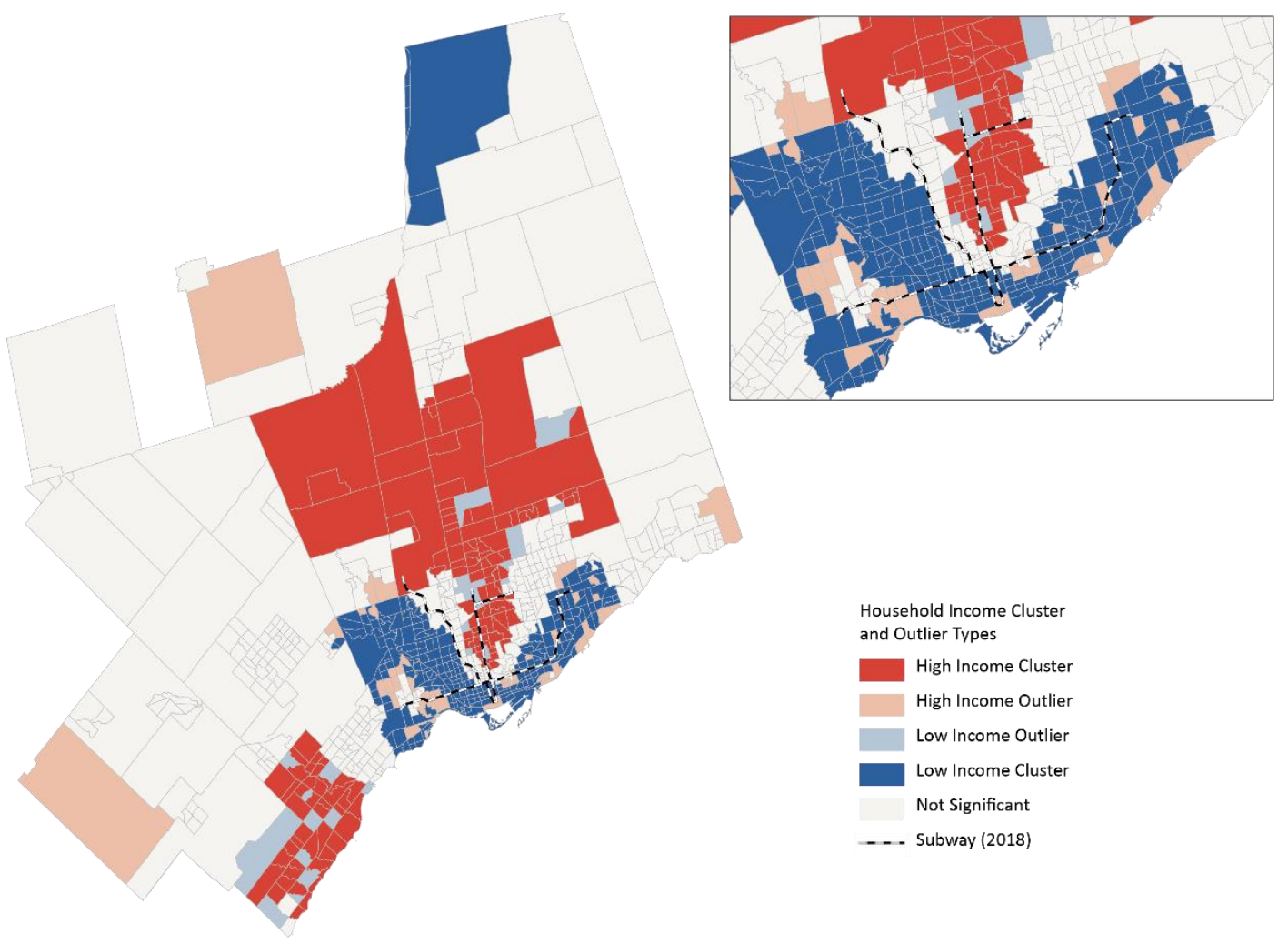

A.3: Statistically Significant Household Income Clusters and Outliers among Neighbourhoods, Toronto CMA, 2005
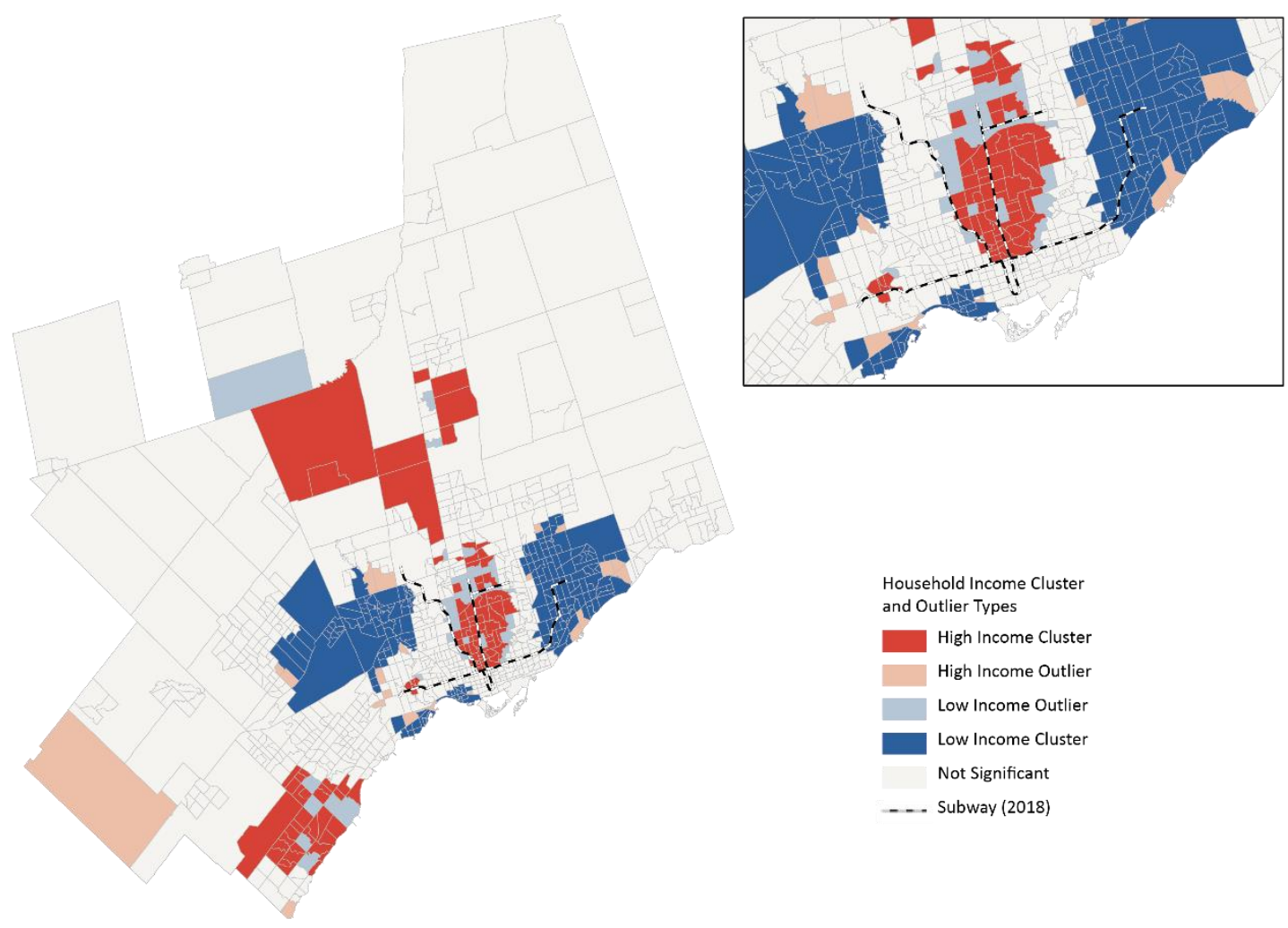


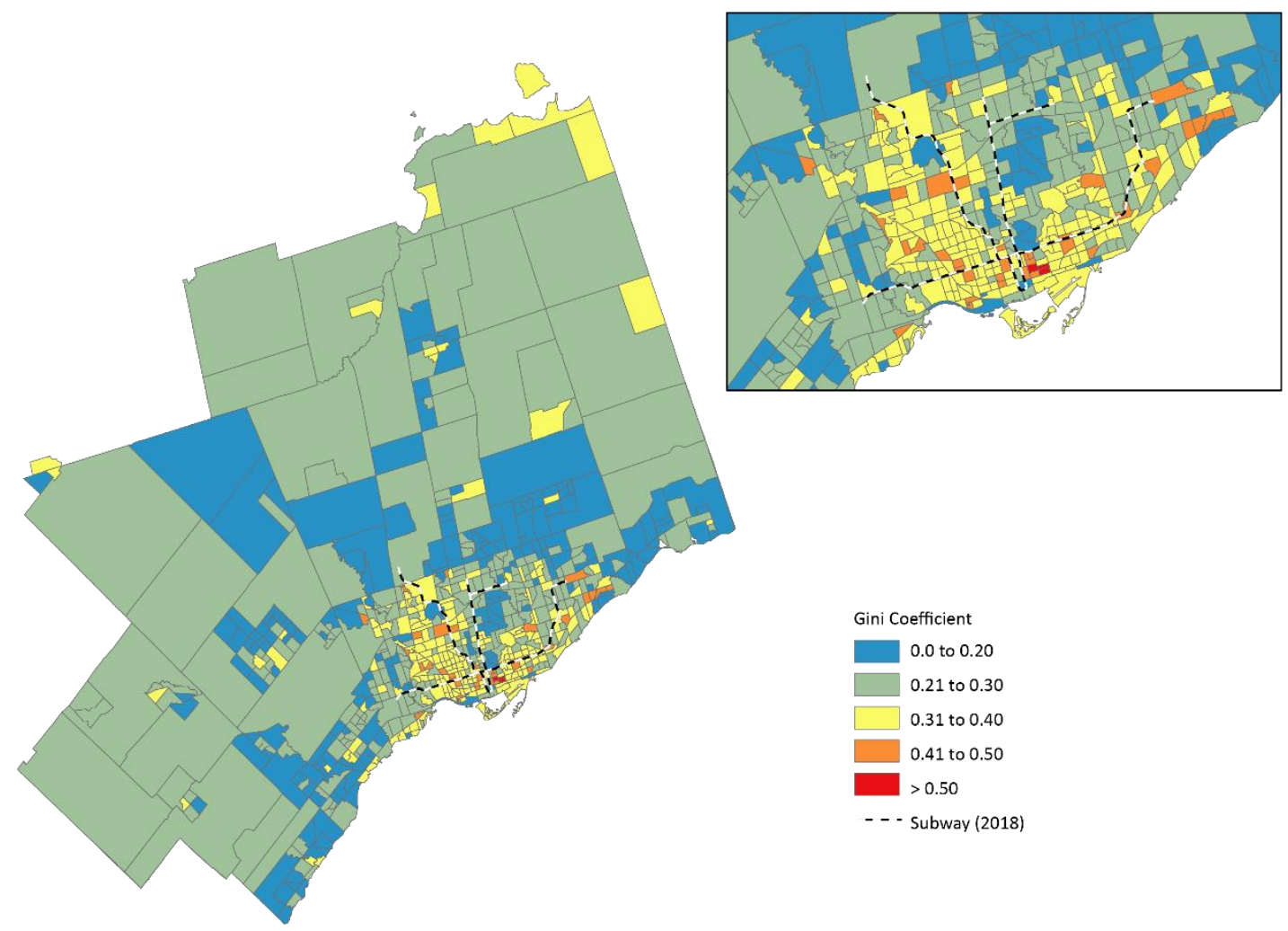

A.5.: Gini Coefficient of Income Inequality Within Census Tracts, Toronto CMA, 1995

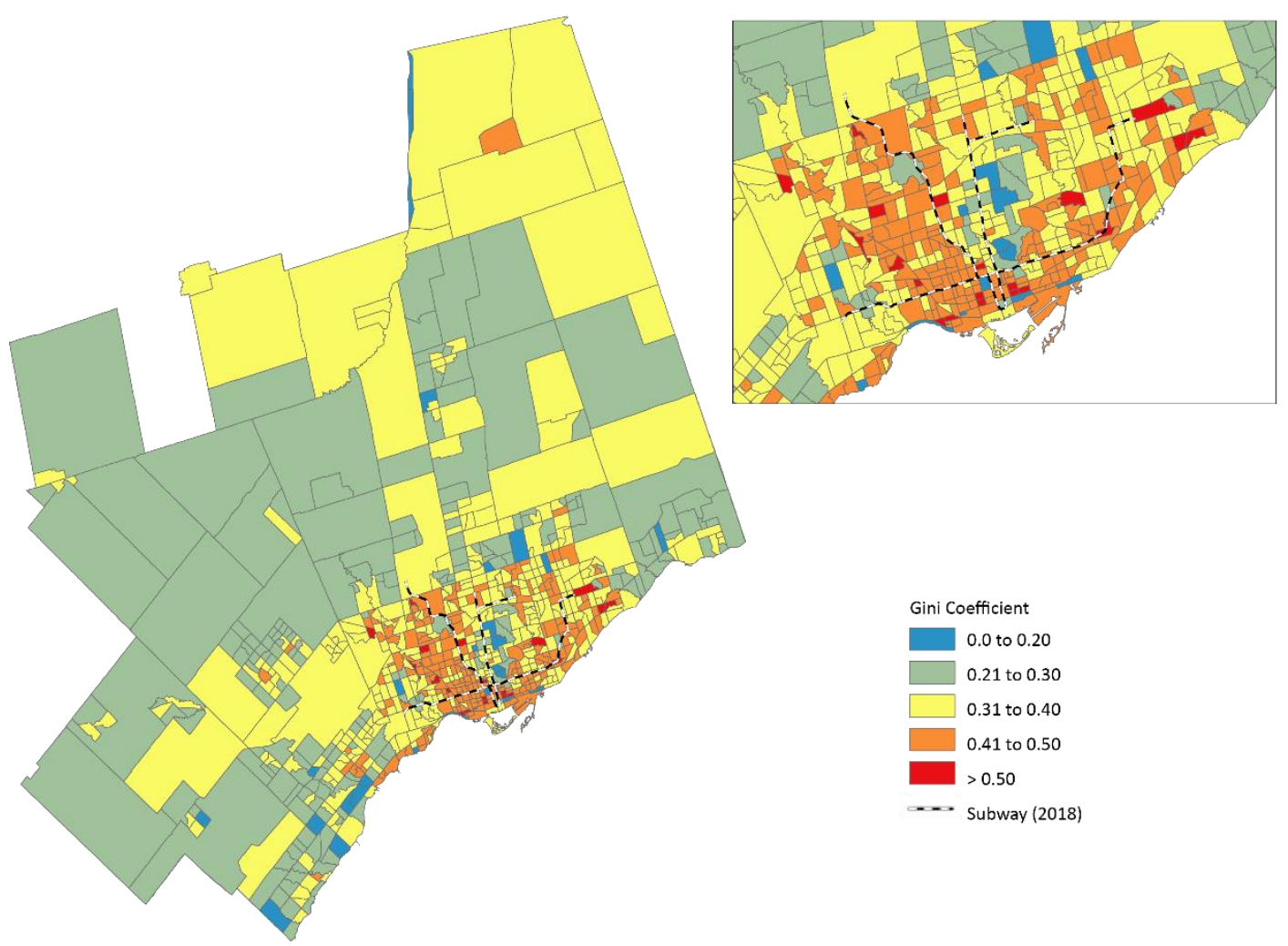


A.6.: Gini Coefficient of Income Inequality Within Census Tracts, Toronto CMA, 2005
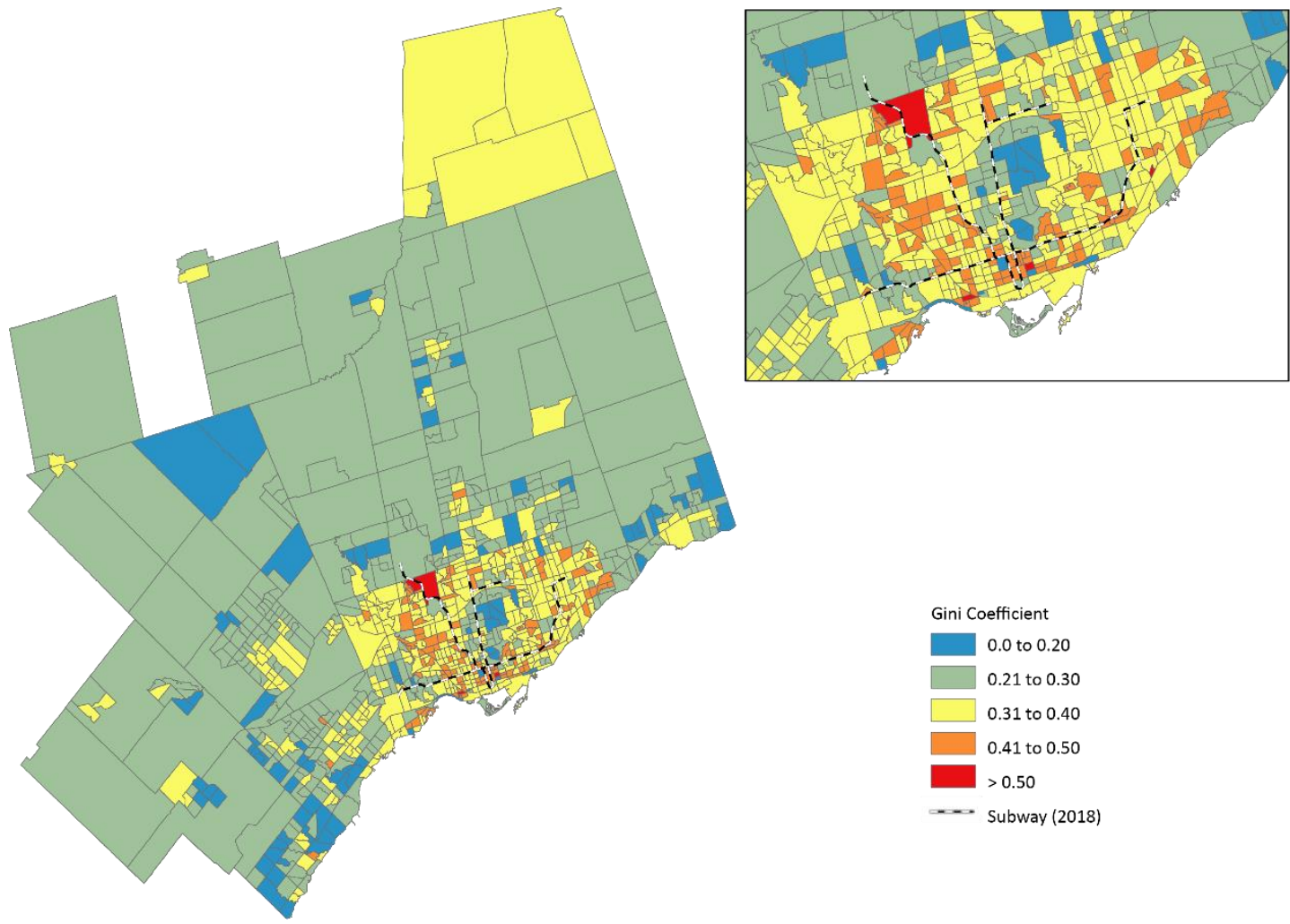

A.7.: Neighbourhood Sorting Index Within Census Tracts, Toronto CMA, 1985

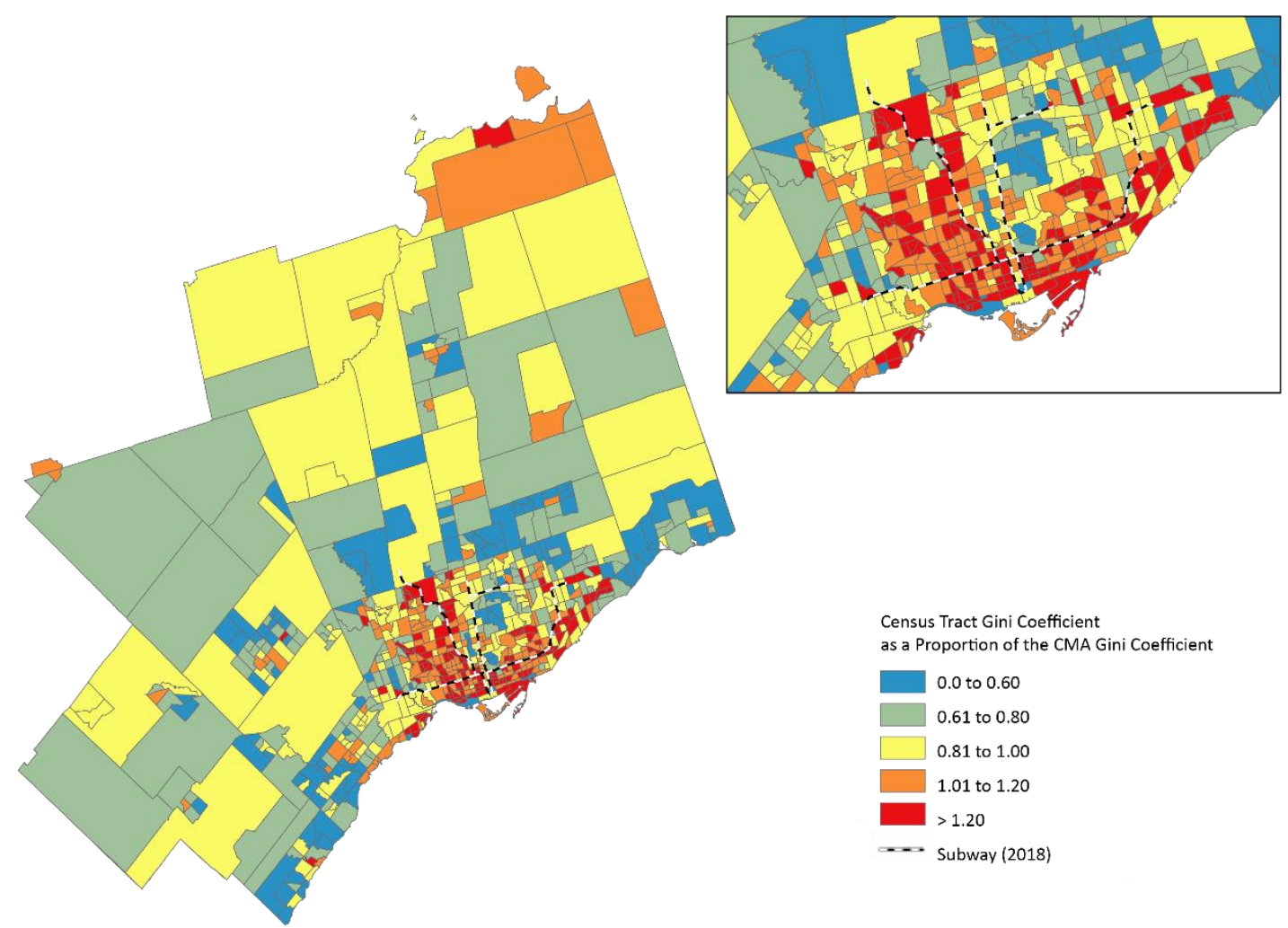



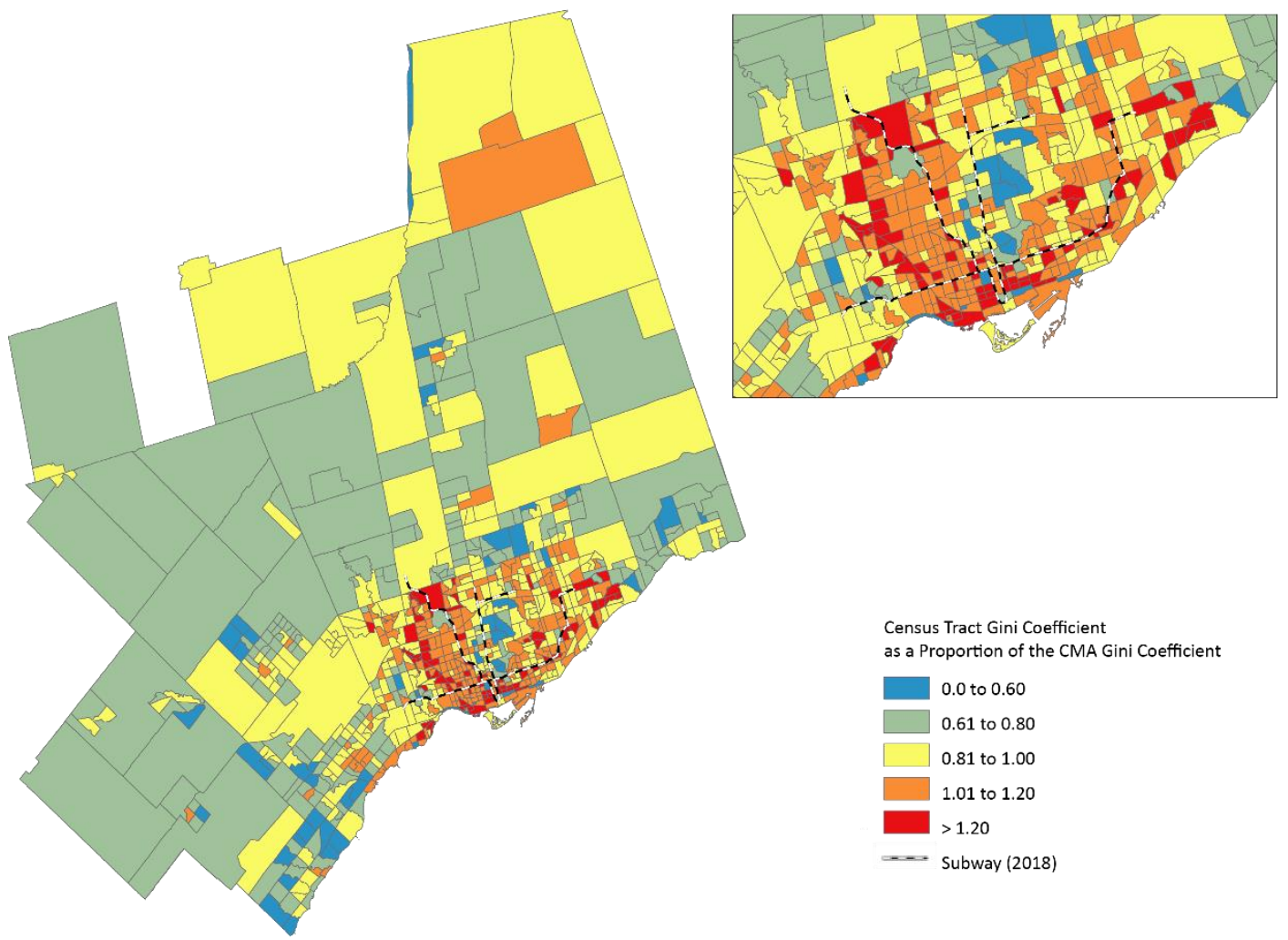

Census Tract Gini Coefficient

as a Proportion of the CMA Gini Coefficient

0.0 to 0.60

0.61 to 0.80

$\square 0.81$ to 1.00

1.01 to 1.20

$>1.20$

-.. Subway (2018)

A.9.: Neighbourhood Sorting Index Within Census Tracts, Toronto CMA, 2005
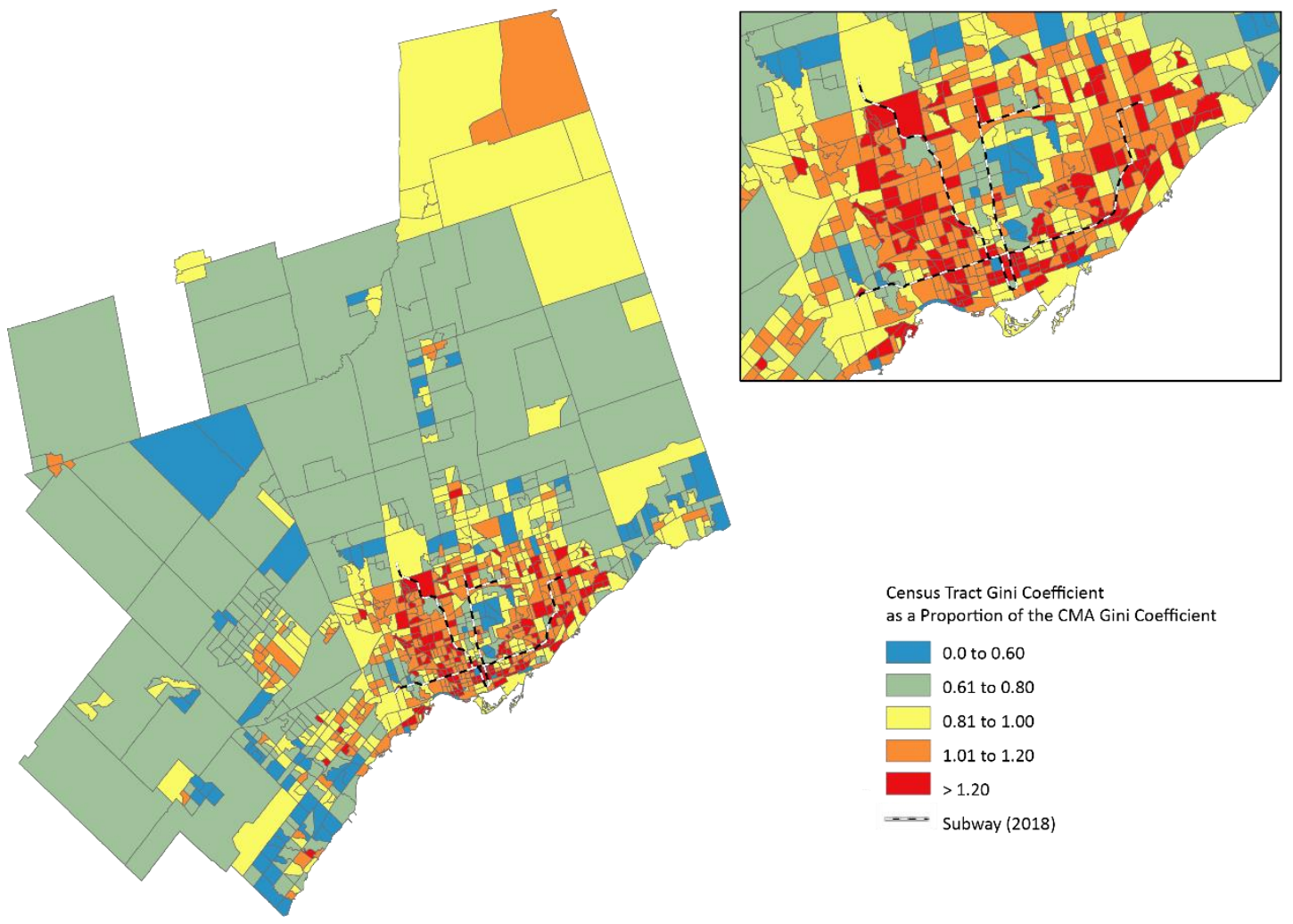

Census Tract Gini Coefficient

as a Proportion of the CMA Gini Coefficient

0.0 to 0.60

0.61 to 0.80

0.81 to 1.00

1.01 to 1.20

$>1.20$

-.. Subway (2018) 


\section{ApPendix B: SUMmary STATISTICS BY YEAR}

\section{B.1.: 1985 Summary Statistics}

\begin{tabular}{|c|c|c|c|c|c|}
\hline Statistic & $\mathrm{N}$ & Min & Median & Mean & Max \\
\hline Population & 1,130 & 0 & 3,235 & 3,032 & 8,674 \\
\hline Households & 1,130 & 0 & 1,040 & 1,062 & 4,657 \\
\hline Dwellings & 1,130 & 0 & 1,041 & 1,062 & 4,657 \\
\hline Average Dwelling Value (2015 \$) & 1,123 & 0 & 279,548 & 305,717 & $1,552,553$ \\
\hline Dwelling Units Built Between 1980 and 1985 & 1,130 & 0 & 31 & 116 & 1,602 \\
\hline Dwelling Units Built Before 1960 & 1,130 & 0 & 164 & 411 & 2,460 \\
\hline Owner Households & 1,130 & 0 & 598 & 619 & 2,222 \\
\hline Renter Households & 1,130 & 0 & 230 & 443 & 4,606 \\
\hline Single-Detached Dwellings & 1,130 & 0 & 365 & 458 & 1,935 \\
\hline Apartments with 5 or More Storeys & 1,130 & 0 & 17 & 300 & 4,526 \\
\hline Population Density & 1,130 & 0 & 2,524 & 3,547 & 59,651 \\
\hline Unemployment Rate & 1,121 & 0 & 0 & 0 & 0 \\
\hline Blue Collar Workers & 1,130 & 0 & 677 & 711 & 2,463 \\
\hline White Canadians & 1,130 & 0 & 1,336 & 1,363 & 4,410 \\
\hline Black Canadians & 1,130 & 0 & 32 & 81 & 1,075 \\
\hline Asian Canadians & 1,130 & 0 & 34 & 112 & 2,065 \\
\hline South Asian Canadians & 1,130 & 0 & 34 & 94 & 1,399 \\
\hline Residents Who Moved Between 1980 and 1985 & 1,130 & 0 & 1,254 & 1,316 & 6,262 \\
\hline Immigrants & 1,130 & 0 & 922 & 1,091 & 4,459 \\
\hline Average Household Income (2015 \$) & 1,123 & 0 & 93,324 & 92,928 & 371,830 \\
\hline Average Monthly Rent (2015 \$) & 1,123 & 0 & 1,132 & 1,206 & 5,020 \\
\hline Average Owner Payments (2015 \$) & 1,120 & 0 & 1,285 & 1,320 & 3,120 \\
\hline Population with a Bachelors' Degree or Higher & 1,130 & 0 & 231 & 334 & 2,545 \\
\hline
\end{tabular}




\begin{tabular}{|c|c|c|c|c|c|}
\hline Statistic & $\mathrm{N}$ & Min & Median & Mean & Max \\
\hline Population & 1,145 & 0 & 3,951 & 3,722 & 12,157 \\
\hline Households & 1,141 & 0 & 1,330 & 1,303 & 5,525 \\
\hline Dwellings & 1,141 & 0 & 1,330 & 1,303 & 5,525 \\
\hline Average Dwelling Value (2015 \$) & 1,136 & 109 & 412325 & 165356,441 & 11 1,889,971 \\
\hline Dwelling Units Built Between 1990 and 1995 & 1,141 & 0 & 25 & 94 & 1,166 \\
\hline Dwelling Units Built Before 1960 & 1,141 & 0 & 175 & 420 & 2,540 \\
\hline Owner Households & 1,141 & 0 & 785 & 762 & 2,180 \\
\hline Renter Households & 1,141 & 0 & 344 & 541 & 5,513 \\
\hline Single-Detached Dwellings & 1,141 & 0 & 505 & 566 & 2,035 \\
\hline Apartments with 5 or More Storeys & 1,141 & 0 & 90 & 367 & 5,418 \\
\hline Population Density & 1,145 & 0 & 3,138 & 4,395 & 86,836 \\
\hline Unemployment Rate & 1,141 & 0 & 0 & 0 & 0 \\
\hline Blue Collar Workers & 1,141 & 0 & 841 & 843 & 3,333 \\
\hline White Canadians & 1,141 & 0 & 2,560 & 2,562 & 6,453 \\
\hline Black Canadians & 1,141 & 0 & 124 & 240 & 2,670 \\
\hline Asian Canadians & 1,141 & 0 & 170 & 358 & 4,029 \\
\hline South Asian Canadians & 1,141 & 0 & 125 & 289 & 3,215 \\
\hline Residents Who Moved Between 1990 and 1995 & 1,141 & 0 & 1,580 & 1,592 & 6,875 \\
\hline Immigrants & 1,141 & 0 & 1,423 & 1,553 & 8,240 \\
\hline Average Monthly Rent (2015 \$) & 1,137 & 571 & 1,187 & 1,249 & 2,996 \\
\hline Average Owner Payments (2015 \$) & 1,136 & 830 & 1,536 & 1,580 & 2,757 \\
\hline Average Household Income (2015 \$) & 1,134 & 0 & 62,994 & 64,379 & 356,109 \\
\hline Population with a Bachelors' Degree or Higher & 1,141 & 0 & 472 & 561 & 3,110 \\
\hline
\end{tabular}


B.3.: 2005 Summary Statistics

\begin{tabular}{|c|c|c|c|c|c|}
\hline Statistic & $\mathrm{N}$ & Min & Median & Mean & Max \\
\hline Population & 1,146 & 6 & 4,479 & 4,458 & 12,273 \\
\hline Households & 1,146 & 0 & 1,555 & 1,571 & 5,716 \\
\hline Dwellings & 1,146 & 0 & 1,550 & 1,568 & 5,716 \\
\hline Average Dwelling Value (2015 \$) & 1,142 & 0 & 430,73 & 472,903 & $31,896,813$ \\
\hline Dwelling Units Built Between200 and 2005 & 1,146 & 0 & 30 & 180 & 3,040 \\
\hline Dwelling Units Built Before 1960 & 1,146 & 0 & 195 & 401 & 2,350 \\
\hline Owner Households & 1,146 & 0 & 1,051 & 1,061 & 2,920 \\
\hline Renter Households & 1,146 & 0 & 305 & 507 & 5,670 \\
\hline Single-Detached Dwellings & 1,146 & 0 & 597 & 654 & 2,275 \\
\hline Apartments with 5 or More Storeys & 1,146 & 0 & 90 & 417 & 5,615 \\
\hline Population Density & 1,146 & 4 & 3,707 & 5,010 & 87,665 \\
\hline Unemployment Rate & 1,143 & 0 & 0 & 0 & 0 \\
\hline Blue Collar Workers & 1,146 & 0 & 820 & 840 & 2,833 \\
\hline White Canadians & 1,146 & 0 & 2,352 & 2,525 & 7,353 \\
\hline Black Canadians & 1,146 & 0 & 179 & 305 & 2,515 \\
\hline Asian Canadians & 1,146 & 0 & 325 & 575 & 5,225 \\
\hline South Asian Canadians & 1,146 & 0 & 301 & 595 & 5,775 \\
\hline Residents Who Moved Between 2000 and 2005 & 1,146 & 0 & 1,772 & 1,863 & 6,582 \\
\hline Immigrants & 1,146 & 0 & 1,904 & 2,020 & 7,770 \\
\hline Average Monthly Rent (2015\$) & 1,141 & 0 & 1,163 & 1,215 & 3,058 \\
\hline Average Owner Payments (2015 \$) & 1,140 & 0 & 1,601 & 1,636 & 2,814 \\
\hline Average Household Income (2015 \$) & 1,144 & 0 & 96,390 & 107,676 & 953,257 \\
\hline Population with a Bachelors' Degree or Higher & 1,146 & 0 & 860 & 958 & 3,950 \\
\hline
\end{tabular}


B.4.: 2015 Summary Statistics

\begin{tabular}{|c|c|c|c|c|c|}
\hline Statistic & $\mathrm{N}$ & Min & Median & Mean & Max \\
\hline Population & 1,151 & 0 & 4,995 & 5,150 & 23,401 \\
\hline Households & 1,148 & 20 & 1,740 & 1,861 & 11,890 \\
\hline Dwellings & 1,148 & 15 & 1,738 & 1,861 & 11,890 \\
\hline Average Dwelling Value (2015 \$) & 1,146 & 0 & 664,090 & 732,166 & $2,902,556$ \\
\hline Dwelling Units Built Between 2010 and 2015 & 1,146 & 0 & 20 & 155 & 6,285 \\
\hline Dwelling Units Built Before 1960 & 1,146 & 0 & 200 & 382 & 2,285 \\
\hline Owner Households & 1,146 & 0 & 1,170 & 1,239 & 5,140 \\
\hline Renter Households & 1,146 & 0 & 375 & 624 & 6,810 \\
\hline Single-Detached Dwellings & 1,148 & 0 & 662 & 737 & 4,095 \\
\hline Apartments with 5 or More Storeys & 1,148 & 0 & 125 & 546 & 11,500 \\
\hline Population Density & 1,151 & 0 & 3,970 & 5,567 & 84,436 \\
\hline Unemployment Rate & 1,146 & 0 & 0 & 0 & 0 \\
\hline Blue Collar Workers & 1,146 & 15 & 1,025 & 1,080 & 5,450 \\
\hline White Canadians & 1,146 & 0 & 2,262 & 2,488 & 11,060 \\
\hline Black Canadians & 1,146 & 0 & 235 & 386 & 3,455 \\
\hline Asian Canadians & 1,146 & 0 & 275 & 629 & 8,960 \\
\hline South Asian Canadians & 1,146 & 0 & 400 & 849 & 15,220 \\
\hline Residents Who Moved Between 2010 and 2015 & 1,146 & 10 & 1,610 & 1,869 & 18,210 \\
\hline Immigrants & 1,146 & 0 & 2,142 & 2,361 & 14,245 \\
\hline Average Monthly Rent (2015 \$) & 1,146 & 0 & 1,278 & 1,328 & 3,622 \\
\hline Average Owner Payments (2015\$) & 1,146 & 0 & 1,646 & 1,706 & 3,250 \\
\hline Average Household Income (2015 \$) & 1,145 & 32,799 & 101,077 & 114,330 & 896,861 \\
\hline Population with a Bachelors' Degree or Higher & 1,146 & 15 & 1,205 & 1,419 & 12,575 \\
\hline
\end{tabular}


B.5.: Summary Statistics for All Years

\begin{tabular}{|c|c|c|c|c|c|}
\hline Statistic & $\mathrm{N}$ & Min & Median 1 & Mean & Max \\
\hline Population & 4,572 & 0 & 4,152 & 4,095 & 23,401 \\
\hline Households & 4,565 & 0 & 1,435 & 1,451 & 11,890 \\
\hline Dwellings & 4,565 & 0 & 1,435 & 1,450 & 11,890 \\
\hline Average Dwelling Value (2015 \$) & 4,547 & 0 & 392,350 & 467,859 & $\begin{array}{c}2,902,55 \\
6\end{array}$ \\
\hline Dwelling Units Built in Previous 5 Years & 4,563 & 0 & 25 & 137 & 6,285 \\
\hline Dwelling Units Built Before 1960 & 4,563 & 0 & 185 & 404 & 2,540 \\
\hline Owner Households & 4,563 & 0 & 905 & 921 & 5,140 \\
\hline Renter Households & 4,563 & 0 & 310 & 529 & 6,810 \\
\hline Single-Detached Dwellings & 4,565 & 0 & 525 & 604 & 4,095 \\
\hline Apartments with 5 or More Storeys & 4,565 & 0 & 75 & 408 & 11,500 \\
\hline Population Density & 4,572 & 0 & 3,365 & 4,635 & 87,665 \\
\hline Unemployment Rate & 4,551 & 0 & 0 & 0 & 0 \\
\hline Blue Collar Workers & 4,563 & 0 & 850 & 869 & 5,450 \\
\hline White Canadians & 4,563 & 0 & 2,050 & 2,237 & 11,060 \\
\hline Black Canadians & 4,563 & 0 & 121 & 254 & 3,455 \\
\hline Asian Canadians & 4,563 & 0 & 180 & 420 & 8,960 \\
\hline South Asian Canadians & 4,563 & 0 & 165 & 458 & 15,220 \\
\hline Residents Who Moved in Previous 5 Years & 4,563 & 0 & 1,550 & 1,661 & 18,210 \\
\hline Immigrants & 4,563 & 0 & 1,590 & 1,759 & 14,245 \\
\hline Average Monthly Rent (2015 \$) & 4,547 & 0 & 1,187 & 1,250 & 5,020 \\
\hline Average Owner Payments (2015\$) & 4,542 & 0 & 1,544 & 1,562 & 3,250 \\
\hline Average Household Income (2015\$) & 4,546 & 0 & 89,533 & 94,909 & 953,257 \\
\hline \multicolumn{3}{|c|}{ Population with a Bachelors' Degree or Higher 4,563 } & 64 & $49 \quad 820$ & 12,575 \\
\hline
\end{tabular}




\section{Appendix C: ORIGINAL RegReSSION OUTPUTS WITH HIGH-VIF VARIABLES}

\section{C.1.: Regression Results for 5 Panel Models Before Removal of High VIF Variables}

Dependent variable:

Gini coefficient

\begin{tabular}{lcc}
\hline baseline pooled & fixed effects \\
& year only & census tract only two-way
\end{tabular}

(1)

(2)

(3)

(4)

(5)

\begin{tabular}{|c|c|c|c|c|c|}
\hline \multirow[t]{2}{*}{ Average Dwelling Value } & $-0.084^{* * *}$ & $-0.043^{* * *}$ & $0.005^{* *}$ & $-0.089^{* * *}$ & 0.005 \\
\hline & $(0.004)$ & $(0.003)$ & $(0.003)$ & $(0.003)$ & $(0.003)$ \\
\hline \multirow[t]{2}{*}{$\begin{array}{l}\text { Proportion of Dwellings } \\
\text { Constructed in Previous } 5 \text { Years }\end{array}$} & $0.020^{* *}$ & $-0.063^{* * *}$ & $-0.023^{* * *}$ & $-0.082^{* * *}$ & $-0.030^{* * *}$ \\
\hline & $(0.008)$ & $(0.007)$ & $(0.005)$ & $(0.008)$ & $(0.005)$ \\
\hline \multirow[t]{2}{*}{$\begin{array}{l}\text { Proportion of Dwellings } \\
\text { Constructed Before } 1960\end{array}$} & $0.033^{* * *}$ & $0.056^{* * *}$ & $0.054^{* * *}$ & $0.055^{* * *}$ & $0.072^{* * *}$ \\
\hline & $(0.004)$ & $(0.004)$ & $(0.002)$ & $(0.009)$ & $(0.005)$ \\
\hline \multirow[t]{2}{*}{ Proportion of Owner Households } & -0.255 & 0.017 & -0.084 & 0.076 & -0.061 \\
\hline & $(0.213)$ & $(0.075)$ & $(0.054)$ & $(0.082)$ & $(0.046)$ \\
\hline \multirow[t]{2}{*}{$\begin{array}{l}\text { Proportion of Single-Detached } \\
\text { Dwellings }\end{array}$} & $0.017^{* * *}$ & -0.007 & $-0.027^{* * *}$ & -0.002 & $-0.017^{* * *}$ \\
\hline & $(0.005)$ & $(0.004)$ & $(0.003)$ & $(0.009)$ & $(0.005)$ \\
\hline \multicolumn{6}{|l|}{ Proportion of Apartment } \\
\hline \multirow[t]{2}{*}{$\begin{array}{l}\text { Dwellings with More than } 5 \\
\text { Storeys }\end{array}$} & -0.008 & $0.014^{* * *}$ & $0.034^{* * *}$ & 0.005 & $0.072^{* * *}$ \\
\hline & $(0.006)$ & $(0.005)$ & $(0.003)$ & $(0.009)$ & $(0.005)$ \\
\hline \multirow[t]{2}{*}{ Population Density per 1,000 } & $0.0004^{* *}$ & $-0.0005^{* * *}$ & 0.0002 & $-0.001^{* * *}$ & 0.0002 \\
\hline & $(0.0002)$ & $(0.0001)$ & $(0.0001)$ & $(0.0003)$ & $(0.0002)$ \\
\hline \multirow[t]{2}{*}{ Unemployment Rate } & $-0.082^{* *}$ & $0.674^{* * *}$ & $0.348^{* * *}$ & $0.651^{* * *}$ & $0.194^{* * *}$ \\
\hline & (0.039) & $(0.031)$ & $(0.024)$ & $(0.034)$ & $(0.021)$ \\
\hline \multirow[t]{2}{*}{ Proportion of Blue-Collar Workers } & $-0.182^{* * *}$ & $-0.327^{* * *}$ & $-0.135^{* * *}$ & $-0.345^{* * *}$ & $-0.096^{* * *}$ \\
\hline & $(0.021)$ & $(0.016)$ & $(0.012)$ & (0.019) & $(0.012)$ \\
\hline Proportion of Black Canadians & $-0.195^{* * *}$ & $-0.094^{* * *}$ & $-0.043^{* * *}$ & 0.016 & $-0.042^{* * *}$ \\
\hline
\end{tabular}




\begin{tabular}{|c|c|c|c|c|c|}
\hline & $(0.018)$ & $(0.014)$ & $(0.010)$ & $(0.021)$ & $(0.013)$ \\
\hline \multirow[t]{2}{*}{ Proportion of Asian Canadians } & -0.0001 & $0.040^{* * *}$ & $0.064^{* * *}$ & $0.154^{* * *}$ & $0.060^{* * *}$ \\
\hline & $(0.010)$ & $(0.007)$ & (0.005) & $(0.013)$ & $(0.007)$ \\
\hline \multirow[t]{2}{*}{$\begin{array}{l}\text { Proportion of South Asian } \\
\text { Canadians }\end{array}$} & $-0.135^{* * *}$ & $-0.090^{* * *}$ & $-0.044^{* * *}$ & $-0.050^{* * *}$ & $-0.019^{* * *}$ \\
\hline & $(0.011)$ & $(0.008)$ & $(0.006)$ & $(0.012)$ & $(0.007)$ \\
\hline \multirow[t]{2}{*}{$\begin{array}{l}\text { Proportion of Movers in Previous } \\
5 \text { Years }\end{array}$} & $0.036^{* *}$ & $0.050^{* * *}$ & $0.049^{* * *}$ & $0.045^{* * *}$ & $0.044^{* * *}$ \\
\hline & $(0.015)$ & $(0.012)$ & (0.009) & (0.014) & $(0.008)$ \\
\hline \multirow[t]{2}{*}{ Proportion of Immigrants } & $0.154^{* * *}$ & $0.129^{* * *}$ & $0.050^{* * *}$ & $0.088^{* * *}$ & $0.118^{* * *}$ \\
\hline & $(0.010)$ & $(0.009)$ & $(0.006)$ & $(0.015)$ & $(0.008)$ \\
\hline \multirow[t]{2}{*}{ Spatial Autocorrelation Z-Score } & & -0.001 & -0.0003 & -0.0001 & $-0.0005^{* *}$ \\
\hline & & $(0.0004)$ & $(0.0003)$ & $(0.0004)$ & $(0.0002)$ \\
\hline \multirow[t]{2}{*}{ Low Socioeconomic Status } & $-0.027^{* * *}$ & $-0.009^{* * *}$ & -0.001 & $-0.010^{* * *}$ & $0.004^{* * *}$ \\
\hline & $(0.003)$ & $(0.002)$ & $(0.002)$ & $(0.003)$ & $(0.002)$ \\
\hline \multirow[t]{2}{*}{ Middle Socioeconomic Status } & $-0.010^{* * *}$ & $-0.025^{* * *}$ & $-0.017^{* * *}$ & $-0.029^{* * *}$ & $-0.006^{* * *}$ \\
\hline & $(0.003)$ & $(0.003)$ & $(0.002)$ & $(0.003)$ & $(0.002)$ \\
\hline \multirow[t]{2}{*}{ High Socioeconomic Status } & $-0.023^{* * *}$ & $-0.041^{* * *}$ & $-0.029^{* * *}$ & $-0.042^{* * *}$ & $-0.015^{* * *}$ \\
\hline & $(0.004)$ & $(0.003)$ & $(0.002)$ & $(0.004)$ & $(0.002)$ \\
\hline \multirow[t]{2}{*}{ Very High Socioeconomic Status } & $0.024^{* * *}$ & $-0.049^{* * *}$ & $-0.045^{* * *}$ & $-0.040^{* * *}$ & $-0.024^{* * *}$ \\
\hline & $(0.003)$ & $(0.004)$ & $(0.003)$ & $(0.005)$ & $(0.003)$ \\
\hline \multirow[t]{2}{*}{ Average Household Income } & -0.0001 & $-0.005^{* * *}$ & 0.001 & $-0.003^{* * *}$ & 0.0001 \\
\hline & $(0.001)$ & $(0.001)$ & $(0.001)$ & $(0.001)$ & $(0.0005)$ \\
\hline \multirow[t]{2}{*}{ Average Monthly Rent } & -0.004 & $-0.062^{* * *}$ & $-0.063^{* * *}$ & $-0.037^{* * *}$ & $-0.025^{* * *}$ \\
\hline & $(0.004)$ & $(0.003)$ & $(0.002)$ & $(0.004)$ & $(0.002)$ \\
\hline \multirow[t]{2}{*}{$\begin{array}{l}\text { Average Monthly Owner } \\
\text { Payments }\end{array}$} & $-0.037^{* * *}$ & $0.075^{* * *}$ & $-0.015^{* * *}$ & $0.095^{* * *}$ & $-0.018^{* * *}$ \\
\hline & $(0.006)$ & $(0.005)$ & $(0.004)$ & $(0.006)$ & $(0.004)$ \\
\hline \multirow[t]{2}{*}{ Proportion Renter Households } & -0.054 & 0.121 & 0.011 & $0.235^{* * *}$ & 0.050 \\
\hline & $(0.213)$ & $(0.075)$ & $(0.054)$ & $(0.082)$ & $(0.046)$ \\
\hline
\end{tabular}




\begin{tabular}{|c|c|c|c|c|c|}
\hline Proportion Highly Educated & $-0.207^{* * *}$ & $-0.138^{* * *}$ & $-0.104^{* * *}$ & $-0.064^{* * *}$ & $-0.126^{* * *}$ \\
\hline & $(0.015)$ & $(0.012)$ & (0.009) & $(0.017)$ & $(0.010)$ \\
\hline Lagged Gini Coefficient & $\begin{array}{l}0.162^{* * *} \\
(0.020)\end{array}$ & & & & \\
\hline Distance to City Hall & & $\begin{array}{c}-0.014^{* * *} \\
(0.002)\end{array}$ & & & \\
\hline Distance to City Hall² & & $\begin{array}{l}0.003^{* * *} \\
(0.0003)\end{array}$ & & & \\
\hline 1995 (dummy) & & & & & $\begin{array}{c}0.087^{* * *} \\
(0.002)\end{array}$ \\
\hline 2005 (dummy) & & & & & $\begin{array}{l}0.056^{* * *} \\
(0.002)\end{array}$ \\
\hline 2015 (dummy) & & & & & $\begin{array}{l}-0.003 \\
(0.004)\end{array}$ \\
\hline Constant & $\begin{array}{l}1.830^{* * *} \\
(0.222)\end{array}$ & $\begin{array}{c}0.774^{* * *} \\
(0.090)\end{array}$ & & & \\
\hline Observations & 3,361 & 4,495 & 4,495 & 4,495 & 4,495 \\
\hline $\mathrm{R}^{2}$ & 0.784 & 0.805 & 0.868 & 0.663 & 0.894 \\
\hline Adjusted $\mathrm{R}^{2}$ & 0.782 & 0.804 & 0.867 & 0.544 & 0.856 \\
\hline F Statistic & $\begin{array}{c}503.034^{* * *}(\mathrm{df}= \\
24 ; 3336)\end{array}$ & $\begin{array}{c}709.602^{* * *}(\mathrm{df}= \\
26 ; 4468)\end{array}$ & $\begin{array}{c}1,218.982^{* * *}(\mathrm{df}= \\
24 ; 4467)\end{array}$ & $\begin{array}{c}272.283^{* * *}(\mathrm{df}= \\
24 ; 3324)\end{array}$ & $\begin{array}{c}1,033.659^{* * *}(\mathrm{df}= \\
27 ; 3321)\end{array}$ \\
\hline
\end{tabular}




\section{REFERENCES}

Allen, J., \& Taylor, Z. (2018). A new tool for neighbourhood change research: The Canadian Longitudinal Census Tract Database, 1971-2016. The Canadian Geographer / Le Géographe Canadien, 62(4), 575-588. doi:10.1111/cag.12467

Angrist, J. D. \& Pischke, J. (2015). Mastering 'Metrics: The Path from Cause to Effect. Princeton University Press.

Arcaya, M., Schwartz, G., \& Subramanian, SV. (2018). A multi-level modeling approach to understanding residential segregation in the United States. Environment and Planning B: Urban Analytics and City Science, 45(6), 1090-1105. https://doi.org/10.1177/2399808318760858

Bourne, L.S. (1993) Close together and worlds apart: An analysis of changes in the ecology of income in Canadian cities. Urban Studies 30 (8): 1293-1317.

Canada, Government of (2017). Canada's National Housing Strategy. Retrieved from https://www.placetocallhome.ca/pdfs/Canada-National-Housing-Strategy.pdf

Canadian Centre for Economic Analysis (CANCEA) \& Canadian Urban Institute (CUI). (2019). Toronto Housing Market Analysis: From Insight to Action.

Chen, W., Myles, J., and Picot, G. (2012). Why have poorer neighbourhoods stagnated economically while the richer have flourished? Neighbourhood income inequality in Canadian cities. Urban Studies 49 (4): 877-896.

Chetty, R., \& Hendren, N. (2018). The Impacts of Neighborhoods on Intergenerational Mobility I: Childhood Exposure Effects*. The Quarterly Journal of Economics, 133(3), 1107-1162. https://doi.org/10.1093/qje/qjy007

Currie, J. (2011). "Inequality at Birth: Some Causes and Consequences," American Economic Review, American Economic Association, vol. 101(3), 1-22.

Deluca, S. (2012). What Is the Role of Housing Policy? Considering Choice and Social Science Evidence. Journal of Urban Affairs, 34(1), 21-28. https://doi.org/10.1111/j.1467-9906.2011.00598.x

Dinca-Panaitescu, M. et al. (2017). The Opportunity Equation in the Greater Toronto Area: An update on neighbourhood income inequality and polarization. United Way Toronto \& York Region and the Neighbourhood Change Research Partnership. ISBN 978-0-921669-41-8

Ellen, I. G., \& Turner, M. A. (1997). Does neighborhood matter? Assessing recent evidence. Housing Policy Debate, 8(4), 833866. https://doi.org/10.1080/10511482.1997.9521280

ESRI (2018). ArcGIS Desktop: Release 10.6.1. USA: Environmental Systems Research Institute.

Fong, E. \& Shibuya, K. (2000). The Spatial Segregation of the Poor in Canadian Cities. Demography, 37(4): 449-459.

Galster, G. (2012). "Neighborhoods and their Role in Creating and Changing Housing." The Sage Handbook of Housing Studies (Clark and Gibb eds) Sage Publications.

Ganong P, \& Shoag D. (2015). Why Has Regional Income Convergence in the U.S. Declined? Journal of Urban Economics 102 : 76-90.

Glaeser, E., Scheinkman, J., \& Shleifer, A. (2002). The injustice of inequality. Journal of Monetary Economics 50: 199-122. 
Goetz, E. G. \& Chapple, K. (2010). You gotta move: advancing the debate on the record of dispersal. Housing Policy Debate, 20(2), 209-236.

Hlavac, Marek (2018). stargazer: Well-Formatted Regression and Summary Statistics Tables. R package version 5.2.2. https://CRAN.R-project.org/package=stargazer

Hulchanski, D. (2007). The Three Cities Within Toronto: Income Polarization among Toronto's Neigbourhoods, $1970-2005$. Toronto: University of Toronto Cities Centre.

Hulchanski, D. \& Maaranen, R. (2018). Neighbourhood Socio-Economic Polarization \& Segregation in Toronto: Trend and Processes since 1970. Neighbourhood Change Research Partnership, University of Toronto. Presentation to TU Delft (September 2018).

Imbroscio, D. (2011). Beyond Mobility: the Limits of Liberal Urban Policy. Journal of Urban Affairs, 34(1), 1-20. https://doi.org/10.1111/j.1467-9906.2011.00578.x

James, G. et al. (2014). An Introduction to Statistical Learning: With Applications in R. Springer Publishing Company, Incorporated.

Johnston, R., et al. (2005). Neighbourhood Social Capital and Neighbourhood Effects. Environment and Planning, vol. 37, 14431459.

Kim, J. \& Jargowsky, P.A. (2005). The Gini Coefficient and Segregation on a Continuous Variable. Washington, D.C.: National Poverty Centre. Working Paper \#05-2.

Lens, M.C. \& Monkkonen, P. (2016). Do Strict Land Use Regulations Make Metropolitan Areas More Segregated by Income?, Journal of the American Planning Association, 82:1, 6-21, DOI: 10.1080/01944363.2015.1111163

Mayer, S. E. (2000). Income Inequality, Economic Segregation and Children's Educational Attainment. Manuscript. University of Chicago.

Murdie, R., et al. (2013). Eight Canadian Metropolitan Areas: Who Lived Where in 2006? Toronto: University of Toronto Cities Centre, Research Paper 229.

Murdie, R., et al. (2014). Eight Canadian Metropolitan Areas: Spatial Change Patterns of Neighbourhood Change, 1981-2006. Toronto: University of Toronto Cities Centre, Research Paper 234.

OECD (2016). Making Cities Work for All: Data and Actions for Inclusive Growth. OECD Publishing, Paris. http://dx.doi.org/10.1787/978926463260-en

OECD (2018). OECD Social and Welfare Statistics: Income Distribution. doi: 10.1787/459aa7f1-en Retrieved from https://data.oecd.org/inequality/income-inequality.htm

Procyk, S. (2014). Understanding Income Inequality in Canada, 1980-2014. United Way Toronto \& Neighbourhood Change Research Partnership, Factor-Inwentash Faculty of Social Work, University of Toronto.

Quillian, L. ( 2007). Does Segregation Create Winners and Losers? Education and Spatial Segregation on the Basis of Income and Race. Paper presented at the annual meeting of the Population Association of America, New York City, March 29-31.

R Core Team (2018). R: A language and environment for statistical computing. R Foundation for Statistical Computing. Vienna, Austria. URL https://www.R-project.org/.

Reardon, S., \& Bischoff, K. (2011). Income Inequality and Income Segregation. American Journal of Sociology, 116(4), 10921153. doi:10.1086/657114 
Rothstein, R. (2017). The color of law: a forgotten history of how our government segregated America (First edition.). New York; London: Liveright Publishing Corporation, a division of WWNorton \& Company.

Sampson, R. J. (2019). Neighbourhood effects and beyond: Explaining the paradoxes of inequality in the changing American metropolis. Urban Studies, 56(1), 3 32. https://doi.org/10.1177/0042098018795363

Saiz, A. (2010). The Geographic Determinants of Housing Supply. Quarterly Journal of Economics, 125(3), 1253-1296. https://doi.org/10.1162/qjec.2010.125.3.1253

Statistics Canada. (n.d.) Table 18-10-0005-01 Consumer Price Index, annual average, not seasonally adjusted.

Statistics Canada. (1986). 1986 Census of Population.

Statistics Canada. (1996). 1996 Census of Population.

Statistics Canada. (2006). 2006 Census of Population.

Statistics Canada. (2016). 2016 Census of Population.

Taylor, Z. \& Allen, J. (2018). Canadian Longitudinal Tract Database. https://doi.org/10.5683/SP/EUG3DT. Scholars Portal Dataverse, V2, UNF:6:ZGi846/Su7dwN76j8+3oaA==[fileUNF]

Tiebout, C. (1956). A Pure Theory of Local Expenditures. Journal of Political Economy 64 (5): 416-424.

Toronto, City of. (2017). Toronto Official Plan. Retrieved from https://www.toronto.ca/wp-content/uploads/2017/11/981f-cpofficial-plan-chapter-3.pdf

Toronto, City of. (2018). Zoning By-law No 569-2013. Retrieved from https://www.toronto.ca/wpcontent/uploads/2018/07/97ec-City-Planning-Zoning-Zoning-By-law-Part-1.pdf

United Nations (2015). Inequality and the 2030 Agenda for Sustainable Development. Development Issues No.4. Department of Economic and Social Affairs.

Walks, R. A. (2013). Income Inequality and Polarization in Canada's Cities: An Examination and New Form of Measurement. Toronto: University of Toronto Cities Centre, Research Paper 227.

Walks, R.A., and Bourne, L.S. (2006) Ghetto's in Canada's cities? Racial segregation, ethnic enclaves and poverty concentration in Canadian urban areas. Canadian Geographer 50 (3): 273-297.

Watson, T. (2009). Inequality and the Measurement of Residential Segregation by Income. Review of Income and Wealth 55:820-44.

Wilkinson, R. G., \& Pickett, K. (2009). The spirit level: Why more equal societies almost always do better. London: Allen Lane.

Wilkinson, R. G., \& Pickett, K. (2018). The inner level: How More Equal Societies Reduce Stress, Restore Sanity and Improve Everyone's Well-being. London: Penguin Press.

Yang, R., and Jargowsky, P.A. (2006) Suburban development and economic segregation in the 1990s. Journal of Urban Affairs 28 (3): 253-273.

Yglesias, M. (2015). Everything you need to know about income inequality. Vox. Retrieved February 22, 2019 from https://www.vox.com/2014/5/7/18076944/income-inequality 